
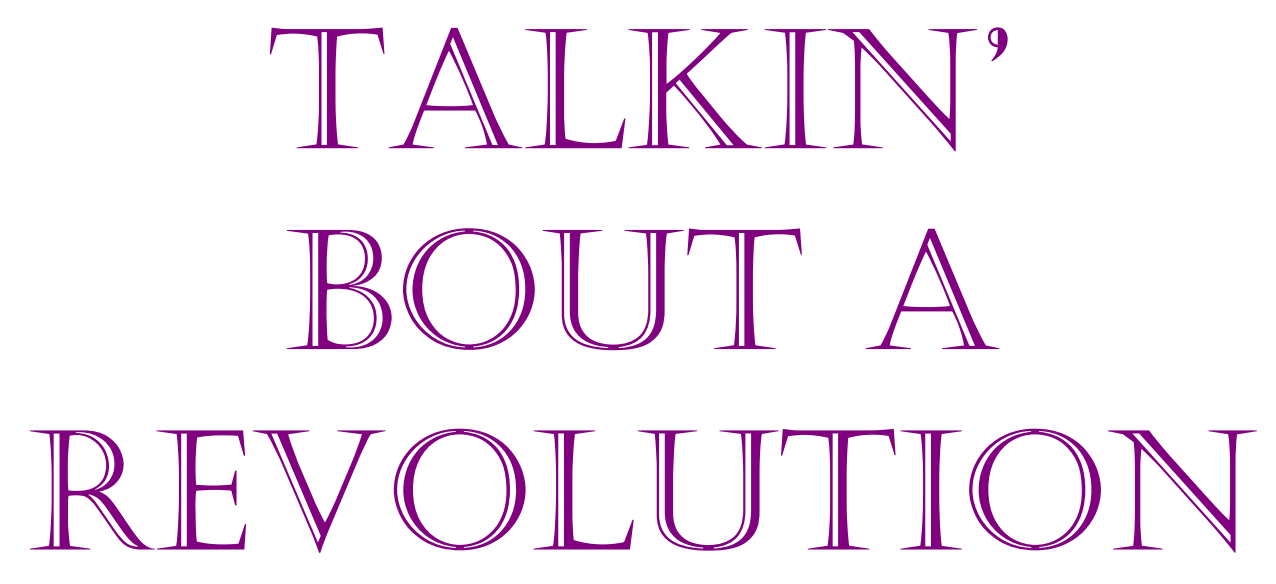

\title{
CULTURAL EFFECTS ON THE TRANSITION FROM ORAL TO WRITTEN LITERATURE
}

\author{
by
}

Emily Poelina-Hunter

submitted to Victoria University of Wellington in fulfilment of the requirements for the degree of Master of Arts in Classical Studies

Victoria University of Wellington 
Thank you to my family, especially Mum and Dad, Nyikina Inc., and all of my friends who supported me through this thesis with unwavering support. A few people deserve special mention: Dr Judy Deuling, Dr Bronwyn Stokes, Colleen Hattersley, Jo Whalley, Jen Oliver, Nicole Semple, Alastair Pharo and Alex Wilson. 


\section{TABLE OF CONTENTS}

Introduction

The importance of traditional narratives $\quad 10$

$\begin{array}{ll}\text { Concepts of myth and storytelling } & 12\end{array}$

$\begin{array}{ll}\text { Story } & 14\end{array}$

$\begin{array}{ll}\text { Legend } & 17\end{array}$

$\begin{array}{lr}\text { History } & 18\end{array}$

$\begin{array}{lr}\text { Myth } & 19\end{array}$

Bookarrarra: a Nyikina approach to myth 23

How oral traditions are supported by a hunter-gatherer-fisher culture 24

$\begin{array}{ll}\text { Literature } & 27\end{array}$

Bookarrarra, booroo and nganka: myth, land and language $\quad 28$

$\begin{array}{ll}\text { Language and colonization } & 33\end{array}$

Nyikina attitudes towards writing $\quad 36$

$\begin{array}{ll}\text { Conclusions } & 42\end{array}$

Glossary of Nyikina terms 44

Nyikina Plate sources $\quad 45$

Nyikina Plates $\quad 46$

$\begin{array}{lll}\text { Chapter } 2 & \text { MINOAN CASE STUDY } & 51\end{array}$

$\begin{array}{lll}\text { Part I: } & \text { The beginnings of religon } & 51\end{array}$

Introduction to sedentary Minoan culture: Myrtos 55

Characteristics of the Cretan Hieroglyphic Script 59

Part II The rise of sedentism and its effects on Minoan Culture $\quad 62$

Origins of the syllabic Cretan Hieroglyphic Script 63

$\begin{array}{ll}\text { Literacy } & 66\end{array}$

Who was using the Cretan Hieroglyphic Script? 68

$\begin{array}{ll}\text { Writing: a gift from the gods } & 70\end{array}$

$\begin{array}{ll}\text { Eteocretans } & 72\end{array}$

$\begin{array}{ll}\text { Regional variances } & 74\end{array}$

Proto-Linear A $\quad 76$

$\begin{array}{ll}\text { Characteristics of Linear A } & 78\end{array}$

Offshore influences $\quad 80$

Cypro-Minoan Script $\quad 81$

Conclusions $\quad 82$ 
Minoan Plate sources

Minoan Plates

\section{Chapter 3}

Introduction: the Euboean settlement at Cumae

Adaption of a foreign alphabet

Literary remains from Etruria

The Pyrgi sheets

The Zagreb mummy wrappings

The legends of Tarchies and Lasa Vecuvia

Prophecy and ritual texts on Etruscan mirrors 106

Influences on Latin 109

Dextrograde or sinistrograde? 109

Conclusions

Etruscan Plate sources

Etruscan Plates 


\section{Introduction}

Using language and writing to distinguish cultures from each other is commonplace. They are defining characteristics of culture that enable members to identify themselves within their group - by having communication they are tied together. Oral communication is the key identifier for Nyikina people of northern-Western Australia. However, Nyikina language is severely endangered, and risks being lost altogether. If the language were to die, Nyikina people would lose a huge part of their cultural identity. Working with the Nyikina community as part of a language revitalisation project sparked my interest in the transition from oral to written literature within the Mediterranean. Why did Nyikina not develop their own script, but Minoans and Etruscans did? It would be beneficial to have Etruscan literature or sound recordings describing how the Etruscan language was influenced by Phoenician and Greek cultures, and to know why they created their own alphabet using elements from both colonising influences. Hence, the experience and situation regarding the Nyikina language may provide a general paradigm for understanding and extrapolating the contextual situations of Minoans and Etruscans with respect to their languages, and vice-versa. This was the spring-board to a Masters thesis exploring such changes.

So we shall begin with Nyikina culture to start our journey of understanding by initially focusing on traditional narratives. This thesis is also motivated by more fundamental questions concerning the connections between culture and communication. How does culture affect the evolution of communication within a group? The hunter-gatherer culture has an impermanent aspect to its world-view, which encourages and is encouraged by an oral tradition. However, hunter-gatherer 
groups have made the transition to sedentism under the right environmental conditions, such as in the Mediterranean. How does their world-view then change to allow the population to grow and support itself? Does their world-view change naturally as the human being evolves, or does an event of significance within their community or physical environment trigger a sudden change to their world-view? Some cultures did maintain a nomadic lifestyle without developing a new world-view that allows for sedentism to occur. Also, some cultures can maintain a nomadic lifestyle and still develop a literary tradition alongside an oral tradition, for instance, Arabic culture. This study aims to help to understand the difference between a hunter-gatherer culture which maintained its oral tradition up until colonisation and two cultures that created a script and developed literary traditions: Nyikina, Minoan and Etruscan, respectively.

Nyikina culture refers to an Aboriginal Australian group, living in the Kimberley region of northern Western Australia. Nyikina language has certainly been affected by the colonisation of northern Western Australia which began in the late nineteenth century, and now the number of full Nyikina speakers has plummeted to less than 30 people and it is classed as severely endangered. Current language and cultural revitalisation is not primarily a Nyikina project, but involves linguists and anthropologists who are not Nyikina, an upshot of this classification. Nyikina can be written phonemically using the Roman-based alphabet, which is now being used to create physical materials of previously oral songs and stories. Historically however, indigenous Nyikina people communicated orally and did not create a script to write their language in the sense of an alphabetic, cuneiform or hieroglyphic script. Their adoption of writing was a result of colonisation. 
Minoan culture refers to a Bronze Age civilisation on the Mediterranean island of Crete. Minoan culture presents a case of an indigenous development of a symbology, which became a pictographic syllabic script before developing into a linear variant. The development of the Minoan Cretan Hieroglyphic Script (CHS) and Linear A occurred concurrently with the evolution of sedentism, religion and technology. The cultural effects of a growing population in a continuous, sedentary society create a social need for distinguishing individuals and groups, and so symbols from the CHS were also used as personal and group identity tokens. The stratification of society in Minoan culture led to the formation of a scribal priestly class that oversaw aspects of Minoan religion, particularly in the context of the palace complexes. The CHS was probably in the hands of this elite group, and many of its symbols have religious connotations. The development of methods for inscribing the CHS, as opposed to impressing it with seal stones, led to the development of Linear A. Linear A symbols are in fact linear versions of some symbols from the CHS. The scripts were used for personal and religious use before becoming adopted into the administrative aspect of Minoan palace complexes and scribal hands. Thus, unlike Mycenaean Linear B texts, Minoan scripts do not appear to have been created for pragmatic or economic reasons.

Etruscan culture refers to the peoples who dominated Italy after the Villanovan period and before the spread of Roman culture. Etruscans certainly had their own language before the colonisation of the southern regions of Italy by Euboean Greeks. The Greek settlement at Cumae heavily influenced the types of communication and interaction that the Etruscan people from the north engaged in, 
especially in the sense that the Euboean Greek, or Cumaean alphabet, is the one that most closely resembles the Etruscan alphabet. The Euboean alphabet was a strand of the Greek alphabet that was initially influenced by Phoenician trade between the Greek island of Euboea and Phoenicia. This, coupled with the fact that Phoenician contact with the Etruscans was simultaneous to Greek colonisation of the Italian coast near Etruria, meant that two established alphabets were available to the Etruscans, and this can be seen in the Etruscan alphabet itself, which retains some Phoenician letters, and drops the Greek ones that the Etruscan language did not utilise. While it seems logical that the introduction of Greek and Phoenician alphabets would enter the Etruscan culture through trade and colonisation, the surviving Etruscan texts are comprised of religious declarations and sacred calendars. This may suggest that the Etruscans viewed writing as sacred, or simply that economic and administrative texts were written on perishable materials.

While these three case studies may appear unrelated at first glance, the following chapters will reveal that their disparate origins allow one to see what was particular about their histories that led them to being as they were. The Nyikina case study clearly shows that this Aboriginal culture did not develop a written script for the communication of their language. However, since the colonisation of northern Western Australia, Nyikina culture has had a foreign alphabet imposed on them. Chapter 1 examines the effect of this on Nyikina language and efforts to establish a written literature, as opposed to their traditional oral literature. Since the nineteenth century CE, Western ideas about writing have clashed with indigenous oral traditions. Nyikina became severely endangered in the twentieth century CE, and now in the 
twenty-first century $\mathrm{CE}$, language revitalisation programs are attempting to rectify the damage inflicted on Nyikina culture by colonisation.

Etruscan culture is the focus of Chapter 3. Like Nyikina people, Etruscans had their own civilisation and language at the time when their land was colonised by the arrival of Greeks in the eighth century BCE. Influence from Phoenician settlements to the north, and the Greek settlements in the south of Etruria certainly impacted on the script that the Etruscans used to write their language. They used a combination of alphabetic signs from the Euboean Greek alphabet and the Phoenician alphabet to visually communicate their oral traditions.

Chapter 2 presents a contrast to Nyikina culture and Etruscan culture, in the Minoans who appear to have created their own indigenous script without a manipulative colonising influence. To emphasise its uniqueness, the Minoan case study is placed between the Nyikina and Etruscan case studies. There were surely contemporary examples of Egyptian and Near Eastern hieroglyphic scripts at the disposal of the Minoans, but the Cretan Hieroglyphic Script (CHS) was controlled and developed independently during the Middle Minoan period. The close connection of many CHS symbols to religious votive goods and iconography suggests that an elite scribal priestly class, most probably within the context of the palace complexes, were the guardians of the script. Linear A then developed from the CHS, followed by Linear B in the Late Minoan period. At this point in time, Mycenaean expansion into the Mediterranean appears to have affected the function of Linear B, as it is used to write a Greek language - not the language which Linear A and the CHS wrote. 
The reason for using Minoan and Etruscan case studies, and not Greek, is that Greek affects both these cultures, but in different ways. The Minoan Case Study analyses a culture that developed its own script without overwhelming foreign influence. It was not until the Neo-palatial period that a Greek language was written using Minoan Linear B. The Etruscan Case Study examines a post-Greek Dark Age culture which had its own language, but which was heavily influenced by the Greek (specifically Euboean Greek) alphabet during Iron Age colonisation of Etruria in Southern Italy.

Before a discussion of sedentism, a study of the indigenous Aboriginal language group called Nyikina will be presented. The case study will focus on precolonial Nyikina culture and define the cultural effects on the maintenance of an oral tradition. Having established the aspects of this oral culture that inhibited the creation of writing, I will present a discussion of the rise of sedentism in the Neolithic period that challenged specific cultural aspects which had previously supported an oral tradition of communication between community members, gods and nature, and which facilitated the move towards pictographic and syllabic scripts. Language and writing are both cultural inventions and are thus specific to the culture that creates them. Though scripts are both highly adaptable between language groups and flexible for writing different languages, how a particular society uses language and writing is a reflection of their cultural values and world-view. ${ }^{1}$

\footnotetext{
${ }^{1}$ It is my own personal opinion that the idea that language and writing are cultural inventions can be challenged from a Nyikina point of view. In Australia it is believed that the language comes from the land, that it resides in the land from the time when the creation ancestors put it there. Just because a language is not spoken anymore does not mean that it is gone. It is still 'inside' with the knowledge it encodes. Like all things Dreamtime, we just can't see it at the moment - just like a map, everything is there, but you can only interact with the bit where you happen to be. This is why it is problematic to teach other languages in areas where the local language is no longer remembered. This may be one explanation for why Australian languages, in this case, Nyikina, were not written - because it was not prescribed by bookarrarra, the Nyikina concept of Dreamtime.
} 
The Minoan chapter will analyse the creation of an indigenous script. By following the development of writing on Minoan Crete, one can trace the evolution of Minoan culture. The final study, on Etruscan writing in Italy, has a mixture of features which contributed to the invention of the Etruscan alphabet including Greek colonisation, trade, adopting a foreign alphabet to an established local language and preconceived ideas about writing use. Writing is not a natural part of human evolution, but an occurrence that is influenced by culture. Becoming a literate culture is achieved through processes outside of culture as well, such as climate stabilisation, and changes to habitable conditions. 


\section{Chapter 1}

\section{Nyikina Case Study}

Nyikina culture is the focus of this case study for three reasons; I am Nyikina, I was invited to do this study by an indigenous organisation, Nyikina Inc., and because the study involves Nyikina co-researchers. ${ }^{2}$ Researchers who conduct participant observation and have a 'lived experience with a society for an extended period of time' are putting themselves into the social world they are studying, not merely analyzing secondary source documents from their laboratory or office. ${ }^{3}$ Maxine Birch writes that '[b]eing a researcher in the field and then being a researcher in the academic world produces many contradictions and tensions. ${ }^{4}$ The primary tension arises when trying to produce an academic text which is traditionally void of personal retrospective and inclusive of bias-free data. The academic limits of Positivism, which privileges quantitative methods, can clash with the values of Naturalism, 'promoting ethnography as the central, if not the only legitimate, social research method. ${ }^{5}$ Some information reproduced in this case study may be relevant to other non-Nyikina (and non-indigenous) peoples from the Kimberley area and greater Australia, but the discussion does not generalise about all indigenous Australian people.

\footnotetext{
${ }^{2}$ Nyikina Inc. formed in 2004, is the non-profit organisation which permitted this thesis research to be carried out within our community, on our land by our own people. Self control of research is an important issue for Nyikina Inc. Anne Poelina is the Secretary Public Officer and Lucy Marshall the Chairperson who has authorised my research.

${ }^{3}$ Harper, 1998, 2.

${ }^{4}$ Birch, 1998, 172-173.

${ }^{5}$ Harper, 1998, 2.
} 
Each indigenous Australian culture is distinct. The Nyikina word 'booroo' will be used in this thesis when referring to a local area associated with the Nyikina community that has additional kinship and traditional narrative links. ${ }^{6}$ Nyikina narratives belong in their booroo, not in Greece or Italy or Crete or Queensland or South Australia. The indigenous connection to booroo has been described as "much broader than the western concept of ownership through land title. ${ }^{7}$ One cannot apply results or information gained from a study on Central Desert people to Kimberley people, as Australia is a vast country with a vast variety of Aboriginal communities having their own cultures and languages. Therefore it is necessary to locate the Nyikina people. By locating Nyikina peoples' geographical place in Australia [Plate 1], one can then move on to understanding the deeper meaning of booroo to a Nyikina person, and the oral stories connected with it.

2007 marked the $40^{\text {th }}$ anniversary of Aboriginal people in Western Australia being recognised as national citizens for census purposes. Colonial control of what is kept and taught as Australian history is specifically designed to ensure that colonisation continues into the twenty-first century, and so indigenous Australian accounts of history differ from colonial accounts. Dehumanising indigenous people and discounting indigenous culture was part of the colonisation process of Australia. ${ }^{8}$ Indigenous voices are muted and oral traditions have been discounted as unreliable methods of recording history. In Penny Taylor's book, Telling it like it is; a guide to making Aboriginal and Torres Strait Islander History, she defines history in a number of ways. Taylor's definition that supports the oral tradition states:

\footnotetext{
${ }^{6}$ A glossary of Nyikina terms is located on page 44.

${ }^{7}$ Department of Indigenous Affairs (DIA), 2005, Department of Indigenous Affairs, Perth, p24.

${ }^{8}$ Schmidt, 1990, 37.
} 
History is the stories that people tell the next generation to explain who they are, where they come from, and why they are there. It is therefore about identity. History is stories about the achievements and survival of our culture, important events in our past, our heroes and heroines, our leaders, the role models that we pass on to our children. It is therefore about pride and self esteem. ${ }^{9}$

Aboriginal personal and community/collective narratives provide an inside account of the cyclic and entwined relationship of history, which is continuously represented in the present and in the future. Learning and knowing Nyikina narratives which are located within a particular sense of the past, present and future have positive results for Nyikina people in relation to identity, pride, and self esteem.

\section{The importance of traditional narratives}

The Nyikina oral tradition of communication contains traditional narratives, which are the family of stories that are important to Nyikina people. They are stories that have been told for generations and passed down to the young people in order to explain where Nyikina people came from, what values are held by the community, and why things are done. Elders who know Nyikina traditional narratives hold a wealth of cultural capital. Stories connect their audience to the animals, people, and places of the traditional narratives and imbue people with a sense of self-pride and identity with Nyikina culture. In the twenty-first century, self-pride and identity are important issues for young people of all cultures, a point which explains why traditional oral narratives are still used in contemporary Nyikina culture. A recent phenomenon for the Nyikina people has been the writing down of previously oral narratives, as the elders get older, and Nyikina culture adapts to preserve its cultural capital. By learning the traditional narratives young people can gain an understanding of their place in their country, the concept of 'country' also

\footnotetext{
${ }^{9}$ Taylor, 1992, 2.
} 
encompassing ancestry and ontology in this sense. A positive future can be built on the foundations of knowing one's place and one's past.

Traditional narratives and stories are vitally important to an oral culture like Nyikina. Like ancient Greek oral poets such as Homer, the formulation and structure of traditional narratives help storytellers to remember particular details to preserve and the knowledge of earlier generations. Telling a story, which captures the attention of young people, while simultaneously teaching inherent values and skills, is an art. Certain stories explain how Nyikina people came to exist in today's world, and how their predecessors paved that path; thus further reinforcing place within ancestry and the role of youth in the future. To survive, a story or myth must be repeated and interpreted. This is especially so for narratives in oral cultures. For a traditional narrative to be told, the teller needs to know it, consider it to be relevant, and have an audience. If the audience disappears, the survival of traditional narratives cannot be assured, as it is the audience that will become the tellers and pass the narratives on to the next generation. And if the elder who knows the stories and songs and has the permission to orate them becomes too old or dies before passing on the knowledge, then the story also dies. In some cases, a story will not be performed for many years out of respect for the elder who 'owned' (developed, taught and maintained) it. Elders may determine a new 'owner' for a story. ${ }^{10}$

\footnotetext{
${ }^{10}$ I wish to thank Colleen Hattersley for sharing her experience in the Northern Kimberley among the Worrorra/Ngarinyin people in 1989 at a place called Marrumbabidingarri, near the Mitchell Plateau. Here she witnessed a junba (storytelling through song, dance and body design) that had been 'inside' (not performed) for 15-20 years since the 'owner' of the junba passed away. This first re-performance was done by elders, but the story now lives on with a new generation and a new 'owner' as decided by the elders of the group.
} 
There are a number of factors which cause the disappearance of an audience for a Nyikina storyteller. The invasion, colonisation, and occupation of Australia led to the forced alienation, dislocation, and institutionalisation of indigenous peoples, and has severely damaged the continuance of an oral, hunter-gatherer-fisher culture. The separation of communities and families broke the connections for transference of knowledge. The traditional stories themselves, however, can be used as a tool to relink family and community in the wake of colonisation because Nyikina narratives tie Nyikina people to Nyikina land. By acknowledging this power, teaching and learning, the traditional stories can reiterate personal and communal pride and produce happier, stronger people who can then become future Nyikina leaders.

\section{Concepts of myth and storytelling}

By explaining my definitions of story, history, legend and myth, I hope that the reader can understand my approach in this case study and follow my reasoning and analysis of Nyikina traditional stories. Because I have been trained in Classical Studies, I view myth through a classical scope, using my background researching societies that changed from being oral cultures to written cultures over the ages. ${ }^{11}$ These societies built stone towns and cities, market places and temples and left behind clay tablets, legal documents, and novels which scholars and archaeologists can date, analyze, and decipher. Aboriginal myths and stories live in the land, and are written on the landscape. Living in the Kimberley region for eight months, however, allowed me to research non-written forms of indigenous literature and to develop a different perception of myth. Prior to conducting research in Western Australia (W.A.), I had understood myth as one of a series of chronological stages, preceding history, legend,

\footnotetext{
${ }^{11}$ I completed my Bachelor of Arts in Religious Studies and Classical Studies in 2004, and First Class Honors in Classical Studies in 2006 at Victoria University of Wellington, before moving to the Kimberley in February 2007 to do indigenous research.
} 
and story. Classical Studies employs a linear concept of time to order these terms story being the most recent [Plate 2]. From the basic timeline in Plate 2 (without dates), one can see that myths are ancient narratives, relating stories from the earliest era which a culture perceives. History is in the middle; formal history is manmade and created for social and political reasons. Society needs history to record events and the individual needs history to validate the events of their life in the face of mortality. Legend is separated from history by a measured space of time, as will be explained below. Numerous retellings of a historical event are required to make a legend. Story is at the end of the timeline at the point closest to the twenty-first century, or present day. A collection of stories makes a history, and over a long period of time the stories can become myth. This progression agrees with the anthropological method of organising mythology, as described by Claude LéviStrauss, where one should situate 'in the beginning, cosmological and cosmogonic myths, and later on, much later on, what can be considered as legendary tradition and family histories.' 12

This linear western approach to myth influenced many anthropologists who have studied non-western cultures. As a result, these non-western cultures, including Nyikina, have had their myths and concepts of time modelled on an alien framework. However, it is not conducive to apply a Classical Studies framework of myth to nonMediterranean culture. By adopting new, localised approaches to a culture's own mythological framework, an 'outsider' (in the anthropological sense) can appreciate specific cultural concepts and the meanings of myth. Below, a discussion of Nyikina

\footnotetext{
${ }^{12}$ Lévi-Strauss, 1978, 36.
} 
story, legend, history, and myth will attempt to create a possible Nyikina framework for understanding concepts of myth and storytelling.

\section{Story}

A story is a memory held in a person's mind. The following story was told to me by Joy Cooper, a Nyikina co-researcher. It details an incident involving her father and Yoongoorrookoo, a snake that originates from bookarrarra.

I think really hard about it, but they told me that there was lotsa kids, you know, out swimming. You know how kids like walking out from the station, their camp, go swimming down the river, in that part, you know how Myroodah Bridge is? Right in that corner there... That's where that place, where he belongs to, you know?

Well, they say that he went swimming with all of his friends and they stayed there for a long while swimming, I think... And they said that they started to leave from there, that it was that long already, too, and took off back home except he wasn't around. They were searching around for him, they couldn't find him. He musta had a one big dive and went in for good, you know, in the water. And he stayed there for maybe a month, or a week, you know. I don't know... And everybody at home asked every other kid, "Where, one other kid missing?" And they said, "I don't know where he is. He musta drowned or something", you know? And they started crying for him. Everybody was hitting their heads, blood coming out of their heads. Crying and all, they couldn't stop crying, you know, day and night, worrying about him.

And after they musta a little bit forget about it, keep on doing what they was doing, you know, working around there. They thought he gone for good, you know? No-one won't bring him back. Till they stayed for little bit longer, I think it was the rain cloud, you know? The cloud from the sky it started making the rain. And the cloud came in, it was a dark 
cloud, you know? Came from the water, came outta the water that was.... It was caught up, you know? And he was with that cloud. He came down from the cloud in the rain. They saw him, this kid, "Who this kid coming down?", you know? Not coming down - they just saw him walking on the ground, you know? Walking towards them, there this one kid coming over, and they recognise him. It was him! And they all got happy that they saw him back home. That's when he was a little boy. Yeah, he was in there, the river underneath, with the snake, you know Yoongoorrookoo?

And then the cloud, like, it was water out of the river that turned into the cloud. And then when it rained, he came down with the rain?

Yeah, he came down with the rain. Cos that's what Yoongoorrookoo do, you know? If you make humbug in the river, if he doesn't know you or you are a stranger, that's how he make rain and wind you know? So that you know that rainbow thing for you, (Joy made an arch with her arm and is pulling it towards herself when talking about the rainbow thing), that where he draws you in you know? Like a round thing - like he rakes you in. Push you in to swallow you in. Like a hook...

[My father] he never talked about it. Maybe it was good one, I don't know. Good in his head or I don't know. You know like he was, was frightened, or just it was silly-one kind of kid, just swimming and forget about thing, you know... Cos all I know, that in the river, after that, when he got older and had us at the back station, house, you know, like he was married to my mum and had kids and me, you know? Living in Looma. Looma or Camballin one of those two places over there. And some of those people they went out fishing out there, the same spot. Other side that place where he got drowned. But the other part of the riverside there...When they was fishing down there in the sand bank, wanjarra they call it. They could, this person who saw him, he saw him just exactly like him. An old man with grey hair, tall one, with short 
trousers, walking on (at) the river, you know? And he called out to him, "hey, hey, come back here", but he just disappeared then.

Who was the old man?

That was my dad, you know?

After he bin pass away?

No, before; he was still alive. They saw him exactly like him, maybe he was giving him the sign that when it's time he was to come back, go back there, you know? Must be that was his rai, [conception spirit], you know? Giving him a sign?

So that's where he might be now?

Yeah.

In the river.

If he's there... I don't know. Because he was a maban man too. ${ }^{13}$

Joy's story about her father is a memory from one generation ago, and is set on the Mardoowarra (Fitzroy River) where Yoongoorrookoo, the giant serpent from bookarrarra lives. The tale could be seen as a cautionary story to emphasise the respect that Yoongoorrookoo and the Mardoowarra need to be given.

\footnotetext{
${ }^{13}$ This story was told to me and recorded on audiotape on 18/11/2007, before being transcribed (also by me) as closely to Joy's words as possible on the 29/11/2007. The setting was at Balkinjirr (Lower Liveringa) near to both Looma and Camballin - See Plate 3.
} 


\section{Legend}

Legend is a story from history that has its origin in truth but over time has gained elements of fantasy. It is not as far fetched as myth can be, but has been elevated out of history into a realm of heroic proportions. These are great events that have been told over and over again. When you tell a good story over and over, it turns into a great story. In Greek society these are commonly the basis for drama, such as the legend concerning Agamemnon, king of Mycenae as told in Aeschylus' Agamemnon. The following Nyikina legend is about Woonyoomboo, the first Nyikina man.

In a place called Moorrool-Moorrool near Derby there was a bookarrarra, or Dreamtime man, called Woonyoomboo, who had lots of children. One day he went to look for food for his children. He found a billabong which he named Mijirrikan. It had lots of different fish swimming in it. Woonyoomboo went back to his family and said, "We must cut this majala tree, this fresh water mangrove which grows by the river. We will use it to poison the water and catch the fish."

On the way back to the billabong with his children they camped at different places. Each place has a story, e.g. Lanji-Lanji was where he dropped a plant accidentally, and it started growing there. The same thing happened at Bindinyan, where the tree remains today. The next day they went past Liveringa to Mijirrikan, the billabong.

The next morning he showed his children how to use the majala. He walked into the water carrying the majala under his arm so it did not get wet. When he had waded in up to his waist he put the majala in the water and beat it with his waddy stick, to release the poison. The colour of the water changed to red and purple and all the different types of fish started floating to the surface. First of all came the smaller ones like catfish and barramundi, and Woonyoomboo called out to the water 
spirit: "Koolooloolooloo". The larger fish like stingray and sawfish took longer to come up. ${ }^{14}$

In this legend the pioneer of Nyikina culture, Woonyoomboo, teaches a very important lesson - how to use the fresh water mangrove plant (Barringtonia acutangula), or majala, to fish without using a net, line, or spear. The majala plant has properties which stuns the fish, by temporarily reducing the oxygen level of the water. Once the effect of the poison wears off, the remaining fish recover. Woonyoomboo gives the names for things and places that modern Nyikina people still use today, as a way of perpetuating bookarrarra and validating their ancestors' importance in everyday life.

\section{History}

History comes next on my time line into the past. History is (usually) a chronological collection of stories. It can belong to a person or society. History can be critically researched and truthfully describe events so that future generations can know how things really happened. In some cases, however, history is someone's perspective and comes across with the distinct point of view of the author. In ancient Greece the role of a historian was a new concept and the first Greek 'historian', Herodotus, who wrote his Histories in the $5^{\text {th }}$ century BCE, recorded the history of the civilisations he encountered, or what they told him was their history, during his travels across the known world. ${ }^{15}$ Australian history has faced the same problem of "perspective

\footnotetext{
${ }^{14}$ This story is closely adapted from the book Woonyoomboo written and illustrated by students of the Nyikina Mangala Community School in the Jarlmadangah Burru Community. Additional text by Annie Milgin. Nyikina transcribed, edited and translated into English by Annie Milgin, John Watson, Harry Watson, Darby Nargarin and Colleen Hattersley. (c) Jarlmadangah Burru Aboriginal Corporation (JBAC) 2002. Published by JBAC.

${ }^{15}$ The dating of Herodotus is not exact, but from references to historical events in Histories Herodotus seems to have been travelling, researching, writing and performing c.450-420 BCE. Histories were probably published c.415 BCE, and his death was during the Peace of Nicias, 421-415 BCE. See the
} 
history' in regard to European accounts of colonisation and portrayals of indigenous people in Australia. British colonial accounts of settling towns, the behaviour of Aboriginal people, and how the colonists were dealing with the 'Indigenous Problem' were sent back to the Motherland to appease the monarchy and allay fears of potential immigrants. White Australians (often male) controlled the content and distribution of what is regarded as Australian history, but not necessarily indigenous Australian history. Making indigenous accounts of colonisation part of Australian history is necessary for balance and for acknowledging the voices of the survivors who still battle against the effects of colonisation. Validating indigenous voices and their accounts of history will be discussed below, as rewriting history is an important step in the creation of positive identities for Aboriginal people.

\section{Myth}

Myth is the oldest of the four narratives. My main criteria for a myth are twofold: the setting is in ancient times, and animals and/or divine characters are present. Some people use myth synonymously with words like 'fake' and 'untrue', such as the British-Australian myth that Captain Cook 'discovered' Australia. ${ }^{16}$ I am not interested in evaluating the truth value of myths. Within the context of this thesis, a myth is a very old story involving gods and the creation of things, and what happened when humans first started to inhabit the world. Cultures across the world all have foundation myths for fundamental questions in ancient time. The first humans wondered where fire came from. Where does the sun go at the end of the day? What happens when we die? Myths explained these phenomena. The weather and the seasons were controlled by gods in the sky, the sea, and the ground. Natural disasters 
were the result of an upset god and good harvests were the result of happy gods. With enough people living in the same community, with the same beliefs and rituals for living in harmony with gods, cults and religion came about. Myths about Universals like Love, Greed, and Fate were told to children in times before centralised economies, organised agriculture, and military states, before history was invented. The following examples are the Greek creation myth and the Nyikina myth about the transformation of a natural feature of the land.

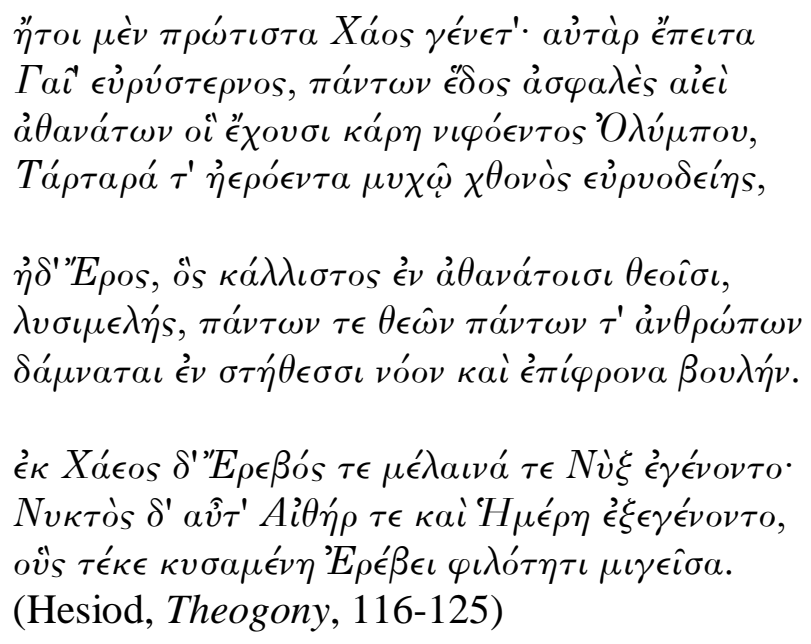

In truth, first of all Chasm came to be, and then broad-breast Earth, the ever immoveable seat of all the immortals who posses snowy Olympos' peak and murky Tartarus in the depths of the broad-pathed earth, and Eros, who is the most beautiful among the immortal gods, the limb-melter - he overpowers the mind and the thoughtful counsel of the gods and of all human beings in their breasts.

From Chasm, Erebos and black Night came to be; and then Aether and Day came forth from Night, who conceived and bore them all after mingling in love with Erebos. ${ }^{17}$

This Greek myth is a basic foundation myth because no human characters are present and it describes the beginning of time. A story in ancient history may be called a myth in a time of modern history. The following Nyikina myth is about the rocky outcrop at Looma community.

\footnotetext{
${ }^{17}$ Translation by Glenn W. Most from: Hesiod, Theogony, Works and Days, Testimonia, edited and translated by Glenn W. Most, Harvard University Press, 2006. 12-13.
} 
kinya wanangarri yingan yoolboorrooyoonoo jada.

bookarrarra yirrmana.

kooya yijirra koord yirrmana. yoorr yimana wilan.

kinya yirrka baba ngalar yirrina yirrababanayina kooya ...

malina.

yoorr yimana.

yirrka baba kalboo yidin kamirri.

kaliya.

That hill sitting up there has been there from long ago.

In the beginning the blue tongue lizard and her children were trying to

escape a flood.

Their mother died. She drowned in the floodwater.

Her children climbed that rock.

They looked back. They kept on searching for their mother.

But they could not find her.

Those children of hers are still sitting up there.

The end. ${ }^{18}$

Defining differences between story, legend, and myth in Aboriginal culture is contradictory when viewed from a classical perspective. In the introduction to

Gularabulu Stephen Muecke defines the three types of stories told to him by Paddy

Roe, a Nyikina storyteller;

Bugaregara stories are sometimes called myths; they are about supernatural beings that created land-marks, stars, rocks and rivers and gave mankind language and laws for conduct.

Trustori is the equivalent of our word "legend" - the characters of the story are human and can be located in time and space, within the memory of the narrator. The heroes of these stories can perform fantastic acts.

Devil stori may be about quite recent events as well as distant ones. Here something inexplicable or anomalous happens which can only be explained by the presence of some spirit being.

\footnotetext{
18 This story was told to Bronwyn Stokes on 15 September 1978 in Nyikina language, not English by an elder (now deceased) at Looma, Western Australia. The English version is a slightly modified version of her original (1978) translation into English. This version of the story was agreed upon at the Nyikina Cultural Workshops held in March 2004, to be included in the booklet Mandajarra Nyikina: Cultural resources for Nyikina language and culture course a printed document (Dynamic Digital Print, Tweed Heads, NSW) which is part of the materials produced from the workshop. At the workshop, a Nyikina elder gave his permission for his father's story to be recorded, written down and included in this package. 'Narrangkani' is an adverb or time word meaning 'in the Beginning' and different from bookarrarra which is a noun.

${ }^{19}$ Roe, 1983, vii.
} 
Muecke's equation of a trustori (an Aboriginal true story) with 'our word legend' in the above quotation problematic - presumably Muecke is referring to a nonindigenous audience, and is creating a contrast between 'us' (people like Muecke) and 'them' (indigenous, Nyikina people, who use the term trustori). If the reader, indigenous or non-indigenous, can imagine the events of a trustori to be a true story then it is not a legend. A legend needs to be in a more distant past. Some authors and Indigenous people, for example Jean A. Ellis and Oodgeroo Noonuccal, prefer to use the term 'legend' instead of Dreamtime myth. ${ }^{20}$ Such distinction may be due to the conception that the Dreamtime is the beginning of history. From an Aboriginal perspective, the Dreamtime cannot be locked into a time and space, but is 'everywhen'. ${ }^{21}$ Other authors, for example Janet Mathews and Johanna Lambert in Wise Women of the Dreamtime, Aboriginal Tales of Ancestral Powers, use the term 'myth.' Lambert argues that:

Dreamtime stories are myths when one considers the mythic process as a mode of perceiving, experiencing, and expressing the relationships between our visible world and the invisible forces, patterns, and intelligence that have existed since before the world's creation. $^{22}$

Lambert uses the purpose or essence of myth in a classical sense to explain why she calls Australian Aboriginal Dreamtime narratives myths. Hence in a sense both early Greek poetry of Hesiod and Nyikina culture used narrative from the earliest times of existence to explain the inexplicable forces in the world. Some myths provide explanations of forces and universals. The following discussion attempts to define bookarrarra - the Nyikina concept of the Dreamtime.

\footnotetext{
${ }^{20}$ Noonuccal, 1992, 5.

${ }^{21}$ Stanner, 1979, 28. Everywhen is an an anthropological term coined by Stanner to describe the sense of a concept, story or being as being existent across all time ubiquitously. See Plate 2 for a visual interpretation of bookarrarra being everywhen as it permeates out from the centre and is limitless. ${ }^{22}$ Lambert in Parker, 1993, 5-6.
} 


\section{Bookarrarra: a Nyikina approach to myth}

The notion of a timeline cannot be reconciled with an Aboriginal concept of the Dreamtime. Putting the 'time' in Dreamtime is a western concern. For example, Erich Kolig writes:

Some Aboriginal philosophers structure the Dreamtime now in a primordial, basic creative epoch in which animal-like creatures such as the sacred Rainbow Serpent roamed the earth, and a later, historical era of man. ${ }^{23}$

Kolig chronologically separates the transitional beings of the Dreamtime from the mortal humans of today. One may also question if his Aboriginal philosophers were actually Aboriginal, or if they were non-Aboriginal people trying to put Aboriginal concepts into western frameworks. ${ }^{24}$ As mentioned above, the Dreamtime, or bookarrarra, ${ }^{25}$ is not confined to the ancient past, but is everywhen. ${ }^{26}$ Bookarrarra shaped the way things are today and forever. The landscape which was created before humans came about is still our landscape today. A Nyikina concept of bookarrarra at least, tries to communicate that it never stopped. Yoongoorrookoo, the giant serpent still lives in the Fitzroy River, right now. When considering how to visually represent a Nyikina concept of time, the figure shown in Plate 2 is the outcome. Bookarrarra permeates through from the centre of the diagram out past the twenty-first century. The inner circle represents the time when the landscape was being formed, a time without humans. The next layer is when the first humans like Woonyoomboo lived, still creating the landscape. The 'History' layer is an unspecified stretch of time after

\footnotetext{
${ }^{23}$ Kolig, 1996, 277.

${ }^{24}$ As I was doing at the outset of my research. I now have a Nyikina framework for approaching myth and storytelling concepts, and a Classical Studies framework for assessing Mediterranean, for example Minoan, Greek, and Etruscan, approaches to myth.

${ }^{25}$ I would like to thank Dr Bronwyn Stokes for pointing out that languages related to Nyikina have similar terms. Nyulnyul speakers pronounce their word for the Dreamtime 'bookarrikarra', Upper Nyikina pronounces it 'bookarrakarra'. For the sake of consistency, (and my family associations with Lower Nyikina) I have used bookarrarra to refer to what I have generally termed Nyikina concepts of Dreamtime, and not differentiated between Upper Nyikina and Lower Nyikina dialect groups.

${ }^{26}$ Bookarrarra is the agreed spelling for 'Bugaregara' as determined by linguists, including Hattersley, working with Nyikina people in 2000 at Fitzroy Crossing.
} 
the era of the first humans, including colonisation and trustori, and the outside ring marks present day, the twenty-first century.

The connection between the spirit world, booroo, birds and animals is perceived as a reality in a contemporary Nyikina context, not a myth. For this reason, instead of using the term myth, the terms, 'traditional narrative' and bookarrarra refer to the stories traditionally called myths. Nyikina traditional narratives, however, cannot fit into a framework of myth, history, legend and story bounded by the Western European concept of a timeline. Relinquishing the classical frameworks of definitions is necessary to fully appreciate the fluid relationship between traditional and contemporary Nyikina culture.

\section{How oral traditions are supported by a hunter-gatherer-fisher culture}

Archaeological practices now maintain that the culture of the hunter-gatherer-fisher is more complex than originally thought in regards to 'socio-cultural factors, demography, and economy. ${ }^{27}$ Social archaeology supports the idea that the traditional hunter-gatherer-fisher economy of indigenous Australians, such as Nyikina, reflects bookarrarra practices, by walking the land in the footsteps of ancestors. $^{28}$ Bookarrarra narratives tell the stories of Nyikina ancestors which were interchangeably human, animal and spirit. Traditional narratives are often about discovery and the physical creation of the land by travelling through the land, encountering an animal for the first time and naming it or making rivers and hills with their bodies or footprints.

\footnotetext{
${ }^{27}$ Lourandos, 1997, 1.

${ }^{28}$ David, Baker and McNiven (eds.), 2006, 126.
} 
These traditional narratives are also the foundations of Nyikina culture, with the ancestor or hero finding a wife, learning about cooking food, and dreaming the conception of a child. ${ }^{29}$ Ancient knowledge about reading the land was passed down through oral storytelling, for example understanding weather patterns and remembering the movements of animals. ${ }^{30}$ Nyikina hunter-gatherer-fishers knew what to eat, how to cook it, and when it would be in season. As a result, Nyikina people survived in harmony with their booroo before colonisation and 'never attempted to alter their tribal landscape' in a permanent sense, ${ }^{31}$ for although they burnt the landscape, this was part of a renewal cycle which was in harmony with nature: Nyikina people looked after the land and the land looked after Nyikina people. $^{32}$ When Australia began to be colonised by Europeans the indigenous style of land management was not recognised and the country was labelled Terra Nullius (vacant land) because as far as colonisers could tell the indigenous inhabitants of Australia were not (ab)using it for gain or profit and therefore that land was available for settlers. ${ }^{33}$ The British colonisers of Australia were entrenched in the classical ideology that if the land was not being cultivated, or marked out with boundaries, that it was not 'owned' or 'property.' 34

The nature of Aboriginal Australian hunter-gatherer-fisher societies is the very thing that sustains an oral traditional narrative. Nyikina culture is specific to the

\footnotetext{
${ }^{29}$ Nangan and Edwards, 1976, for Nyikina and Garadjeri myths. Capell, 1950, for more Garadjeri myths.

${ }^{30}$ This skill is comparable to Etruscan augurs using the Libri Tagetici to learn how to read lighting strikes, thunder rumbles, and flight patterns of birds.

${ }^{31}$ Cowan, 1994, 17.

${ }^{32}$ By periodically using controlled fires to clear booroo, Nyikina people encouraged kangaroos to scratch in the ground, thus making the indentations that would catch the grass seeds when the wind blew in 'the windy time' and there would be feed for the animals, which they would need to hunt for their own survival; Uncle Harry Watson (Jarlmadangah Burru), via. pers.com with Colleen Hattersley, 5/11/2008.

${ }^{33}$ Banner, 2005, 95.

${ }^{34}$ Banner, 2005, 101.
} 
Kimberley region in northern Western Australia. The culture is part of the environment, and it works with the weather, seasonal changes, animals and landforms that inhabit the Kimberley. Settlement in a single area was against the Nyikina worldview, their bookarrarra. Moving within their environment meant that large numbers in a group were not viable. Leaving permanent marks on the landscape was not necessary. Instead, stories, songs, and dances which resided in the landscape revered ancestors and early beings. The importance of nganka (spoken language) as a part of Nyikina identity is comparable to the Greek respect for oral rhetoric, which continued to be valued more highly than writing into Classical society. Though the Greeks had writing, their long ancient revered traditions of oral performance, storytelling, and argument were sustained alongside the burgeoning use of writing. ${ }^{35}$

Art was painted or scarred on bodies, made with feathers or carved on bark. All these media are impermanent. Rock art is perhaps the only lasting visual representation of Nyikina art from pre-colonisation, though the rock art was not developed to the sophisticated degree of that belonging to other language groups. ${ }^{36}$ This may be due to the significance Nyikina culture and mythology places on animal ancestors. Worroran, Ngarinyin and Wunambal images of the Wandjina (spirit beings), dominant in Kimberley rock art, are primarily:

$\ldots$ in the northern and western regions, and in the southern and eastern regions animal ancestral beings replace them. Myths and paintings of pythons are common, and the python myths run continuously into Northern Territory to link the myths recorded there by Berndt (1951). The pythons have attributed to them powers similar to those of the Wandjina, and the ancestral pythons may transform themselves into rainbows or whirlpools. ${ }^{37}$

\footnotetext{
${ }^{35}$ R. Thomas, 1992, 3.

${ }^{36}$ Exactly why Nyikina rock paintings did not achieve the sense of monumentality portrayed by other language groups is not certain. Indeed, further research is needed in the field of specific Nyikina art to identify possible reasons. One possibility is proposed by Crawford (1972), below.

${ }^{37}$ Crawford, 1972, 304. Wilson, 2006, 16-17.
} 
Yoongoorrookoo is such an important Nyikina figure that the Mardoowarra is central and rock art, or cave painting is liminal.

The concept of authority in Nyikina culture applies to people who have the relevant skills, knowledge, and birth. There is men's business and women's business. There are also degrees of knowledge. For example, a child's version of a particular traditional story has meanings that are relevant to the age of the audience. ${ }^{38}$ The same traditional story has details added when the children become young adults. Likewise, the full adult version is given after they reach the maturity to appreciate and respect the meaning of the story. And if as adults the audience display the right attributes and qualities, then they can be taught special skills by elders and jalngangoorroo (medicine/magic people) in order to pass knowledge and culture on to the next generation. However, in the twenty-first century, certain cultural frameworks have been isolated to remote Nyikina communities. The hunter-gatherer-fisher lifestyle is no longer fully followed; even those who live in communities like Noonkanbah and Jarlmadangah Burru live in houses and buy food at a shop. But when ceremonies are held on booroo, traditional rules still apply. ${ }^{39}$

\section{Literature}

There is much written on indigenous Australian culture and traditional narratives in general, but specific research about Nyikina people is a small part of this panindigenous body of knowledge. Research done by indigenous people themselves, and

\footnotetext{
${ }^{38}$ Berndt, 1985, 94.

${ }^{39}$ Jarlmadangah Burru has even created small protocol books to help visitors understand the cultural framework should they be in the community at time of initiations or funerals, for example: Balkayi and Booroo, by Watson, Johnene et al, JBAC, 2000.
} 
indigenist researchers, (those incorporating indigenous paradigms into their methodologies and applying respect, reciprocity and responsibility to their work) occurs even less often. ${ }^{40}$ The colonial historical, ethnographical and anthropological research of Australian Aborigines can be condescending in tone, over-generalised and misinformed, due to lack of ethical methodologies. ${ }^{41}$ Thus, some research paradigms have been seen by indigenous communities as intrusive and detrimental. As an indigenist researcher, my strategies of inquiry and methods must encourage harmonious relations between researchers to facilitate results that all parties find appropriate, and that are valuable for readers.

\section{Bookarrarra, booroo and nganka: myth, land and language ${ }^{42}$}

The oral tradition of passing on historical knowledge is the oldest type of literature in Australia and in the world. ${ }^{43}$ Nganka (spoken language) is an essential aspect of culture and therefore cultural capital. Before a symbology, alphabet, or script develops within a culture there is first oral communication between people. Bookarrarra, nganka, and booroo are all part of Nyikina Aboriginal identity or Aboriginality. There are two kinds of identity - community and personal identity. A strong sense of community identity is the base for personal identity. The Overcoming Indigenous Disadvantages report found that:

In addition to cultural and economic benefits, access to traditional lands has important social benefits. Along with maintaining a "being

\footnotetext{
${ }^{40}$ Rigney, 1996.

${ }^{41}$ For historian examples: E. Kolig, the Berndts, E.M. Curr, C.M.H. Clark, K Windschuttle. To be fair, some authors felt they were working with the best interests of Aboriginal people by recording their 'dying culture'. Their cultural and social beliefs will often shine through their writings despite attempts at scientific treatment of subject matter, and in reading their analyses one realises that their target audiences were not Aboriginal people, but other Europeans. See also, Edmonds and Furphy (2006).

${ }^{42}$ As well as nganka, jabal is a possible Nyikina word suggested by a secondary source that means 'story'. It could be that some speakers have it, but it was not recognised by a Nyikina Inc. coresearcher, and life long Nyikina speaker, when I made personal enquiries in July 2009.

${ }^{43}$ Mudrooroo, 1997, 7.
} 
in country" (or "sense-of-place") connection, substantial health benefits can flow from maintaining access for fishing, hunting and gathering activities, both in terms of physical activity and dietary implications. $^{44}$

The "being in country" feeling is one of rightness, belonging and identifying with the community on that land. Reclaiming land through Native Title and rewriting Aboriginal Australian history are two ways in which communities can reinforce Aboriginality. A conference held in Broome entitled The Kimberley: Our Place, Our Future produced a report in 1998 aimed at finding ways to develop the Kimberley economy without harming the cultural, social, and environmental capital of the region. The conference featured representatives from the Kimberley and government departments such as Aboriginal and Torres Strait Islander Commission (ATSIC), and National Native Title Tribunal (NNTT). Marty Sibosado gave an account of Kimberley history, which began in the 1880 s, 118 years after the 'discovery' of Australia, ${ }^{45}$ when the sheep and cattle stations were built (with Aboriginal labour) in the region. The pearling industry (collecting and processing pearls) in Broome was also a part of this settlement.

Later, when the Award wage was introduced in about 1968, Aboriginal workers had to leave the stations that many had grown up on because station bosses could not or would not pay them the government regulated wage for their labour. As a result workers moved to missions like Beagle Bay, Lombadina, or Bidyadanga, or towns like Broome and Fitzroy Crossing. ${ }^{46}$ In the mid-1970s people started getting traditional land back in the West Kimberley for the Aboriginal communities. ${ }^{47}$ In 1988 these communities were listed in Kimberley Aboriginal Communities according

\footnotetext{
${ }^{44}$ DIA, 2005, 182.

${ }^{45}$ Kimberley Land Council (KLC), 1998, 55.

${ }^{46}$ KLC, 1998, 56.

${ }^{47}$ KLC, 1998, 57.
} 
to their region in the Kimberley. In the Derby area ten communities (from twentyseven) listed Nyikina as their language. ${ }^{48}$ Other communities that listed Nyikina as their language were Kalyeeda and Noonkanbah in the Fitzroy Crossing area, ${ }^{49}$ Nillir Irbanjin (One Mile Reserve) in Broome, ${ }^{50}$ and Moordyal in the Dampier Peninsular area. $^{51}$ The map in Plate 1 shows the locations of Nyikina places on Nyikina land inhabited by Nyikina people. ${ }^{52}$

Aboriginal people have individual language groups which connect them to their land, through bookarrarra. Bookarrarra, land, language, and people are interrelated in an indigenous world-view. Nyikina narratives from the northwest Kimberley, however, are not be shared with Bundjalung people of northern New South Wales. Linguists have connected most Aboriginal languages of Australia through structure and grammar under the term Pama-Nyungan. However, languages from tropical regions of north Western Australia and the northwest of the Northern Territory are different and called non-Pama-Nyungan languages [Plate 4]. ${ }^{53}$ The Nyikina language is spoken by people in the Kimberley, in north Western Australia and belongs to the Nyulnyulan language group making it a non-Pama-Nyungan language [Plate 5]. The Nyikina language encompasses the area east of Broome and south of Derby and includes a length of the Fitzroy River from the mouth in King Sound down to Noonkanbah. The presence of Nyikina language and places with Nyikina names marks this area as traditional Nyikina booroo [Plate 1].

\footnotetext{
48 CNulungu Catholic College, 1988, 20-24.

49 (C) Nulungu Catholic College, 1988, 28, 30.

50 CNulungu Catholic College, 1988, 10.

${ }^{51}$ CNulungu Catholic College, 1988, 16.

${ }^{52}$ Latest information from August 2007.

${ }^{53}$ This may be due to a migratory influx from Indonesia predating European colonisation. See Walsh \& Yallop (eds.), 1993, 16, 17.
} 
The Nyulnyul language was 'studied more intensively than any other Kimberley languages in the early decades of the century' largely because of the Beagle Bay Mission Fathers. ${ }^{54}$ There are ten languages in the Nyulnyulan family, which in 1984, Hudson \& McConvell divided into two language groups, Bardi (in the West) and Nyikina (in the East). Bardi was then divided into dialects: Bardi, Jawi, Nyulnyul, Jabirrjabirr, Nimanburru, Ngumbarl and Jukun; and Nyikina was divided into: Nyikina, Warrwa and Yawuru. ${ }^{55}$ Linguists and anthropologists from Arthur Capell, who classified the ten languages of the Nyulnyulan family in the 1940s, to Colleen Hattersley in the present day, have worked on Nyikina language. The Nyikina non-profit organisation, Madjulla Inc., worked with Hattersley in 2003 and 2004 to produce Mandajarra Nyikina: Cultural resources for Nyikina language and culture courses. ${ }^{56}$ It is fortunate to have such linguistic and anthropological research among the sources for review, as pieces of cultural information are contained within.

One must note that the linguistic terms 'language' and 'dialect' can make matters confusing when discussing Nyikina; it belongs to the Nyulnyulan family but has Warrwa and Yawuru dialects within it. Nyikina can also be divided into Upper Nyikina and Lower Nyikina dialect groups, an internal classification which geographically locates the speakers. There are the Yimardoowarra people of the Lower Fitzroy River (Nyikina name for the river is Mardoowarra) and the Korabye Korabye people of the Upper Region of the Mardoowarra as far up the river as Noonkanbah. I agree with McGregor when he suggests that one should do away with

\footnotetext{
${ }^{54}$ McGregor, 1988, 50.

${ }^{55}$ McGregor, 1988, 49.

${ }^{56}$ Mandajarra Nyikina: Cultural resources for Nyikina language and culture courses is a printed document (Dynamic Digital Print, Tweed Heads, NSW) which was the product of Nyikina Cultural Workshops held in March 2004. Written by Colleen Hattersley, Lucy Marshall, and Rosemary McKenry, and using the Nyikina Historical Wordlist @ B Bronwyn Stokes 1980-2004 under license.
} 
using the term 'dialect' in regard to Kimberley languages, since using the term 'dialect' may make the language seem culturally inferior to other languages, especially when language names refer to booroo and communities. ${ }^{57}$ As a result Nyulnyul, Nyikina and Yawuru are all fully languages in their own right, not dialects.

Language is extremely important for cultural identity, ${ }^{58}$ as R. Bowden and B Bunbury show:

This is what we tell the young people. You have to know your language because you'll never be able to learn your Dreaming and if you don't know your Dreaming you can't identify where you belong. If you don't identify where you belong you might as well say you're dead. $^{59}$

Ancestors from Nyikina bookarrarra gave the language to the places where they travelled and lived, ultimately bestowing it on the humans who later inhabited the area. Studies from non-Kimberley people have narratives which explain that they speak their language for the same reason. ${ }^{60}$ Territory and language are inextricably linked and connected to each other through bookarrarra, booroo and identity. Rather than existing side by side, or overlapping in their importance within Aboriginal culture, they are interwoven, as R. Berndt and C. Berndt acknowledge in the introduction to The Speaking Land: Myth and Story in Aboriginal Australia, "No traditional Aboriginal 'story' was told without reference to the land, or a specific stretch of country where the incidents it narrates were believed to have taken place." ${ }^{61}$ Speaking the Nyikina language of the booroo keeps alive a tradition rooted in bookarrarra and demonstrates a connection to the land.

\footnotetext{
${ }^{57}$ McGregor, 1988, 3.

${ }^{58}$ Schmidt, 1990, 22.

${ }^{59}$ Bowden, R and Bunbury, B., 1990, 32-33.

${ }^{60}$ Walsh \& Yallop (Eds.), 1993, 200, 204.

${ }^{61}$ Berndt \& Berndt, 1989, 5.
} 


\section{Language and colonisation.}

Whenever two cultures with different languages interact with each other there is a need for communication and a simple speech emerges, called pidgin. ${ }^{62}$ Words from both languages are used with a prevalence of words from the dominant language. Pidgin is used only for basic communication; if only necessary for trade then it will remain simplistic, but with prolonged contact a creole develops. ${ }^{63}$ West Australian Kriol is English based, but prior to European contact Aboriginal people in the North and North West of Australia had contact with Indonesia and developed a creole with Sulawesi Macassan traders. Different Kriol languages are specific to different communities; Ngukurr Kriol is different from Fitzroy Kriol (and is written differently). ${ }^{64}$ Colonisation and the displacement of indigenous people from their kandri into new communities forced another linguistic innovation, Aboriginal lingua franca, where various indigenous languages combined to make a new language. ${ }^{65}$

In 1870, Europeans established a settlement in Darwin and the next thirty years saw a rapid expansion of the community with cattle stations and the gold rush. The lingua franca that developed was called Northern Territory Pidgin English and served the large numbers of European and Chinese immigrating into Aboriginal land. A Mission was established at Roper River (Ngukurr) 'where creolisation began to occur shortly after 1908.' The Aboriginal population was threatened to the point of near annihilation, but was saved by an Anglican mission station. ${ }^{66}$ Eight different language groups needed to find a way to teach the Aboriginal children at the school

\footnotetext{
${ }^{62}$ Although sometimes the development of pidgin is overcome by translators or a larger group of bilingual speakers.

${ }^{63}$ Walsh \& Yallop (eds.), 1993, 6. Creole is a broad term for a merged or created dialect/language that is more developed than pidgin. Kriol is the name of the Aboriginal-English creole discussed here.

${ }^{64}$ I would like to thank Colleen Hattersley for clarifying this point.

${ }^{65}$ Schmidt, 1990, 12-13.

${ }^{66}$ Walsh \& Yallop (eds.), 1993, 147-8.
} 
and, over the years, it was these children who developed the creole into the main language of the community: Kriol. The following is an example of Ngukurr Kriol:

La Ngukurr melabat garrim eitbala langgus. Wen naja traib wandim tok la dis traib, dei tok mijalb garrim Kriol. Jad impotan langgus im Kriol. Olabat gan sabi bla wanim olabat toktok.

At Ngukurr, we have eight languages. When another tribe wants to talk to this tribe, they talk to each other in Kriol. The important language is Kriol. They can all understand whatever they want to discuss. $^{67}$

According to Annette Schmidt, religious institutes were sympathetic to preserving indigenous languages for communication and for making a historical record of a dying culture, since the extinction of Aboriginal Australians was an expected outcome, and was exacerbated by colonial efforts to eradicate indigenous culture as part of an assimilation scheme. ${ }^{68}$ However, the reality was that many missionaries studied language as an academic pursuit while they punished actual speakers for using their own languages. The mission view seems to have been that language was acceptable and exotic among the elders, but abhorrent in the children who needed a 'proper' education. The pastoralists actually encouraged indigenous language and culture because it meant they had workers who knew the land. ${ }^{69}$

Language is an identifier for a culture, and 'once a group has lost its language, it will generally lose its separate identity and will, within a few generations, be indistinguishably assimilated into another, more dominant, political group. ${ }^{, 70}$ Creoles have been described as 'replacing' and 'causing the demise of other Aboriginal languages' by Schmidt in Loss of Australia's Aboriginal Language Heritage. ${ }^{71}$ This

\footnotetext{
${ }^{67}$ Walsh \& Yallop (eds.), 1993, 149.

${ }^{68}$ Schmidt, 1990, 19.

${ }^{69}$ Marshall discusses this in Reflections of a Kimberley Woman, (2004).

${ }^{70}$ Dixon, 1980, 79.

${ }^{71}$ Schmidt, 1990, 9.
} 
report classes Nyikina as a severely threatened language with the number of speakers estimated to be between twenty to fifty speakers in 1990 when the report was published. In 2005 The National Indigenous Languages Survey (NILS) Report estimated that there were 20 Nyikina speakers in the 40+ age group, which classed Nyikina as a 'severely endangered' language. ${ }^{72}$ The grading was based on "somewhat unreliable' evidence given that the last survey was Schmidt's in $1990 .^{73}$ The reliability of such gradings can also be compromised by information given by respondents and by 'people using different criteria for speakerhood'. ${ }^{74}$ Communities may class people who 'identify' with the language, or people who use certain words as speakers, and this meant that NILS had to create various grading systems for the survey respondents to use, such as the Reliability Index. ${ }^{75}$

The Nyikina language courses run by Nyikina Inc. aim to keep the Nyikina language alive so as to hold onto Nyikina identity for Nyikina people and their families. The colonisation process separated families, removed people from their booroo and emphasised a European way of life in society, education, politics and religion, as if an Aboriginal way was wrong. ${ }^{76}$ Since urbanisation, the growth of the media and the onset of globalisation have also played a part in de-emphasising indigenous identity. However, since the 1980s there has been revitalisation of

\footnotetext{
${ }^{72}$ The National Indigenous Languages Survey (NILS) Report, 2005, Table F.3 Number of speakers of Australian Indigenous languages (various surveys), p219. The measures of endangered languages have been developed by researchers studying North American, European and African languages where settled groups numbered in their thousands, and 500 speakers is considered danger level. In Australia, only a few exceptional groups have ever numbered over 500, so on the global scale the languages have always been 'endangered'. A score of 20 speakers is not good, but in Australia, a score of 100 speakers would be healthy whereas in global terms it would be practically moribund. I would like to thank Colleen Hattersley for pointing this out and also for reminding me that this is rarely taken into account when the official figures are presented.

${ }^{73}$ The NILS Report, 2005, 189.

${ }^{74}$ The NILS Report, 2005, 128.

${ }^{75}$ The NILS Report, 2005, 127-128.

${ }^{76}$ Schmidt, 1990, 18.
} 
Aboriginal languages in Aboriginal communities in an effort to rectify the damage done to Aboriginal language heritage. Schmidt describes the conditions necessary for language survival thus:

This recent resurgence in Aboriginal language pride is conducive to increased language loyalty and use; the survival of Aboriginal languages (or for that matter any language) ultimately depends on how speakers perceive them - their estimation of the social and political value of the languages. In effect, language pride and language use provide the lifeblood to a language. ${ }^{77}$

Young Nyikina people have grown up with role models who had their identity stripped from them by missionaries and station bosses. Reinstalling a sense of pride for Nyikina culture and heritage through use of their language is a step towards positive futures for themselves as individuals and as part of their Aboriginal Nyikina community.

\section{Nyikina attitudes towards writing}

Nyikina is a severely endangered language, as seen in the NILS report, and the community itself has taken it upon themselves to revitalise this crucial part of their cultural capital. Nyikina Inc. is especially instrumental in hiring linguists to work with community members so that they (community members) are involved in the creation of language resources. These include the first official Nyikina-English dictionary, courses for community members - both Nyikina and non-Nyikina - to learn basic speech, and making resources for young school children in booroo schools so that the knowledge remains alive at the grass roots level.

Indigenous communities generally are producing bilingual books with both English and Aboriginal text as educational school resources, for example, Wanyjina:

\footnotetext{
${ }^{77}$ Schmidt, 1990, 21.
} 
Rain-maker told by Mary Pandilo and transcribed by Margaret Sefton. ${ }^{78}$ The story is set out with one paragraph per page, the approximate English translation at the top of the page and Kwini/Belaa language translation underneath. ${ }^{79}$ Key phrases are listed in a coloured box to the right of the page in both languages, for children to build up a vocabulary. The whole story is told at the end of the book in English, along with a pronunciation guide for Kwini/Belaa. ${ }^{80}$ Pandilo and Sefton have also produced other books such as Jilinya: Spirit woman from the sea and Wur bûrrûngkeima, Germanyyanga: Two men who flew from Germany for children. ${ }^{81}$ An example of Kriol publication is Wakwak en imiyu (Crow and Emu) by Judy Galmur. ${ }^{82}$ Resources like this are very important for the revitalisation of Aboriginal languages in Australia, especially among children in their formative years, and highlight the fact that each community or language group must be responsible for producing the literature of their language themselves, as no-one else knows the language like they do. In the Kimberley, Nyikina elders have also been sharing their stories with non-Nyikina authors, so that they can be written down and published for later generations to have, should they not pass on their knowledge in time.

Included among this knowledge of reading the land and bookarrarra stories are accounts of oral histories which are being written down for a range of reasons. Firstly they are Nyikina historical archives; secondly, they give personal indigenous accounts of colonisation in the Kimberley; and often there is a third reason: letting your family, Australia and the world know how you and your culture have been affected by colonisation is brave, therapeutic and cathartic.

\footnotetext{
${ }^{78}$ Pandilo, 2003.

${ }^{79}$ Pandilo, 2003, 2.

${ }^{80}$ Pandilo, 2003, 18-19.

${ }^{81}$ Pandilo, 2003a. Pandilo, 2003b.

${ }^{82}$ Galmur, 1991.
} 
Indigenous control is an important aspect to rewriting the Aboriginal history and culture in Australia and for 'owning' the content written. Julian Rappaport writes that 'The ability to tell one's story, and to have access to and influence over collective stories, is a powerful resource. ${ }^{, 83}$ Such is the cultural capital that Nyikina elders hold. The power to tell Nyikina narratives in one's own words, and not have it edited into the mould of western literature is a step towards creating positive community and personal identities; 'there is a wealth of traditional oral literature, for contemporary Aboriginal people to safeguard and draw on in their own work in creating their own identity. ${ }^{84}$

It is important to note that Aboriginal literature and language revitalisation are growing together. The rise in Aboriginal literature need not impede the learning of the spoken language. Traditional stories especially rely on repetitive oral storytelling to keep the essence of the meaning alive. Catherine Berndt argues that Aboriginal stories can be difficult to capture in writing or even on audio tape, because the visual effect of gestures and facial expressions cannot be seen. Berndt's paper on children's stories and the levels of knowledge they gained from hearing them revealed that along with history, morals, and social organisations, children also learned the art of storytelling. ${ }^{85}$

There are arguments for and against written forms of Aboriginal oral literature. For example, Wayne Atkinson is in favour of written Aboriginal history, as he believes that it complements oral history and is important for preserving oral accounts. However, Kevin Carmody takes the view that indigenous history must be

\footnotetext{
${ }^{83}$ Rappaport, 1995, n5, 801.

${ }^{84}$ Davis and Hodge (eds.), 1985, 5.

${ }^{85}$ Berndt, 1985, 96.
} 
'history by the people for the people' and maintain the values of oral tradition. ${ }^{86}$ Again the issue is one of control. Penny Taylor proposes that:

Writing does not replace storytelling...some people prefer to keep certain things in the oral tradition and not write them down. This makes sure they remain the property of Aboriginal and Torres Strait Islander people and stay close to the old ways of passing on knowledge. This should be respected. ${ }^{87}$

There is criticism against using digital audio equipment when interviewing people in the course of recording oral history. Some people may think that the experiences of ordinary people are not history but useless information; however, it is opinions such as these, held by people in positions of power, which allow the history of disadvantaged people to be misrepresented or ignored. Oral history validates the experiences of indigenous Australians. Recording oral accounts not only empowers minorities, but also creates resources for speech and language, which are historical in themselves. $^{88}$

When Aboriginal stories began to be studied and recorded by linguists and anthropologists in the 1960s and early 1970s they were published for a predominantly white audience and 'the uniqueness of the literature and authentic use of language [was] lost in translation. ${ }^{, 89}$ For example, the Mission Fathers in Beagle Bay were instrumental in the study of Nyulnyulan languages, and Father Francis Heugel at Beagle Bay collected Butcher Joe Nangan's stories in Nyikina language. ${ }^{90}$ In mid1976 Nangan co-wrote his book of Nyikina and Garadjeri traditional stories with Hugh Edwards called Joe Nangan's Dreaming. Nangan had tried on different occasions to have the legends recorded, worried that the effects of colonisation were

\footnotetext{
86 Taylor, 1992, 14.

${ }^{87}$ Taylor, 1992, 11.

${ }^{88}$ Robertson, 2000, 2.

${ }^{89}$ Mudrooroo, 1997, 8.

${ }^{90}$ Berndt \& Berndt, 1989, 13. Nangan and Edwards, 1976, 11.
} 
hindering the transference of cultural capital, and that the stories would be forgotten. ${ }^{91}$ Edwards was a non-fiction author and the style he used to translate Nangan's work reads very much like a Grimm Brothers fairytale. This was, however, the mode of presenting Aboriginal literature at the time, a mode that later Aboriginal authors have criticised as unsuitable for Aboriginal traditional storytelling. Mudrooroo calls Edwards' account of Nangan's narratives 'misappropriation' yet acknowledges Edwards' foreword statement: 'I regret that Joe could not tell the stories himself in his own way. ${ }^{, 92}$

Paddy Roe, another Nyikina elder, told his stories and traditional narratives to Stephen Muecke, who edited them with translations from the 1960s and 1970s in mind. Roe's book, Gularabulu, is an example of Aboriginal English translation. ${ }^{93}$ Preceding the stories themselves, Muecke writes an insightful introduction on his process of editing and then explains his transcription methods and the nuances of Aboriginal English to aid the reader, for example:

Kimberley Aboriginal English often does not distinguish gender in pronouns (females are referred to as "he" or "him") and at the same time introduces dual pronouns which may explicitly include or exclude the person speaking or the person being spoken to. ${ }^{94}$

Some features, such as the use of repetition to highlight the importance of a subject, or even to make sure the audience is listening, are intentional grammatical effects used by a storyteller. These effects can seem confusing to an unfamiliar audience and may slow down the reading of the text. Muecke argues in his introduction that Aboriginal traditional narratives in particular 'might be better presented as

\footnotetext{
91 Nangan and Edwards, 1976, 10.

${ }^{92}$ Mudrooroo, 1997, 141.

${ }^{93}$ Roe, 1983, iv.

${ }^{94}$ Roe, 1983, xi.
} 
translations of the Aboriginal language in which they would have been told. ${ }^{95}$ I agree with this argument for the purposes of Nyikina cultural capital, but few could read Nyikina at the time - since it is not historically a written language, and because levels of English literacy among Nyikina speakers varied. Making videos and interactive computer versions of stories and information may be a solution to the literacy problem because, although whole generations have missed out on developing literacy skills, there is widespread ownership and use of electronic devices such as DVD players, tape decks, CD players and televisions in the Nyikina community. In this way both languages can be equally represented.

As discussed above, English versions of indigenous traditional narratives may not be the best way to represent the content. The non-indigenous editors of Joe Nangan's Dreaming and Gularabulu both suggested that Standard English translations are inadequate. ${ }^{96}$ Edwards lamented that Nangan could not write the stories himself, and Muecke would prefer to see traditional narratives from bookarrarra written in their original Aboriginal language. However, in The Speaking Land, the Berndts make reference to Nangan's stories that are in Nyikina waiting to be translated into "what Nangan himself prefers as their published medium - standard English - to reach a larger range of readers than could the Aboriginal English employed by his friend Paddy Roe. ${ }^{97}$ The Berndts also wanted to include local language translations in The Speaking Land but they lament that it would have made the book too long. ${ }^{98}$ Standard English edits out storytelling devices, such as repetitions and pauses, and attempts to make the text more readable. When it comes

\footnotetext{
${ }^{95}$ Roe, 1983, iv.

${ }^{96}$ Of course, all translations are inadequate in some way, since languages are different, with different traditions and words in literature evoke different things for different people.

${ }^{97}$ Berndt \& Berndt, 1989, 13.

${ }^{98}$ Berndt \& Berndt, 1989, 7.
} 
to written text, readability is crucial for maintaining the focus of the reader, but Muecke's less interventionist method of Aboriginal English transcription makes readers feel more like they were present for Roe's storytelling. In Telling it like it is Taylor writes,

Some historians think you should include all the ums...ahs...and repetitions. Others think writing exactly as the tape was spoken is a subtle form of racism, and make the speaker seem 'uneducated' or 'exotic and different.' 99

This may seem extreme to some people, but indigenous people have been objectified and misrepresented in historical texts. Hence, consultation with participants and coresearchers is highly important in this (and any) study involving indigenous people.

\section{Conclusions}

Colonisation is a process which creates massive upheaval within indigenous cultures whether through assimilation, integration, or decimation. Because Nyikina culture is still trying to survive despite the negative effects of colonisation, the modern Nyikina community has a very strong reason to revitalise their language, since it is one of the most important aspects of their cultural capital. If language is strong, then the culture is strong, because language is a traditional identifier and way of communicating Nyikina bookarrarra which belongs to the oral tradition of storytelling. Since Nyikina people did not invent a script for their language, they have used the Roman alphabet to phonemically write their words so that the oral tradition can be preserved in written literature. Such is the practicality of rescue archaeology that even though there are some community members who disapprove of removing bookarrarra from its oral context, the majority of the community realise that it is a necessary step in the process of language revitalisation.

\footnotetext{
${ }^{99}$ Taylor, 1992, 69.
} 
The following chapter will explore the rise of sedentism, which was not practised by the Nyikina people until European colonisation. We will see how the direct link between natural environment and sedentism can influence the evolution of the culture in question, and how it supports the transition from oral to written literature. 


\section{Glossary of Nyikina terms*}

Bookarrarra: The Nyikina name for the Aboriginal concept of Dreamtime, which is the time when spirit creatures and animal/human beings created the landscape of Australia. The term can also refer to the mythology of Nyikina people. Bookarrarra is the specific Nyikina term - other language groups have different names for Dreamtime.

Booroo: Nyikina term for sacred land, other language groups have different terms. It is also used to mean sand or dirt.

Ibala: Father

Jalngangoorroo: Nyikina term for medicine man, other language groups have different terms.

Majala: Fresh water mangrove plant (Barringtonia acutangula).

Mardoowarra: The Nyikina name for the Fitzroy River

Nganka: Language, talking.

Ngarrangkani: A term that can be used interchangeably with bookarrarra, but has the more specific translation of 'the Beginning'.

Nyikina: The name of an Aboriginal group of people living in the Kimberley region of Western Australia, also the name of the language spoken by the group.

Rai: Spirit, spirit creature.

Wanjarra: Sand bank on the river side.

Woo: "Yes" or "Here"; verbal acknowledgment.

Woonyoomboo: The first Nyikina man, who lived in bookarrarra times.

Yimardoowarra: The people who belong to the Fitzroy River and live along it.

Yoongoorrookoo: The giant snake that originated in bookarrarra times and lives in the Fitzroy River.

*For Nyikina place names see Plate 1, and for other Aboriginal language groups see Plate 5. 


\section{Nyikina Plate sources}

1. Map of Nyikina places.

Made from a combination of Google Maps, the Hema map of The Kimberley, and advice from project mentors.

2. Timeline of myth versus story.

Based on Lévi-Strauss' framework (Lévi-Strauss, 1978).

3. Nyikina approach to myth, stories and time.

My own, with help from Nyikina co-researchers.

4. Traditional locations of the Nyulnyulan languages.

Courtesy of Bill McGregor, 2007.

5. Map showing distribution of Non-Pama-Nyungan and Pama-Nyungan languages.

Walsh \& Yallop. 1993. 17. 


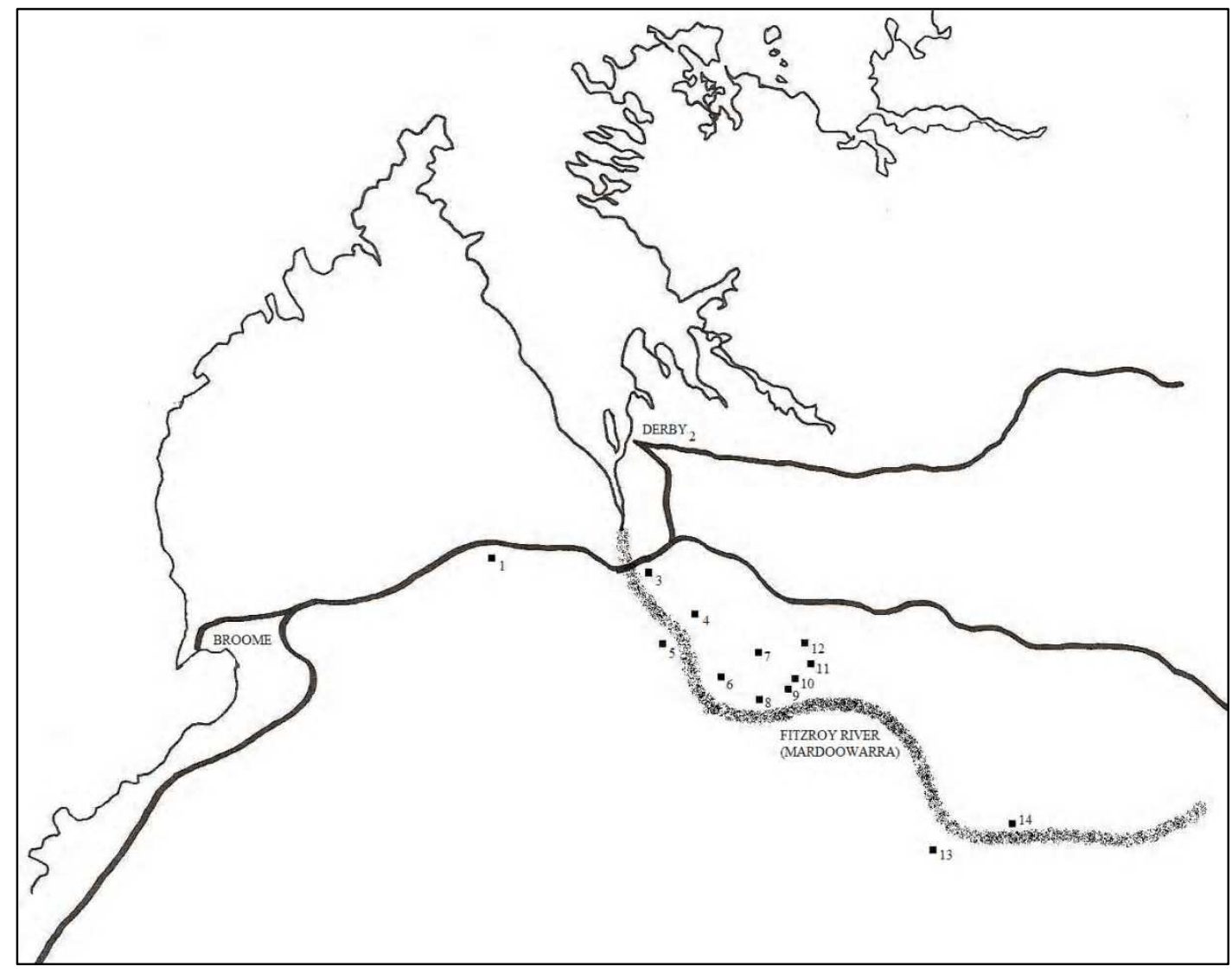

Plate 1: Map of Nyikina places.

Key:

1. Bedunburru

2. Karmulinunga

(Derby town reserve)

3. Pandanus Park

4. Balginjirr (Lower Liveringa)

5. Udialla Springs

6. Mount Anderson

7. Jarlmadangah Burru

8. Luluigui

9. New Looma

10. Looma

11. Liveringa (Upper Liveringa)

12. Camballin

13. Kalyeeda

14. Noonkanbah 


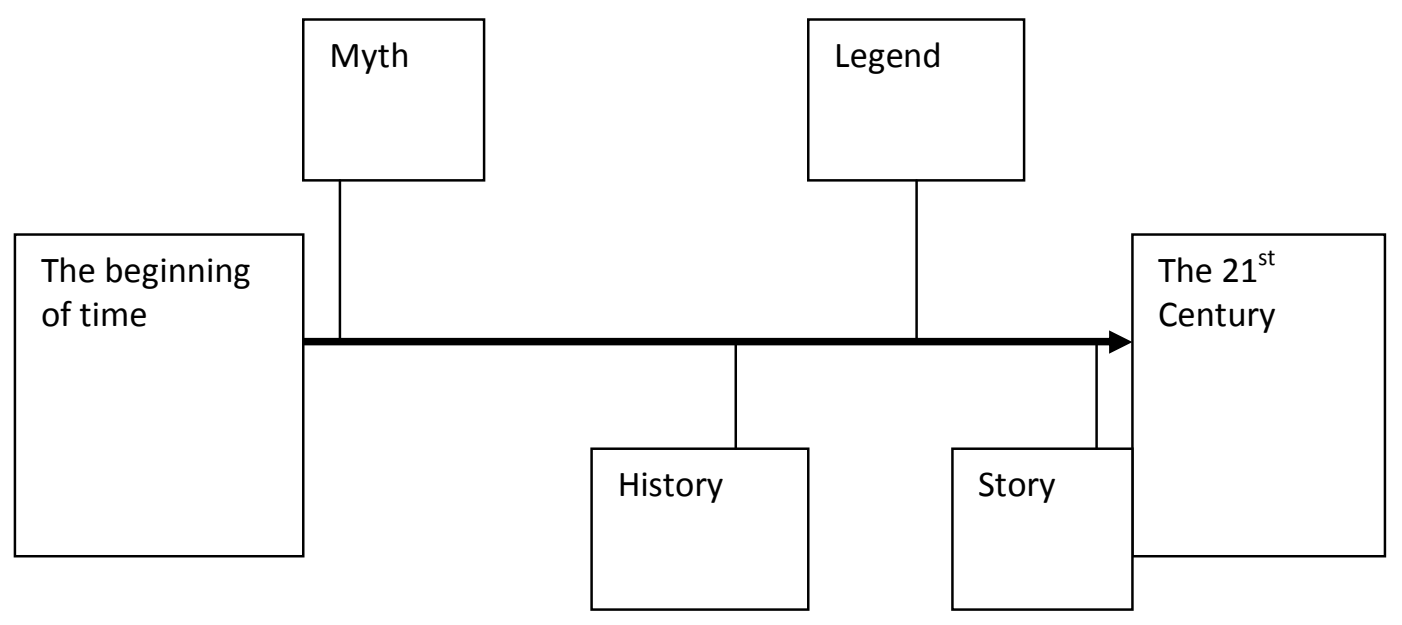

Plate 2: Timeline of myth versus story. 


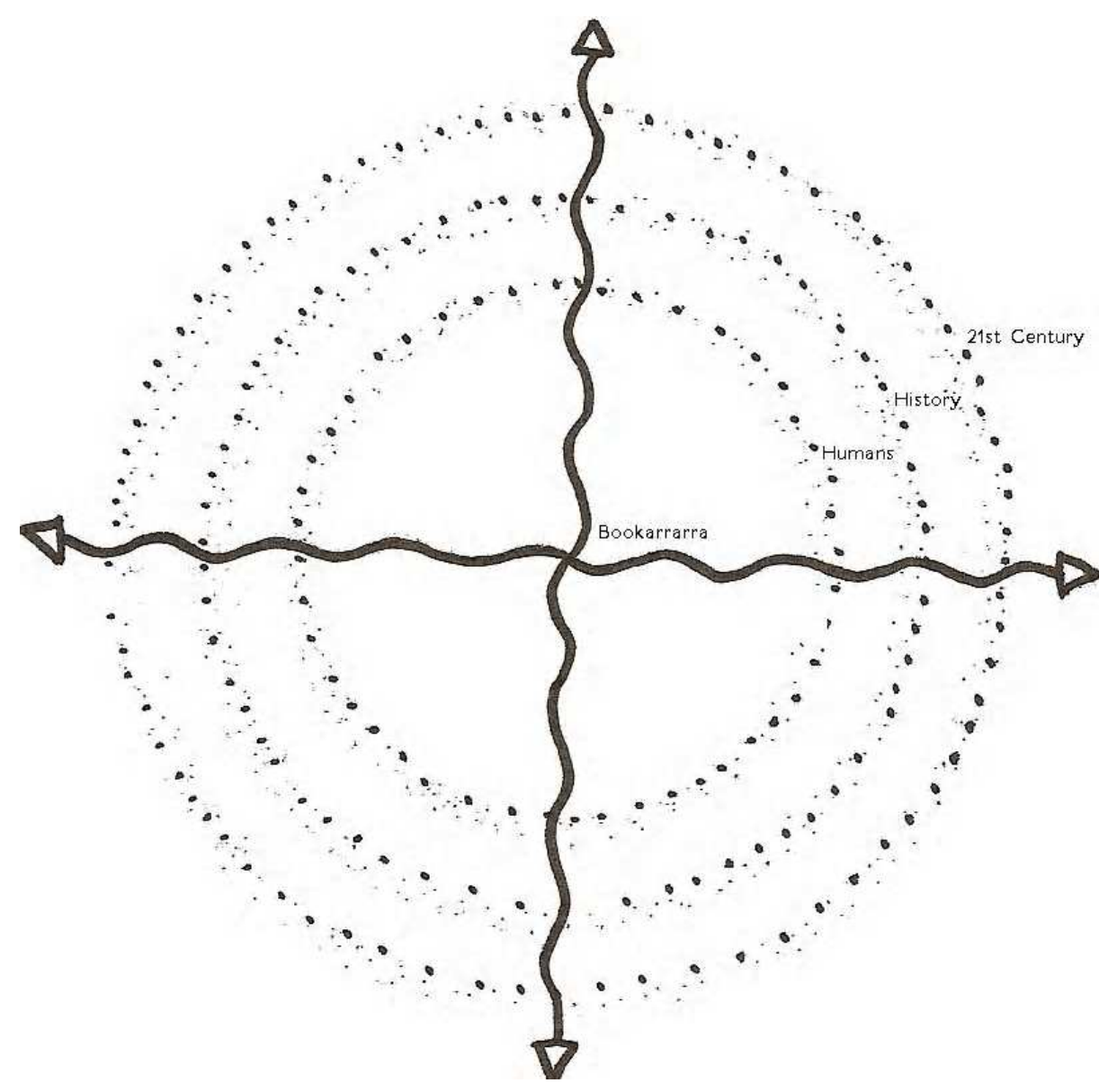

Plate 3: Nyikina approach to myth, stories and time. 


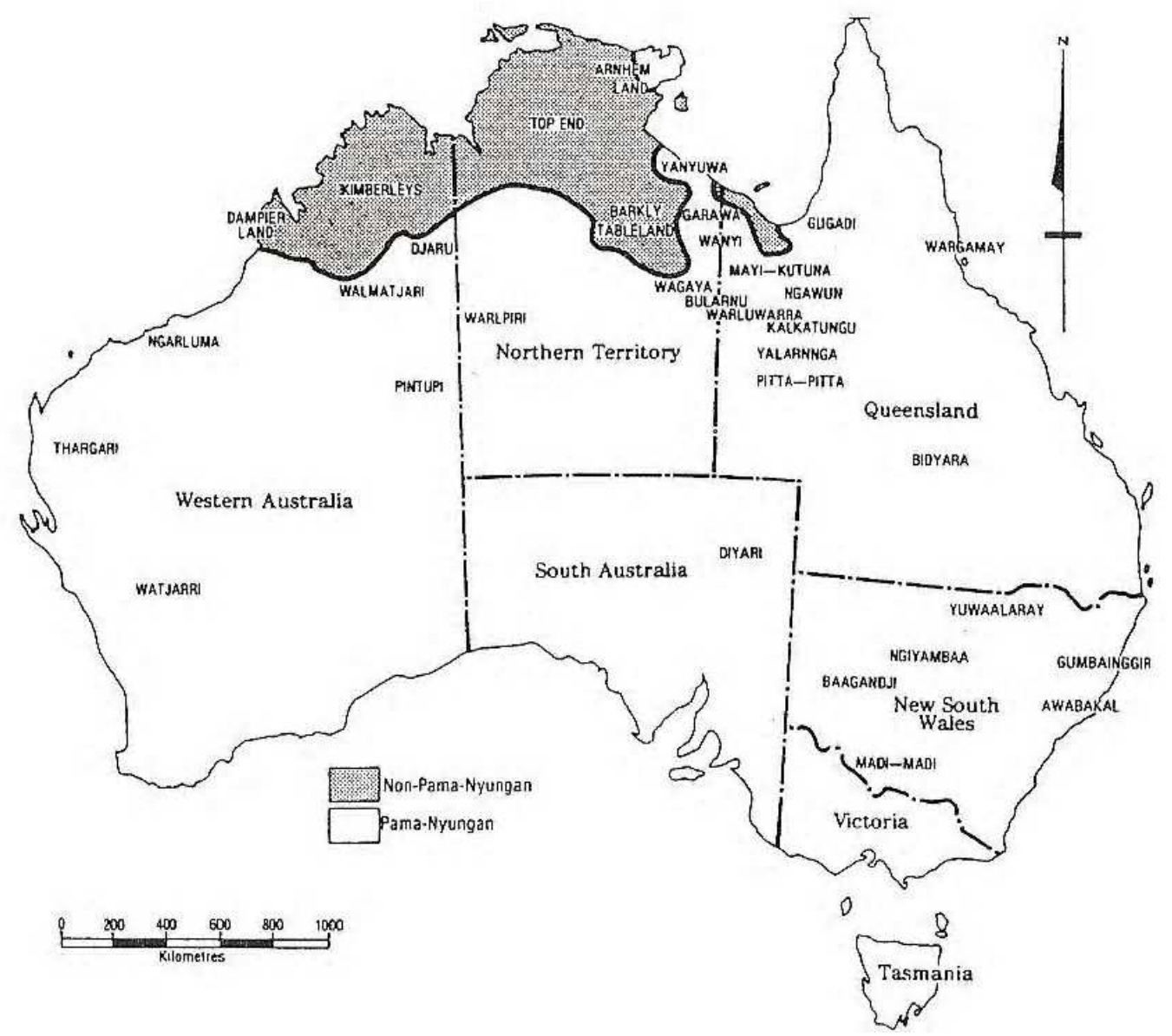

Plate 4: Map showing distribution of Non-Pama-Nyungan and Pama-Nyungan languages. 


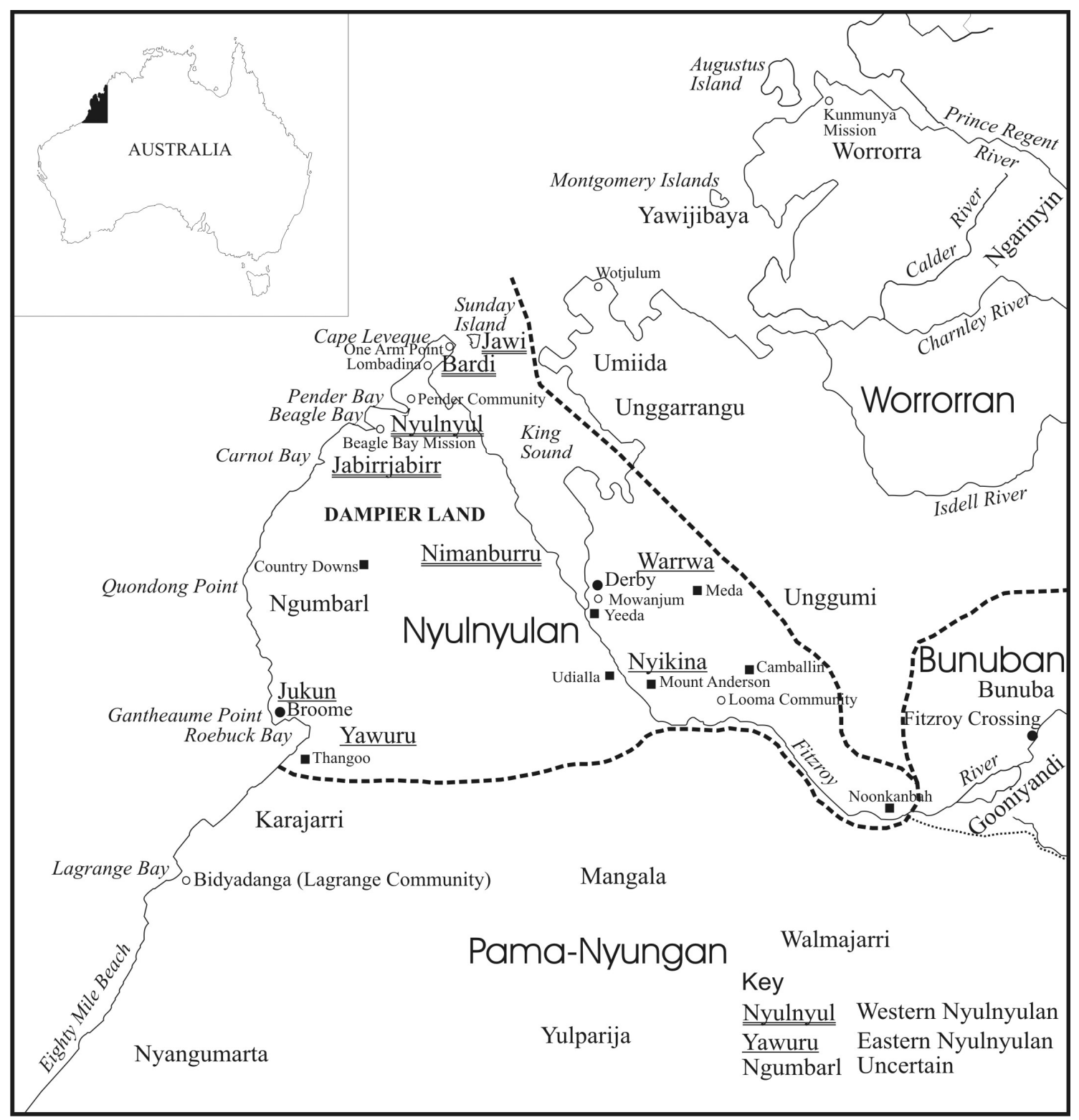

Plate 5: Traditional locations of the Nyulnyulan languages (Bill McGregor, 2007). 


\section{Chapter 2}

\section{Minoan Case Study: Part I}

\section{The beginnings of religion}

Religion was a major pan-societal mechanism which was used by arbiters and leaders/chiefs to control wide-ranging aspects of culture. By the Bronze Age, politics, justice, literature, administration, art and expansion in the Mediterranean were all under the umbrella of religious control. ${ }^{100}$ Hodder argues:

If a degree of sedentariness were to have been involved in any of the strategies being pursued, a knock-on effect might well have been an intensification of social relationships, ceremonialism, feasting and bridewealth payments. All of these would require further material production. ${ }^{101}$

The ceremonialisation of religion can be considered a result of profit from material production, achieved by 'the invention of the wheel and plough' in the late Neolithic period. ${ }^{102}$ With excess goods, trade with other groups of people - whether sedentary or nomadic - was viable, and 'primary produce could then be collected as tribute or "gift" in order to maintain an elaborate political or religious hierarchy of kings or priests. $^{103}$

Once a sedentary society has evolved to have a religion and enough excess produce for trade, the house is not the only significant structure anymore; monumental buildings for worship, treasuries and goods storage are needed. Hodder suggests that interaction with other groups through trade also 'permits the

\footnotetext{
${ }^{100}$ A chronological table of Minoan Bronze Age periods is located at the end of Chapter 2.

101 Thomas, 1988, 61.

${ }^{102}$ Coulmas, 1989, 72.

${ }^{103}$ Goody, 1987,24.
} 
development of new modes of interaction with the material world permitting the ascription of (symbolic) meaning to material objects. ${ }^{, 104}$

A larger population and concepts of materialism and wealth lead to segregation in sedentary communities, and 'fundamental changes in the nature of human character and society. ${ }^{105}$ Hierarchies develop by way of success - for example, in hunting or arbitration - while knowledge develops in medicine or life experience, or by birth into an established group of leaders. ${ }^{106}$ When segregation and hierarchies develop, culture must be the common thread that validates each aspect of community life.

In the first growing sedentary societies, culture is equivalent to religion. Religion in the Neolithic period was probably influenced directly by the environment and the people living there. Hence, nature cults, revering fertility and concepts of renewal, and death or ancestor cults were the first semblances of religion which would become more defined in the Bronze Age. ${ }^{107}$ Under religious cohesion, nature cults regulated horticulture, agriculture, fishing and sea travel seasonally. Additionally, the cults administered proportional tributes and rationing. Death cults honoured the dead and governed the rites of death, dying, and burial or inhumation. Within sedentary societies cultural views, tied to the importance of the home, affected death cult practices, and graves became the equivalent of the home for the dead.

\footnotetext{
${ }^{104}$ Renfrew, 2001, 131.

105 Renfrew, 2001, 128.

${ }^{106}$ Kent, 1989, 10.

${ }^{107}$ Guilaine, 1986, 90.
} 
Religion is one method used by humans to understand the natural world. While an oral culture lives in accordance to the land, a sedentary culture takes control over their environment. ${ }^{108}$ Hodder states: 'I have begun to describe the adoption of agriculture as a social-symbolic process. The natural (wild) is made cultural (domesticated, agri-cultured). ${ }^{, 109}$ His theory is supported by J. Thomas who argues:

[T] he shift to farming was less an economic change, more a change of attitude or ideology, allowing monuments to be built and pottery created, perhaps in connection with new ideas concerning the preparation of food. The willingness of native populations to adopt innovations [through trade contact] might then 'be connected towards a more intensive, ceremonial life and more involved social relations. ${ }^{110}$

Human beings are social creatures. Sharing commonalities is a basic condition for maintaining harmonious relationships in a sedentary culture. As Neolithic humans evolved and learned to live together in permanent locations, social relations and language became more complex than ever before. Group efforts were rewarded with excess goods and materials; technology was advancing and the human brain was capable of more than just being programmed to survive.

With the ability to ascribe meaning to aspects of sedentary life via religion, it was not long before the use of pictures came to represent symbolic, as well as literal significance. ${ }^{111}$ Colin Renfrew outlines the two conditions that must be fulfilled before writing can emerge in a culture: 'the development of sedentary society' and 'the emergence of certain materials as embodying wealth and prestige.' ${ }^{112}$ By the end of the Neolithic period in the Mediterranean and the ancient Near East, these criteria had been fulfilled by a number of sedentary cultures. The close study of the stars and

\footnotetext{
${ }^{108}$ Hodder (ed.), 2001, 276.

${ }^{109}$ Hodder, 1990, 18.

${ }^{110}$ Thomas, 1991, Rethinking the Neolithic, 64.

${ }^{111}$ Hodder (ed.), 2001, 131.

${ }^{112}$ Renfrew, 2001, 127-8.
} 
seasons - another feature of hunter-gatherer societies - had introduced the concepts of time, measurement and mathematics, and notation of these natural changes followed. The transition to writing, once the populations of settlements had increased enough, seemed inevitable. ${ }^{113}$

In modern times, civilisation without writing is difficult to imagine. Flourian Coulmas suggests that 'this is not to say that writing caused civilisation, but the reverse is not the whole truth either. Rather, writing is seen as a result as well as a condition of civilisation, as a product shaped by civilisation and a tool shaping it., ${ }^{114}$ Oral cultures don't have cities. Literacy in Bronze Age cities was not widespread, but the social networks in cities require writing, inventories, and instructions. ${ }^{115}$ Jack Goody acknowledges that '[n]one of these activities are impossible in oral societies. But without the written word the scale and complexity of the operation were limited. ${ }^{116}$ Oral storytelling is known for the ability to retell epic poems, myth cycles and genealogies, but there is a point at which human memory begins to fail without prompts or cues. Hence the question arises as to what the first (pictographic) scripts, or representations of the oral word facilitated.

Coulmas maintains that writing is an invention and a very extraordinary one at that which, for all we know, happened only two or three times in the history of mankind. ${ }^{117}$ In Mesopotamia, the earliest archaeological evidence, dated to c.35003100 BCE, indicates that writing was initially used for civic administrative purposes,

\footnotetext{
${ }^{113}$ The complexity of the change from hunter-gatherer group numbers to the population of sedentary settlements is limited not only by cultural complexity but also by sanitation needs and infectious disease.

114 Coulmas, 1989, 4.

115 Coulmas, 1989, 7.

${ }^{116}$ Goody, 1987, 55.

${ }^{117}$ Coulmas, 1989, 3.
} 
but in a religious context - the temple. ${ }^{118}$ Thus, while the first Mesopotamian texts may be categorised as accounting and record keeping, the practice of writing was used by an elite few as part of temple or religious administration. Indeed, religion pervaded all aspects of ancient human cultures. The transition from oral to written literature is affected by religious control. Likewise, it can not go unnoticed that river valleys provided suitable locations for what became the most powerful empires in the following Bronze and Archaic ages, such as Mesopotamia, Egypt along the Nile, the Indus Valley and ancient China. The cities in these places, which grew from early sedentary farming and agricultural communities, invented their own forms of writing as visual representations of their native languages. ${ }^{119}$ Mesopotamia was probably the 'earliest origin point for writing in the Near East' where writing developed from a 3000 year old system used for accounting c.3500-3300 BCE. ${ }^{120}$ The Egyptians started writing with hieroglyphics c. $3500 \mathrm{BCE},{ }^{121}$ and the Chinese developed a script c.1766 BCE. ${ }^{122}$ Minoan culture independently invented a script, not in a river valley, but on the island of Crete in the Bronze Age. This chapter will explore the cultural effects on the transition from oral to written literature in sedentary Minoan culture on Crete in the Bronze Age.

\section{Introduction to sedentary Minoan culture: Myrtos}

On Crete, the Bronze Age dates from c.3000 - 1100 BCE, and periods are broken into Early Minoan (EM), Middle Minoan (MM), and Late Minoan (LM). ${ }^{123}$ The EM period marked the approximate end of the Neolithic period in Crete, and is

\footnotetext{
${ }^{118}$ Goody, 1987, 54.

${ }^{119}$ Coulmas, 1989, 3.

${ }^{120}$ Carr, 2005, 17. Schmandt-Besserat, 1982, 5.

${ }^{121}$ Newberry, 1934, 115.

122 Coulmas, 1989, 3.

${ }^{123}$ For general Minoan periods see Preziosi and Hitchcock, 1999, 8, 242. For more specific dates, Sturt W. Manning, 1999, Appendix 8, 217 is invaluable. See also fn. 100.
} 
characterised by settlements such as Myrtos, on the hill Fournou Koriphi [Plate 1]. ${ }^{124}$ Even though there are no examples of writing from the site of Myrtos, I have included it as an example of an early Minoan sedentary settlement. It also includes a shrine area, and a religious environment or context is crucial to the development of writing. This EM site on the south coast of eastern Crete was first visited by archaeologists in 1962 and excavated in 1967-8 under the leadership of Peter Warren. ${ }^{125}$ The settlement was on a hill at the edge of a cliff, and the first period of occupation, dated to EMIIA, consists of open 'courtyard' areas, cells of rooms, a stairway, a potter's workshop and rubbish pits. ${ }^{126}$ Some rooms were built as units directly onto the bedrock of the site, for example rooms $38-41$, joined to the stairway labelled 42 on the site plan. $^{127}$

The sedentary community that lived at Myrtos built stone walled houses and connected them via passages and stairways to create a complex arrangement of living areas, kitchen areas, ritual areas, and meeting places. These constructions spatially organised activities into specific areas - and literally segregated community members, while maintaining an interconnected single location. The geography of the site also provided a defensive advantage. ${ }^{128}$ The foundations and finds from the EMIIA layers at Myrtos indicate that it "continues what seems to be a Neolithic Aegean tradition of linking storage, ritual, and female fertility by means of art and material culture., ${ }^{129}$

\footnotetext{
124 Preziosi and Hitchcock, 1999, 49.

${ }^{125}$ Warren, 1972, 1.

${ }^{126}$ Warren, 1972, 11-21.

${ }^{127}$ Site plan folds out at Warren, 1972, 11, or a larger plan is in the pocket of the rear cover.

${ }^{128}$ Warren, 1972, 11.

${ }^{129}$ Preziosi and Hitchcock, 1999, 49.
} 
Minoan religion was heavily based on the nature cult of a maternal goddess, who could be in the guise of mistress of animals, mountains and fertility. ${ }^{130}$

By looking at the plan of Myrtos in Plate 1, and comparing it to Plates 2 and 3, one can ascertain a 'house' or quarters, which had a multi-purpose function combining food preparation, ritual and storage. ${ }^{131}$ Room 88 had a table or bench, a cooking hole, and numerous cooking ware and utensils were found in situ. Room 89 was narrow like room 88 and contained a 'tripartite structure consisting of two little, low benches or tables with a hearth between them.' The tripartite shrine in room 89 is one of the earliest shrines in a domestic context in Minoan Crete. Room 90, a small room accessed via room 91, also had a bench of packed stones like rooms 88 and 89 . This room had 'a large, spouted tub' which had most probably fallen from the stone bench during destruction.

Peter Warren suggests a connection between the tub, a pounder, and a bowl containing grape remnants; that the function of the room was for the storage and making of wine perhaps in relation to the ritualistic room 89 and rooms 91 and 92. Room 91 is described as 'The Shrine Store' and along its walls were both natural rock ledges and built stone benches, and a high concentration of fine pottery [Plate 2]. Room 92, or 'The Shrine', is so named due to the altar and the finding of what has been termed the Goddess of Myrtos [Plate 4]. Warren concludes:

The ... extraordinary shape of the female, the little jug held in the crook of the arm, the impracticability of the piece for everyday, domestic use, the find-spot beside the stone structure, suggests that we have a representation of a goddess originally on an altar, and therefore

\footnotetext{
${ }^{130}$ S. Marinatos, 1960, 36.

${ }^{131}$ Referred to as a 'house' by Preziosi and Hitchcock, 1999, 50.
} 
that Room 92 was a shrine, the oldest of the Minoan household shrines. ${ }^{132}$

Ritual dining and offerings and libations to the nature goddess seem to have occurred in this 'house,' with the room next door providing an area for death cult ritual or ancestor worship. This area in the west wing of the Myrtos settlement was part of a larger building complex that served non-religious purposes. Minoan people had achieved levels of technicality, and their religion had reached such a state of complexity by the end of the EM period that the stage was set for a new development in the MM period.

Around the beginning of the MM period, c.2000 BC, something happened to the pre-palatial culture living on Crete, which led people to produce written records; and from language came script. ${ }^{133}$ The earliest form of such has been called the Cretan Hieroglyphic Script (CHS) [Plate 5]. ${ }^{134}$ Approximately $10 \%$ of MMII-MMIII seals stones and impressions are found in the CHS. ${ }^{135}$ An analysis of the use of the CHS can allow the exploration of situations and periods of social change in history that required the need for a script. The closest comparison to CHS has been derived by Egyptologists, who have three reasons for the creation of Egyptian hieroglyphics. Florian Coulmas enumerates them as follows:

i) the need to record events as a result of an 'awakening historical consciousness'

\footnotetext{
${ }^{132}$ Warren, 1972, 80-86 for the Myrtos information given here.

${ }^{133}$ Krzyszkowska, 2005, 79. Cherry, 1986, 21.

134 The Phaistos Disk has been left out of the Minoan Case Study as I consider it too problematic and question its authenticity. Until more examples of the signs from the Phaistos Disk emerge, translation is unlikely, and the language it represents will remain unknown. See: John Chadwick, "Linear B, Ch..7 The Phaistos Disk", in: Reading the Past: Ancient Writing From Cuneiform to the Alphabet, with an Introduction by J.T Hooker, (1990), 190-195; Jan Best and Fred Woudhuizen (eds.), Ancient Scripts From Crete and Cyprus, (1988), 30-97. For readers of French, see also Y. Duhoux, Le Disque de Phaestos, (1977), Leuven. The Arkalochori gold double axe is also omitted because it has only two or three symbols.

${ }^{135}$ Krzyszkowska, 2005, 96.
} 
ii) the need to record economic transactions as a result of a more complex social infrastructure

iii) a religious need. ${ }^{136}$

The second of these reasons explains the greatest corpus of evidence for Minoan scripts, and the third reason is important for understanding the development of prepalatial and proto-palatial writing. The earliest economic records found on Crete are inscribed in CHS. The CHS was used contemporarily with Linear A, before being largely replaced by it. Palace archive deposits contain documents such as tablets inscribed in CHS as well as tablets inscribed with Linear A in the same room. ${ }^{137}$ Linear A may have been more useful for keeping records since it has the use of fractional measures. ${ }^{138}$ Nonetheless, Linear A lost favour to Linear B, after the Mycenaean culture of mainland Greece overtook the Minoan culture during the second palace period, c.1500 BCE. The archaeological evidence for this script has been found in palace and town remains, consisting of seal stones, nodules, roundels, clay tablets, pottery and masonry.

\section{Characteristics of the Cretan Hieroglyphic Script}

The CHS uses pictograms and a set of mathematical symbols to make very short texts. ${ }^{139}$ Sir Arthur Evans was the first archaeologist to distinguish between two kinds of Cretan script, and writes in Primitive Pictographs and a Prae-Phoenician Script from Crete and the Peloponnese, 'two distinct phases were perceptible, one pictorial and hieroglyphic, the other linear and quasi-alphabetical. ${ }^{140}$ Within the CHS Evans notes two characteristics: the repeated use of reduced symbols, and pictorial

\footnotetext{
${ }^{136}$ Coulmas, 1989, 58.

137 Schoep, 1996, 5, Malia example 57-9. Krzyszkowska, 2005, 93.

${ }^{138}$ The CHS did have a numeral system, but Linear A developed an integer system allowing more complex mathematics: Billigmeier, 1973, 61.

${ }^{139}$ Cherry, 1986, 33.

${ }^{140}$ Evans, 1893-4, 275.
} 
representation of body gestures or gesture-language. ${ }^{141} \mathrm{He}$ gives examples of abbreviated symbols, such as the head of an animal to indicate the whole beast, and a flower or branch as an icon for the plant referred to. ${ }^{142}$ If the latter example, however, had been silver fern on an All Blacks rugby jersey however, it would not be indicating that the shirt is made from silver ferns, or that the man wearing the shirt is called Silver Fern (or has the initials S. F.), but rather there is a greater meaning - that he is a representative of the country of New Zealand.

Likewise, examples of gesture-language in the CHS are ideograms that represent ideas or messages with the use of a symbol. For instance, when a police officer is directing traffic, it is a common sign language that a stiff, unfurled hand means 'stop, do not move.' Therefore, a flat open palm in an ideographic script could indicate the concept of being stationary or being stopped. On the other hand, an arm waving in a certain direction indicates that traffic can move towards that direction. ${ }^{143}$ The following is a basic list of common ritual gestures used in Minoan gesture language;

i) Saluting gesture: raised arm held in front of face, palm facing outward.

ii) Votive gesture: similar to the saluting, especially when both hands are raised.

iii) Adoration gesture: variation of the saluting; hand touching neck or shoulder, one arm stretched elegantly along the side of the body.

iv) Commanding gesture: arm outstretched at shoulder height holding a staff.

v) Dancing gesture: arms akimbo, hands on hips. ${ }^{144}$

\footnotetext{
${ }^{141}$ Evans, 1893-4, 300.

${ }^{142}$ Evans, 1893-4, 300.

${ }^{143}$ Whether this was the meaning attached to symbols 008 and 009 in the Corpus Hieroglyphic Inscriptions of Crete (CHIC) we may never truly know. See Fig. 3, Schoep, 1996, 12.

${ }^{144}$ Adapted from Galanakis, 2005, 99.
} 
The use of gesture-language is fascinating, as it evokes a time before script when gesture was used as an important aspect of communication between people who were too far away to hear each other, or did not fully understand what the person speaking was trying to say. Gesture-language in the CHS, for example, uses both figures of people with their arms in different positions, and body parts in a variety of poses. In the table of the Corpus Hieroglyphic Inscriptions of Crete (CHIC) [Plate 6], syllabograms 1-10 are gesture-language, 11-18 are animal heads and 23-30 can safely be described as abbreviated vegetative symbols (some may include 31-33 in the latter group, perhaps if viewed as distinctive seed forms). ${ }^{145}$ Another characteristic of the CHS is the common use of the 'child formula': 'A child of B.' ${ }^{146}$ Overall, the CHS was used from c.2000-1650 BCE. ${ }^{147}$

The excavations at Myrtos illustrated EM culture was becoming more complex. This is demonstrated though the way they organised their multi-functional buildings spatially to either combine or separate different spaces for different functions. This physical organisation also extended to the social stratification of society and the roles individual Minoans played in community affairs, such as religion. The Myrtos domestic shrine is an antecedent for rooms in palace complexes as well as large scale tripartite shrines on peak sanctuaries. Peak sanctuaries are heavily connected with the palace complexes of the MM and LM periods, as is the CHS. The invention, and use, of their own hieroglyphic script will be discussed further in Part II of the Minoan Case Study.

\footnotetext{
${ }^{145}$ Schoep, 1996, 12.

${ }^{146}$ Best and Woudhuizen, 1988, 10.

${ }^{147}$ Davaras, 1976, 143.
} 


\section{Minoan Case Study: Part II}

\section{The rise of sedentism and its effects on Minoan culture}

Pictographic symbols on seals, for personal (religious) use, became used as identity tokens for individuals or families when settlements grew in size and interaction between settlements increased due to trade and inter-marriage. ${ }^{148}$ As sedentism and group living allowed for crops and farming to feed growing settlements, a sense of community became crucial for co-operative living. Community rituals and ceremonies played an important role in of maintaining group harmony. ${ }^{149}$ Autonomy gave way to collective collaborations and shared language and cult beliefs important for maintaining harmonious relationships, such as sharing land and housing between families. Success in maintaining group relationships within a growing settlement allowed for excess goods. The urbanisation of Crete in the proto-palatial period is a result of pre-palatial sedentism. ${ }^{150}$ The proto-palatial period, MMIA-MMIIB, saw the first palace complexes built, and social and religious life reorganised. ${ }^{151}$

Once a concept of value or wealth became part of the human psyche, power groups distinguished themselves. ${ }^{152}$ For successful intra-relationships between social groups, authoritative figures need to be the caretakers of an important aspect of that society's culture. For example, a ruling family or monarchy must be upholders and facilitators of religion, in order to command and maintain respect from less powerful groups in society. Religious and social control in Minoan times went hand in hand

\footnotetext{
${ }^{148}$ Childe, 1930, 53.

${ }^{149}$ Galanakis, 2005, 98.

${ }^{150}$ Galanakis, 2005, 96.

151 Galanakis, 2005, 72. Evans called the main Minoan centres 'palaces', I use the term 'palace complex' because they clearly had multiple functions - with territorial, economic and religious control being the principal ones.

${ }^{152}$ Reid, 2005, 54.
} 
with political and economic control. Increases in population, caused by communities working together and protecting and caring for each other, created a need for leading voices. Contact with outsiders also perpetuated the need for a single voice representing the many, and hierarchical formations were necessary for interrelationships. With organisational skills harnessed by a leader, projects such as housing and administration were possible. Trade became more viable, and communication with other cultures facilitated the need to find a common way to record the exchange of goods, and the profits, with the rest of the island.

\section{Origins of the syllabic Cretan Hieroglyphic Script}

Evans believed that 'the whole of Greek symbolism may in fact be regarded as a survival maintained by religious conservatism, from a wide field of primitive pictography. ${ }^{153}$ Evans' attempts at tracing the development of pictographic Mycenaean symbols from mainland Greece, led him to Crete. ${ }^{154}$ On Crete Evans collected seal stones and made impressions from those owned by Cretan people.

The symbols on some seal stones reflect items apparently important in cult or ritual activities, such as sacred boughs, a goddess figure, libation jugs and double axes. ${ }^{155}$ Common elements were noted by the border/leaf and the lattice/ladder/crosshatching motifs. ${ }^{156}$ Seal faces with a border/leaf motif have a distinct border carved

\footnotetext{
${ }^{153}$ Evans, 1893-4, 273. Krzyszkowska, 2005, 71, regarding the lexical value of pictorial and decorative motifs.

${ }^{154}$ Evans, 1893-4, 275.

${ }^{155}$ Galanakis, 2005, 74, gives a fuller set of seal stone and signet ring symbols connected with ritual activity. Libation jugs refer to stone or crystal rhyta which had two openings - one for filling and another for pouring out ritual liquid libations. The painted scene on panel A of the Hagia Triadha sarcophagus, c.1400, Heraklion Museum, shows people using the jugs in a ritual context to pour libations, Preziosi and Hitchcock, 1999, 178. The particular type of jug seen on this sarcophagus matches the hieroglyphic symbol 054 in the CHIC tables of Conventionalised Cretan Hieroglyphic signs, Fig. 3, Schoep, 1996, 12.

${ }^{156}$ Yule, 1983, 360-3.
} 
around the ovoid or circular face and then the space inside is divided into two, three or four sections and decorated in abstract leaf or vegetation motifs. ${ }^{157}$ The lattice/ladder/cross-hatching motifs are linear and uniform in design and have links to the later linear development of Cretan scripts.

It is plausible that this imagery was used by a priestly class to mark votive objects and places of cult significance, for instance cave and peak sanctuaries. The religious imagery and motifs was the basis for the CHS used for writing records held in archives at palace complexes, which were considered the centre point of Minoan settlements growing in the Middle Minoan period. Olga Krzyszkowska also proposes that pre-palatial motifs were the precursors to a developed Minoan script, such as the CHS, with astounding examples from Archanes. ${ }^{158}$ The most fascinating example comes from a MMIA funerary building at Archanes-Phourni. The bone baton has 14 individual motifs carved within oval borders, like Egyptian cartouches. ${ }^{159}$

Among the MMI motifs usually associated with the Minoan vegetation cult, appear a leg and a hand, which seem unusual in comparison to the other motifs, but reveal themselves to be members of the corpus of signs in the CHS. ${ }^{160}$ These body parts are symbols of gesture-language in its early form at Archanes. Archanes, Hagia Triadha and Gournia may be official sites not attached to palace complexes, but

\footnotetext{
157 Yule, 1983, 360.

${ }^{158}$ Krzyszkowska, 2005, 70. Galanakis, 2005, 34.

${ }^{159}$ Krzyszkowska, 2005, 70.

${ }^{160}$ Krzyszkowska, 2005, 70.
} 
important to the administrative aspect of the palace complexes. ${ }^{161}$ The Archanes script cannot be confidently ascribed as the ancestor of the CHS, but it is likely. ${ }^{162}$

The Archanes Script is also referred to as the 'Archanes Formula', and seals and impressions of the formula have been dated from MMIA to MMII-MMIII. ${ }^{163}$ The script has a broad distribution on the island inscriptions and impressions using the Archanes script have been found in northern, central and southern Crete and were not just confined to the Knossian region. ${ }^{164}$ This distribution may indicate that it was a script shared by the people in those regions of the island during the pre-palatial period to express religious beliefs, rituals or dedications. ${ }^{165}$ In reference to archaeological examples of CHS, Krzyszkowska writes:

[T] he very same group of signs [from the bone bar] - effectively a formula- recurs on a handful of other pre-palatial seals. One of the best examples is a bordered disc of olive-green steatite acquired by Evans at Knossos and now in the Ashmolean Museum. ${ }^{166}$

Effectively, this means that the Archanes Script has been found at multiple sites, on various media. The fact that the best examples are found at Archanes and Knossos led to the naming of the script. Krzyszkowska suggests that hieroglyphic seals were undoubtedly proto-palatial inventions. ${ }^{167}$ The proto-palatial period (c.1900-1700 BCE) was the time of the first Minoan palace constructions, a time when settlements were big enough to need, build and maintain such monumental centres. As foci, these palace complexes controlled religious, economic, political and social aspects of

\footnotetext{
${ }^{161}$ Smaller, but still very important sites for the study of Minoan scripts, such as Archanes, may have been sites that functioned as the palace complexes did in the later MM and LM periods. Villas like Hagia Triadha seemed to be supplementary to palace functions.

${ }_{162}$ Krzyszkowska, 2005, 96. Owens, 1996a, 193. Owens, 1996b, 108.

${ }^{163}$ Krzyszkowska, 2005, 70. Owens, 1996a, 190. Owens dates the Archanes script from EMIII-MMIA

${ }^{164}$ Owens, 1996a, p191. The script is not attested in East Crete, and West Crete has not been as thoroughly excavated as the rest of the island.

${ }_{165}$ Owens, 1996a, 191.

${ }^{166}$ Krzyszkowska, 2005, 96.

${ }^{167}$ Krzyszkowska, 2005, 80.
} 
regional Minoan culture at Knossos, Phaistos, Malia and Zakros. ${ }^{168}$ The CHS deposit at proto-palatial Knossos indicates that bureaucratic Minoans were literate. ${ }^{169}$ While the northeast was using CHS and the south central was using Proto-Linear A, the two scripts influenced each other and were mixing at Knossos in MMII as both CHS and Linear A can be found in the same deposit in palace archives. ${ }^{170}$

The shape of different seal stones will determine the size of the items that can be carved on it in intaglio. Krzyszkowska proposes that the emergence of multi-facial seals in the late pre-palatial represented attempts to convey meaning through a series of images. ${ }^{171}$ Motifs on early seal stones could have been individual emblems of a person or place of manufacture, but multi-facial seals with two or more motifs may have been the first efforts to use well known images to stand for a particular sound, and thus a syllabary emerged, which became the CHS.

\section{Literacy}

The practice of impressing combinations of two or three pictographs, and therefore carving a seal with two, three or four motifs on its various faces also indicates that the CHS was being used as a syllabic script. ${ }^{172}$ Towards the end of MMII, motifs on a single face of a seal were carved minutely so that multiple syllabograms were side by side and did not require stamping each face of the seal stone to convey a word or

\footnotetext{
${ }^{168}$ I have chosen to use Malia in accordance with the Greek spelling. In some cases, e.g. in French, it is spelt Mallia.

${ }^{169}$ Schoep, 1996, 534. If scribes are keeping administrative records and making inscriptions of a short, dedication or libation formula in ritual settings, then they are literate to the extent that they can use the CHS to indicate meaning and 'read' or understand it.

${ }^{170}$ Schoep, 1996, 534-535.

${ }^{171}$ Krzyszkowska, 2005, 71.

${ }^{172}$ Evans, 1893-4, 300.
} 
message. Multi-faced steatite prisms are the most common form of CHS seal stones. $^{173}$

Another characteristic of the CHS is that it is confined to Crete, unlike Linear A which has been found on the Greek mainland and other islands, as well as in Crete, and Linear B, found on the Greek mainland and Crete. ${ }^{174}$ The widespread distribution of Linear A may be indicative of its use not only for administration, as seems the case with Linear B, but in broader literary aspects. Ilse Schoep observes the following in Minoan Administration on Crete:

One cannot escape the notion that there is an ambiguous situation with, on the one hand, a more disassociated development between sphragistic administration [using seal stones, their impressions and nodule 'receipts'] and written administration, and, on the other hand, a realisation that script on sealstones conveyed a more powerful message than the normal seal-types. Does this dichotomy suggest a more primitive, less complex organisation with pre-fabricated Cretan Hieroglyphic sealstones (including those with logograms and fractions) functioning in an administration where literacy was not that widespread but the importance of the script was already realized. Did illiterate officials acquire literacy through the sealstones? ${ }^{175}$

As seal stones may have originally been used in talismanic ways, it seems that they were used to teach CHS to scribes, perhaps as part of magical scribal teaching. The power of Cretan pictograms seems to have led to their development into ritual impressions and inscriptions.

From ritual use, pictograms became standardised and took on administrative functions. Schoep's observation above indicates that the religious roots of Cretan pictographs were preserved when scribes were trained to use them for other palace

\footnotetext{
${ }^{173}$ Krzyszkowska, 2005, 96.

${ }^{174}$ Schoep, 1996, 109.

${ }^{175}$ Schoep, 1996, 537.
} 
jobs; hence the continued use of CHS when Linear A was developing. ${ }^{176}$ It must be stressed that the CHS was not merely an impressed seal stone script, but was inscribed on two- and four-sided bars, and tablets (especially at Knossos and Malia). ${ }^{177}$ Sealings that had been impressed by a seal stone, with marks indicating the sealing has been stamped over cords wrapped around a bundled and secured object, suggest rolls of papyrus or linen were transported between palace complexes, both within Crete and offshore. The papyrus would be folded or rolled, then tied up with cords and a lump of moist clay was pressed onto the cords and impressed with a signary seal stone. ${ }^{178}$ On receipt of the papyrus or linen document, if the sealing were intact and not broken off, the confidentiality of delivery would be assured. Of course, these biodegradable documents have not survived, but it seems likely that they existed due to the sealings with cord marks on the back, and the popularity of papyrus documents in the cultures surrounding Crete. ${ }^{179}$

\section{Who was using the Cretan Hieroglyphic Script?}

The construction of monumental palace complexes at Knossos, Malia and Phaistos are physical reflections of a cultural change in the Middle Minoan period. ${ }^{180}$ The rise of inscriptions in CHS and Linear A are also physical reflections of the change in this period on Crete. John Cherry writes that officials working in the palace complexes had a store of information vital to the regional communities, and therefore would have been central figures of importance, with organisational control. ${ }^{181}$ This first palace period was also the time when outdoor peak sanctuaries became popular in Crete,

\footnotetext{
${ }^{176}$ Davaras, 1976, 183.

177 Schoep, 1996, 145.

${ }^{178}$ Weingarten, 1986, 281.

${ }^{179}$ Reid, 2005, 338, 348-355.

${ }^{180}$ Cherry, 1986, 21.

${ }^{181}$ Cherry, 1986, 32. This kind of focal influence "may imbue those who can write with a certain mystical power". See also Whittaker, 2005, 29.
} 
possibly originating in East Crete due to the density of known sites. ${ }^{182}$ The importance of religious and socio-political control is evident in the relationship between the archaeological evidence of early CHS and Linear A at palace complexes and on objects found in peak sanctuaries. Cherry suggests that the proto-palatial period was:

a period of highly-restricted, palace-controlled literacy. 19 objects from seven sites have been found to bear Linear A...and despite the overwhelming difficulties [of CHS], it is quite clear that writing was extremely limited in extent (being confined almost entirely to palace contexts) and restricted in its use to three main areas: (i) recording economic data for administrative purposes; (ii) marking commodities with an indication of their origin, nature, destination or ownership, and (iii) brief ritual or religious inscriptions. ${ }^{183}$

Cherry's theories support Evan's assumption that, like Egypt, Babylonia and China, Crete's early pictographs 'were, in the hands of priestly and official castes, developed into a more complicated and exact form of writing' and became the syllabic CHS. ${ }^{184}$

Egyptian hieroglyphics were first used c.3500 BCE for multiple functions on multiple media, but when hieratic developed, hieroglyphics were confined to 'religious and monumental contexts.' 185 The complexity of Egyptian hieroglyphics and the belief in the magical properties of writing and words ensured that literacy was a privileged skill and held by priest-scribes. ${ }^{186}$ The chief priest of the temple in ancient Mesopotamia was called the sanga/shangum. ${ }^{187}$ The temple complexes in Mesopotamia were both administrative and religious, like the palace complexes in Crete; therefore the sanga/shangum had a dual role. ${ }^{188}$ Likewise, the earliest

\footnotetext{
${ }^{182}$ Cherry, 1986, 31. Reid, 2005, 274. See n545.

${ }^{183}$ Cherry, 1986, 31-33.

${ }^{184}$ Evans, 1893-4, 270-271.

${ }^{185}$ Davies, 1987, 10. Hieratic was a cursive version of the hieroglyphic script, as was demotic.

${ }^{186}$ Davies, 1987, 27.

${ }^{187}$ McIntosh, 2005, 206.

${ }^{188}$ McIntosh, 2005, 206.
} 
examples of Chinese signs are oracle bone inscriptions from the Shang dynasty. ${ }^{189}$ Robert Eno's research reveals that 'written records left by the Shang are all religious in nature. ${ }^{, 190}$ Thus, the earliest form of Chinese writing was used only for religious purposes, and the king and diviner were often one and the same. ${ }^{191}$

As these cultures all demonstrate, not only Mediterranean and Near Eastern, but all across the continent of Asia, when script is being invented and developed in its early stages, it is used and controlled by scribes who were trained in the art of writing. The nature of Egyptian, Mesopotamian, Chinese, and Minoan cultures meant that scribes fulfilled administrative temple duties, and belonged to what Evans described in 1893 as 'priestly and official castes.' 192 Moreover, when writing is restricted by an elite group, writing itself is symbolic of this elitism, and the very presence of inscriptions can be more important than what the inscription reads. ${ }^{193}$ Helène Whittaker notes the argument that the seal stones bearing CHS at Malia had a primarily religious function, and their use in writing was of a secondary nature. ${ }^{194}$ Like Egyptian, Mesopotamian and Chinese cultures, it is possible that early Cretan scripts were thought to have had a religious, or supernatural, beginning.

\section{Writing: a gift from the gods}

Mythological origins for the creation of writing support the idea that the primary users and sustainers of CHS were a priestly, official caste. For example, in Egyptian religion, Thoth was believed to be the creator of hieroglyphics, and his attributes were

\footnotetext{
${ }^{189}$ Eno, 1996, 41.

${ }^{190}$ Eno, 1996, 41.

${ }^{191}$ Eno, 1996, 42-44.

${ }^{192}$ Evans, 1893-4, 271. Powell, 1991, 107. Coulmas, 1989, 5.

${ }^{193}$ Whittaker, 2005, 30.

${ }^{194}$ Whittaker, 2005, 30.
} 
a scribe's tablet and reed. ${ }^{195}$ Texts from c.2700 BCE testify that Egyptian scribes worshipped Thoth not only as the inventor of writing but as the god of divine speech, established order (by administration) and one who prevented rebellions. ${ }^{196}$ Plato discusses Thoth's meeting with the god-king Thamus and his imparting letters to the Egyptian people. ${ }^{197}$

Similarly, Mesopotamian religion held that Nabu, son of Marduk the guardian god of Babylon, created writing. ${ }^{198}$ Other deities also shared writing, such as Nidaba and Enlil. ${ }^{199}$ The Chinese myth of the first Emperor, Fu Hsi, dates his rule from c.2852 BCE. $^{200} \mathrm{Fu} \mathrm{Hsi}$ is credited with leading his people from cave dwelling to building houses, developing agriculture, and using arts and crafts. As part of his teachings of civilisation, Fu Hsi showed the people how to practise the art of writing,

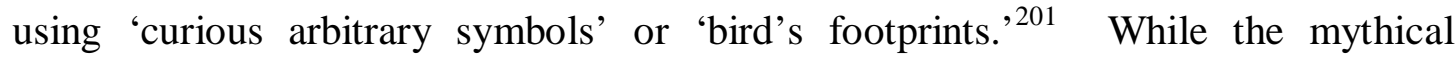
Emperor was on a riverbank trying to turn the symbols into a script capable of communicating thought and language the following occurred:

[A] Dragon Horse, the Unicorn, came up from the river, bearing on its back certain signs from which the Emperor formed the Eight Diagrams and from these signs evolved the written Chinese language. ${ }^{202}$

The river setting is an interesting detail to note in this myth, as it is known that in history, when writing has developed independently, it has happened in river civilisations, such as Egypt and Mesopotamia.

\footnotetext{
195 Powell, 1991, 107.

196 Senner, 1989, 11.

197 Plato, Phaedrus, II: 274 E. Thoth is called Theuth in the Phaedrus.

${ }^{198}$ Hooke, 1962, 41. The alternative spelling of Nabu is Nebo (as in the Bible; see Isaiah 46:1).

${ }^{199}$ Senner, 1989, 10.

${ }^{200}$ Morgan, 1942, 25.

${ }^{201}$ Morgan, 1942, 25.

${ }^{202}$ Morgan, 1942, 25.
} 
Cretan myths trace writing back to the Muses, on whom Diktian Zeus bestowed the discovery of letters and creation of poetry. ${ }^{203}$ In agreement with the writings of Diodorus, Evans has proposed that the Phoenicians modified the signs of the CHS which stem from the Muses, and that these modified signs became the Phoenician alphabet. ${ }^{204}$ As archaeological evidence for tracing Minoan mythology is not as vast as that provided by Egyptian and Mesopotamian texts, which delved into different literary genres such as poetry and letters, one must rely on scant information from ancient authors like Diodorus to glean points for comparison and contrast to other civilisations that independently developed writing. The Cretan attitudes toward writing were positive because it was a gift from the gods. This concept is important because it contrasts quite clearly with views sometimes found in Aboriginal society (and other indigenous societies) which considers writing to be a European destruction of culture rather than a means of preserving or continuing it. ${ }^{205}$

\section{Eteocretans}

The first gods of Crete, called the Idaean Dactyli because they were from Mount Ida and were ten in number (the number of dactyls or fingers a person has), discovered fire and how to use it with copper and iron, and bestowed the knowledge on the Eteocretans. $^{206}$ According to Strabo, Staphylus wrote that the Dorians lived in the east of Crete, Kydonians the west and the Etocretans in the south, and that their

\footnotetext{
${ }^{203}$ Diod. Sic., V 74.1. It is further told that the Greek letters come from Phoenician letters, which come from Syrian letters, which were variations of the letters that the Muses first discovered.

${ }^{204}$ Evans, 1909, 106.

${ }^{205}$ Smith, 1999, 35-40.

${ }^{206}$ Diod. Sic., V 64.3. It is important to note that some ancient authors use 'Eteocretan' to specifically refer to the people living in the Praisos area in the EM and MM periods, and some modern authors use it to refer to the true Cretans who did not immigrate to the island, but were the original, autochthonic inhabitants prior to LM colonisation of Crete by other Mediterranean peoples. See Gordon, 1966, p29, footnote 70 .
} 
principle city was Praisos. ${ }^{207}$ In the Odyssey, Odysseus describes Crete as an island of ninety cities and with multiple languages co-existing due to several ethnic groups: Achaians, Eteokretans, Kydonians, three divisions of Dorians, and Pelasgians. ${ }^{208}$ Diodorus Siculus claimed that Eteocretans were the first people of Crete, born from the soil, and that their first king was Cres, who made many great discoveries and cultivated civilisation with the aid of metallurgy. ${ }^{209}$

The notion of the first ruler sharing knowledge with the gods and then using the knowledge to introduce more complex civilisation to their people is directly comparable to the mythical Chinese Emperor, Fu Hsi, discussed above. Similarly in Crete, after the coming of the Idaean Dactyli came the birth of the nine Kuretes, young warrior gods, perhaps also autochthonous or descended from the Dactyli. The Kuretes furthered the evolution of civilisation by being the first to live in harmony together, domesticate animals, make honey, and introduce armour and the war dance, which became a ritual performance in Minoan religious ceremonies. ${ }^{210}$ During the time of the Kuretes the Titans, including Kronos and Rhea, were born. ${ }^{211}$ Eteocretan and Greek mythology hold that Zeus was saved from the cannibalism of his father, Kronos, and hidden by Rhea in Crete to be raised by the Nymphs in a cave on Mount Ida, and protected by the Kuretes. ${ }^{212}$ His Cretan upbringing gave the Olympic god the epithet of Diktian Zeus, after Mount Dikte in east Crete. In Cretan mythology Minos

\footnotetext{
${ }^{207}$ Strabo, Geography, X 4.6.

${ }^{208}$ Homer, Odyssey, XIX 172-177.

${ }^{209}$ Diod. Sic., V 64.1.

${ }^{210}$ Diod. Sic., V 65.1, 65.4.

${ }^{211}$ Diod. Sic., V 66.1.

${ }^{212}$ Diod. Sic., V 70.3.
} 
became the great king of Crete and founded the towns of Knossos, Phaistos, Kydonia and established the laws of Crete. ${ }^{213}$

\section{Regional variances}

Evans' extensive travels across Crete his studies enabled him to propose regional use of writing styles. Evans found that linear types of script were widespread whereas Eteocretans in the east were the main users of hieroglyphic types. ${ }^{214}$ Schoep supports such regional distribution based on archaeological evidence, and writes: 'Moreover, in Linear A, non-administrative documents have a wider distribution than administrative documents, which is of relevance when discussing the spread of literacy. ${ }^{215}$ In other words, the CHS which had been used for religious inscriptions before the rise of trade between towns and overseas cities continued in use for religious, non-administrative, purposes when Linear A became more popular in the sixteenth and fifteenth centuries BCE. $^{216}$ Thus, literacy was associated with religious items and practice, which supports the notion that priest-scribes were the users and recorders of CHS. Only stone, clay and in some cases, ivory, survived the fiery destruction of the palace complexes and affiliated archival buildings. In the case of clay tablets, fire is responsible for hard-baking such evidence and preserving it for archaeologists (and others) to find.

Colin Renfrew proposes that the people of Crete were not under the power of one group, but were ethnically or regionally aligned to territories, and therefore

\footnotetext{
${ }^{213}$ Diod. Sic., V 78.1-2.

${ }^{214}$ Evans, 1893-4, 275-6.

${ }^{215}$ Schoep, 1996, 121. Schoep studied the physical remains inscribed or impressed with CHS and Linear A for each site. She then analyzed the discrete data to make general conclusions for the distribution of each script. See Schoep, 1996, 'I.1.Find Context of Linear A Documents' 13-101 for site-specific examples.

${ }^{216}$ Costis Davaras, 1976, 182
} 
palaces, until the first palace destructions in LMIB [Plate 6]. ${ }^{217}$ Hence, during the MM period scholars would be better to think of Crete as divided into Knossian, Phaistian, and Malian ethnicities. $^{218}$ John Cherry writes that territorial polities emerged simultaneously in Minoan Crete, but that they were united by socio-religious customs. $^{219}$ Ethnicity is married with beliefs and religion, and this ethos and shared world-view held regions together. Judith Reid reminds us that 'regional control does not necessarily imply palace control., ${ }^{220}$

Indeed, in the MM proto-palatial period there were only three (known) palace complexes for the whole island. It is important to remember that the pastoral economy of Crete may have facilitated the need for a script to record private transactions, while palace complexes may have had extensive administrations linked to local and overseas trading. Schoep's extensive analysis of CHS and Linear A documents puts the earliest secure date for hieroglyphic clay documents at MMIIB (destruction layers of Buildings A and B of Quartier Mu) at Malia in the proto-palatial period and the latest is a medallion from Petras, dated to LMIB in the neo-palatial period. $^{221}$ In MMIIB when Quartier Mu archives at Malia in the northeast were being kept using the CHS, Phaistos in the south-central Messara region was using Linear A. Schoep goes on to propose that, at Phaistos, Linear A may have grown out of the Proto-Linear A script, with tablets in CHS, Proto-Linear A and Linear A found in the palace archive room named Vano $25 .^{222}$ Based on this evidence, Schoep believes the

\footnotetext{
${ }^{217}$ Renfrew, 1996, 3.

${ }^{218}$ Renfrew, 1996, 3.

${ }^{219}$ Cherry, 1986, 31.

${ }^{220}$ Her Italics, Reid, 2005, 357.

${ }^{221}$ Schoep, 1996, 147.

${ }^{222}$ Schoep, 1996, 148. Proto-Linear A is the name given to a particular script which is not quite Linear A proper, or not as standardised as Linear A from other Cretan sites. It is considered the predecessor or Linear A. Vano 25 is a small room located in the Phaistos palace complex in what is known as the archive area.
} 
CHS was created in the northeast and used mainly by the regions which were dependent on Knossos, Malia, and Kato Zakro, and that the popularity of Linear A at Phaistos suggests this palace complex as the place where Linear A originated. ${ }^{223}$

Regional variations in motif characters or styles of depiction may give indications of where the scripts originated in Crete. The fact that both CHS and Linear A can be found in the same deposit in palace archives reveals that Linear A did not replace CHS in a linear evolution of pictograms to syllabograms. ${ }^{224}$ Schoep considers that the languages may be slightly different, but based on the recurrence of syllabograms in the ritual formulae of both scripts; she implies that a one language family is represented. ${ }^{225}$ Konstantinos Galanakis suggests that there may have been different 'teams of scribes' on Crete to account for the regional variances. ${ }^{226}$ It may be also be the case that there are two dialects of the same language family being represented in different scripts. This is supported by Owens' theory that the Archanes Script was the origin for both the CHS and Linear A, both being used for personal and religious purposes into the neo-palatial period, but by two different scribal traditions. $^{227}$

\section{Proto-Linear A}

In the Messara region in south-central Crete, evidence has been found to suggest an early form of Linear A. As mentioned earlier, the archive room Vano 25 in the palace complex at Phaistos, yielded tablets dated to MMII and inscribed with what has been

\footnotetext{
${ }^{223}$ Schoep, 1996, 148.

${ }^{224}$ Schoep, 1996, 93

${ }^{225}$ Schoep, 1996, 539-540.

${ }^{226}$ Galanakis, 2005, 35.

${ }^{227}$ Cherry, 1986, 34.
} 
called Proto-Linear A, or Archaic Linear A. ${ }^{228}$ One possibility is that the three different scripts represent transactions with three different centers - the CHS from Malia or Archanes in the north-east, Proto-Linear from Hagia Triadha and the Linear A script representing onsite scribal hands in the palace complex of Phaistos. Alternatively, it could be that there was one transaction between a north-eastern centre and Hagia Triadha, and Phaistos made their own copy in Linear A as an archive document to record the transaction with their administrative villa at nearby Hagia Triadha. Of course, many other explanations are also possible.

What has been shown is that cursive CHS, inscriptions on clay tablets (and presumably papyrus) from Mallia and Knossos, have commonalities with the Linear A at Hagia Triadha and Phaistos. ${ }^{229}$ The cursive (or inscribed) Linear A script can reveal individual hands of scribes, which, like the CHS, may be indicative of writing skill or regional training and style. ${ }^{230}$ When Carratelli compiled his standardised table of Linear A signs in 1945, the Hagia Triadha signs were markedly different and as such were included in the table as 'HT Variants.' 231 Pope described the Hagia Triadha style as 'remarkably uniform. ${ }^{232}$ However, since 1962, when Pope wrote Aegean Writing and Linear A, further research has shown that inscriptions from Hagia Triadha do have 'a wide range of variant forms' and this could be due to the administrative style particular to the site. ${ }^{233}$ David Packard writes that as early as 1850 BCE Phaistos was using a Linear A script. ${ }^{234}$ This early postulation, coupled with the fact that Hagia Triadha has the largest collection of Linear A inscriptions on

\footnotetext{
${ }^{228}$ Schoep, 1996, 148, 317.

${ }^{229}$ Brice, 1991b, 10.

${ }^{230}$ Dow, 1971, 14.

${ }^{231}$ Brice, 1961, 2. See Table I.

${ }^{232}$ Schoep, 1996, 407.

${ }^{233}$ Schoep, 1996, 410.

${ }^{234}$ Packard, 1974, 20.
} 
168 clay tablets, dated to LMIa, do suggest the creation and prolific use of Linear A in the Messara region. ${ }^{235}$

\section{Characteristics of Linear A}

Linear A was in use from MMIIB to LMIB and shares symbols from the CHS but in a more linear standardised way. ${ }^{236}$ The CHS was pictographic and possibly stemmed from seal stone usage. It was used for religious purposes and then started to be used for administration in the palace complexes in the MM period. The development of Linear A from the CHS has been suggested by Helène Whittaker because, like the CHS, Linear A was still appropriate in ritual contexts and therefore held 'social and symbolic meanings which were not carried over into Linear B. ${ }^{, 237}$

By MMIII, Linear A was becoming the dominant Minoan script and notably it never appeared on seal stones. ${ }^{238}$ From his studies in the late $19^{\text {th }}$ and early twentieth centuries, Evans deduced that approximately one third of the signs in this 'new' script were linear derivations of hieroglyphics, other were still used as ideograms for certain products which were followed by numeral signs and fractions to denote quantity as the CHS had done. ${ }^{239}$ As tablets of clay (and sometimes bronze) became the popular form of storing written information, signs were inscribed with a stylus as opposed to impressed by a seal stone.

The change in writing techniques is a large factor in the development from the pictographic CHS to Linear A, but Linear A and the CHS have yet to be fully

\footnotetext{
${ }^{235}$ Dow, 1971, 14.

${ }^{236}$ Reid, 2005, 338. Evans, 1909, 13.

${ }^{237}$ Whittaker, 2005, 29. Easterling and Handley, 2001, 1.

${ }^{238}$ Dow, 1971, 14.

${ }^{239}$ Evans, 1952, 1.
} 
understood. ${ }^{240}$ However, many scholars do concede that 'Linear A is definitely [a] different language to that of Linear B, and therefore is not Greek. ${ }^{241}$ Some symbols and logograms are borrowed by Linear B, which was deciphered by Ventris in the early 1950s. Hence four distinct signs which represent the important commodities, wheat, oil, olives and figs, are systematically recognised in the CHS, Linear A and subsequent Linear B in the LM period. ${ }^{242}$

In Linear A, lines of script can be compressed to fit a 'word' in before the scribe reaches the edge of the tablet, though punctuation is still developing and the text often continues through to the next line without indication. ${ }^{243}$ Such practices are but one of the difficulties in compiling a Linear A lexicon. In regard to punctuation, headings can be distinguished, as can dots or small dashes to separate 'words'. ${ }^{244}$ Another common characteristic of Linear A writing is called the 'libation formula': 'A made libations to B. ${ }^{245}$ Linear $\mathrm{A}$ is the result of the need for a simpler, more writable script than the CHS, and Reid suggests that the absence of Linear A on seal stones and impressions in the neo-palatial period is indicative of "a "new" administration system. ${ }^{246}$

The palace complexes were dealing not only with domestic trade but also offshore trade in the Mediterranean during the MM period. As a result, officials and scribes were required to keep more records than ever before. Hence Linear A is

\footnotetext{
${ }^{240}$ Best and Woudhuizen, 1988, 10.

${ }^{241}$ Dow, 1971, 16.

242 Packard, 1974, 20.

${ }^{243}$ Brice, 1961, 1.

${ }^{244}$ Brice, 1961, 1.

${ }^{245}$ Best and Woudhuizen, 1988, 11.

${ }^{246}$ Reid, 2005, 337.
} 
quicker to write and easier to learn. ${ }^{247}$ Brice proposes that Linear A was primarily used as basement records for villas and palace complexes:

The composite lists on the Linear A tablets seems to have been rough, short-hand records for the reference of the scribes themselves or of others who were conversant with their idiosyncratic style. They may have been little more than 'office copies', for emergency reference only, and kept only a short while before 'repulping' when all need to refer to them had passed. ${ }^{248}$

Brice's comment that the inscriptions were 'rough' compares Linear A to Linear B, which was more repetitive and clearly written on ruled lines. ${ }^{249}$ Another possible explanation of the 'roughness' of some Linear A inscriptions at Hagia Triadha and Phaistos is that the script was not formally Linear A, but a predecessor or evolutionary script bridging CHS and Linear A. ${ }^{250}$

\section{Offshore influences}

Both Evans and Schoep stress the indigenous origins of CHS and Linear A in Crete. Yet, both explore the influences of nearby cultures, such as Egyptian, Hittite, Syrian, Phoenician, and Greek on the Minoan scripts. The direction in which inscriptions read are varied in the archaeological evidence of both CHS and Linear A. Schoep's analysis notes the distinction that Cretan Hieroglyphic inscriptions can be either sinistrograde (right to left) or dextrograde (left to right), but Linear A was only written in dextrograde and did not appear on seal stones. ${ }^{251}$

Evans' early analyses suggested that the CHS had more in common with Hittite rather than Egyptian hieroglyphics, because Hittites also used a boustrophedon

\footnotetext{
${ }^{247}$ Dow, 1971, 13-14.

${ }^{248}$ Brice, 1991a, 45. Evans, 1952, 3.

${ }^{249}$ Brice, 1991a, 45.

${ }^{250}$ Schoep, 1996, 410.

${ }^{251}$ Schoep, 1996, 277.
} 
arrangement of inscription, as well as writing left to right. ${ }^{252}$ Contact with the Eastern Mediterranean coastal cities is definite. Egyptian scarabs with hieroglyphic inscriptions are paralleled with CHS on seal stones. ${ }^{253}$ Dimitris Matsas interpreted the motifs found on clay documents from Mikro Vouni, Samothrace, as CHS syllabograms. ${ }^{254}$ This discovery suggests that there was offshore intra-palatial contact with Minoans in MMII/MMIIIA. Matsas recognised that religious ideology was a factor that would sustain such contact and trade. ${ }^{255}$ The religious and administrative use of the CHS was continued in the Late Minoan (LM) with the Linear A script. ${ }^{256}$

\section{Cypro-Minoan Script}

Just as the CHS may have had offshore influences, the scripts of Crete, in turn, influenced writing in other cultures. The Cypro-Minoan Script (CMS) seems to have been inspired by the Cretan Linear A, as many signs are interchangeable between the two scripts; Evans found 15 Cypriot parallels with signs in the CHS and Linear A. ${ }^{257}$ Dated to c.1600 BCE, this Late Bronze Age Aegean script was developed to enable written communication between Cypriot and Minoan people. ${ }^{258}$ The assumption that Linear A and not Linear B influenced Cypriot script is based on the evidence of CMS at Enkomi c.1500 BCE, which pre-dates Linear B at Knossos by about 100 years. ${ }^{259}$ This early tablet from Enkomi represents Archaic CMS, and eventually the script developed into the Classical Cypriot syllabary c.1200 BCE, when Cyprus came under Anatolian control. ${ }^{260}$

\footnotetext{
${ }^{252}$ Evans, 1893-4, 316-7.

${ }^{253}$ Yule, 1983, 360.

${ }^{254}$ Matsas, 1996, 3.

255 Matsas, 1996, 3.

${ }^{256}$ Davaras, 1976, 183.

${ }^{257}$ Davaras, 1976. 183. Evans, 1952, 2. Evans, 1984, 348. 15 out of 32 signs.

${ }^{258}$ Owens, 1996b, 109.

${ }^{259}$ Packard, 1974, 22.

${ }^{260}$ Billigmeier, 1976, 299. Daniel, 1941, 252, dates the final transition at c.700 BCE.
} 
Between Archaic CMS and Classical Cypriot are four classes of CMS, which show a gradual development of the script in stages, similar to the situation on Crete. ${ }^{261}$ Cyprus was a leading producer of copper in the Mediterranean during the Bronze Age, and therefore doing business with Cypriot merchants and sailors was very important. $^{262}$ Just as Crete was a stepping-stone island in the Mediterranean trade route, so was Cyprus - especially to Anatolia. As a result CMS has also been found in mainland sites, like Ras Shamra in Northern Syria, carried there by traders and merchants and most probably intelligible to speakers of other languages. ${ }^{263}$

Like Linear A, the CMS was used for administrative and, to a lesser extent religious texts, including curious clay balls with signs inscribed on them. ${ }^{264}$ The clay balls are a medium different from any Minoan inscribed document, and the signs were incised with an instrument blunter than that used on Linear A tablets. ${ }^{265}$ On the other hand, when CMS was inscribed into tablets, and notably pottery, a thin sharp instrument was used. Through these unique media and techniques employed in Cyprus, the Cypriots created their own distinguishable script which adapted and survived for centuries.

\section{Conclusions}

As discussed in this Minoan Case Study, changes in a culture, such as sedentism, have profound effects on the processes used within the culture's society. The Minoan culture was blessed with its geographical position in the Mediterranean, and contact

\footnotetext{
${ }^{261}$ Daniel, 1941, 252.

${ }^{262}$ Wachsmann, 1998, 296.

263 Powell, 1991, 89.

264 Daniel, 1941, 253.

${ }^{265}$ Daniel, 1941, 253.
} 
with Egypt and the Levant possibly had an influence on their invention of the CHS. The heavily ritualised nature of religion and society on Crete also established an early tradition of visual communication with the gods by way of votive offerings and ritual dances. The miniature motifs on seal stones and ritual objects were a ready source for conveying a language, further enriched by incorporating known gesture language in pictorial forms.

Population increases led to stratification of social groups, and from prepalatial times a priestly scribal class handled the special impressions and inscriptions which communicated to the gods. This class continued to control the development of the CHS, and each region had its own priestly scribal class with an individual style. Increased trade connected with population increases broadened the knowledge of Minoan culture in general and perpetuated the need for administration, identification, and storage documents. Further increases in Bronze Age trade benefited from an administrative script that was easy to learn and fast to write. At this point in MMI-II, Linear A was developed and implemented in the Messara region. Its popularity spread over Crete, and even influenced other offshore scripts, such as the CMS.

The CHS was a system first employed for religious purposes that was transformed within Minoan culture to record quick, understandable documents, and was later used to record Greek in Linear B (which is beyond the scope of this Minoan Case Study). The next chapter will explore the effects a colonising culture can have on an indigenous culture in regards to engendering writing, by using the example of the Greek and Phoenician influences on the Etruscan alphabet in the eighth century BCE. The Greek language had been written in Linear B on Crete and the mainland in 
the late Bronze Age, but after the Dark Ages, c.1100-800 BCE, the Greek peoples who began trading prolifically with the Cyclades and the Near East took the Phoenician alphabet and modified it to be phonetic - with vowels and predominantly one letter or symbol for each sound. In the following Iron Age, Greece had begun to colonise many regions of the Mediterranean including southern Etruria. In Chapter 3 the phenomenon of script transference is considered using the example of Cumae, where an Euboean Greek colony was established in the early Iron Age. 
Minoan Bronze Age Chronology ${ }^{266}$

\begin{tabular}{|l|l|}
\hline Early Minoan I & c. $3100-3000$ to $2700-2650$ BCE \\
\hline Early Minoan IB/ Early Minoan IIA Transition & c. $(2700-) 2650$ BCE \\
\hline Early Minoan IIA & c. 2650 to $2450-2350$ BCE \\
\hline Early Minoan IIB & c. $2450-2350$ to $2200-2150$ BCE \\
\hline Early Minoan III & c. $2200-2150$ to $2050-2000$ BCE \\
\hline & \\
\hline Middle Minoan IA & c. $2050-2000$ to c. $1925-1900$ BCE \\
\hline Middle Minoan IB & c. $1925-1900$ to c. $1900-1875$ (to at most c. 1850 BCE) \\
\hline Middle Minoan II & c.1900-1875 to $1750-1720$ BCE \\
\hline Middle Minoan IIIA(-B) & c. $1750-1720$ to $1700-1680$ BCE \\
\hline Middle Minoan IIIB/Late Minoan IA Transition & c. $1700-1680$ to $1675-1650$ BCE \\
\hline & \\
\hline Late Minoan IA & c. $1675-1650$ to $1600-1550$ BCE \\
\hline Late Minoan IB & c. $1600-1550$ to $1490-1470$ BCE \\
\hline Late Minoan II & c. $1490-1470$ to $1435-1405$ BCE \\
\hline Late Minoan IIIA:1 & c. $1435-1405$ to $1390-1370$ BCE \\
\hline Late Minoan IIIA:2 & c. $1390-1370$ to $1360-1325$ BCE \\
\hline Late Minoan IIIB & c. $1360-1325$ to $1200 / 1100$ BCE \\
\hline
\end{tabular}




\section{Minoan Plate sources}

1. Plan of Myrtos.

Warren. (1972). Opposite page 11.

2. Drawing of 'house' or quarters from the south wing of Myrtos.

Warren. (1972). Fig. 28. 82.

3. Basic plan of the 'house' or quarters from south wing of Myrtos.

Preziosi and Hitchcock. (1999). Fig. 22. 50.

4. Goddess of Myrtos.

Warren. (1972). Fig. 92. 208.

5. Table of the Cretan Hieroglyphic Script symbols.

Schoep. (1996). Fig. 3. 12.

6. Proposed palatial control regions.

Cherry. (1986). Fig. 2.2. 21. 


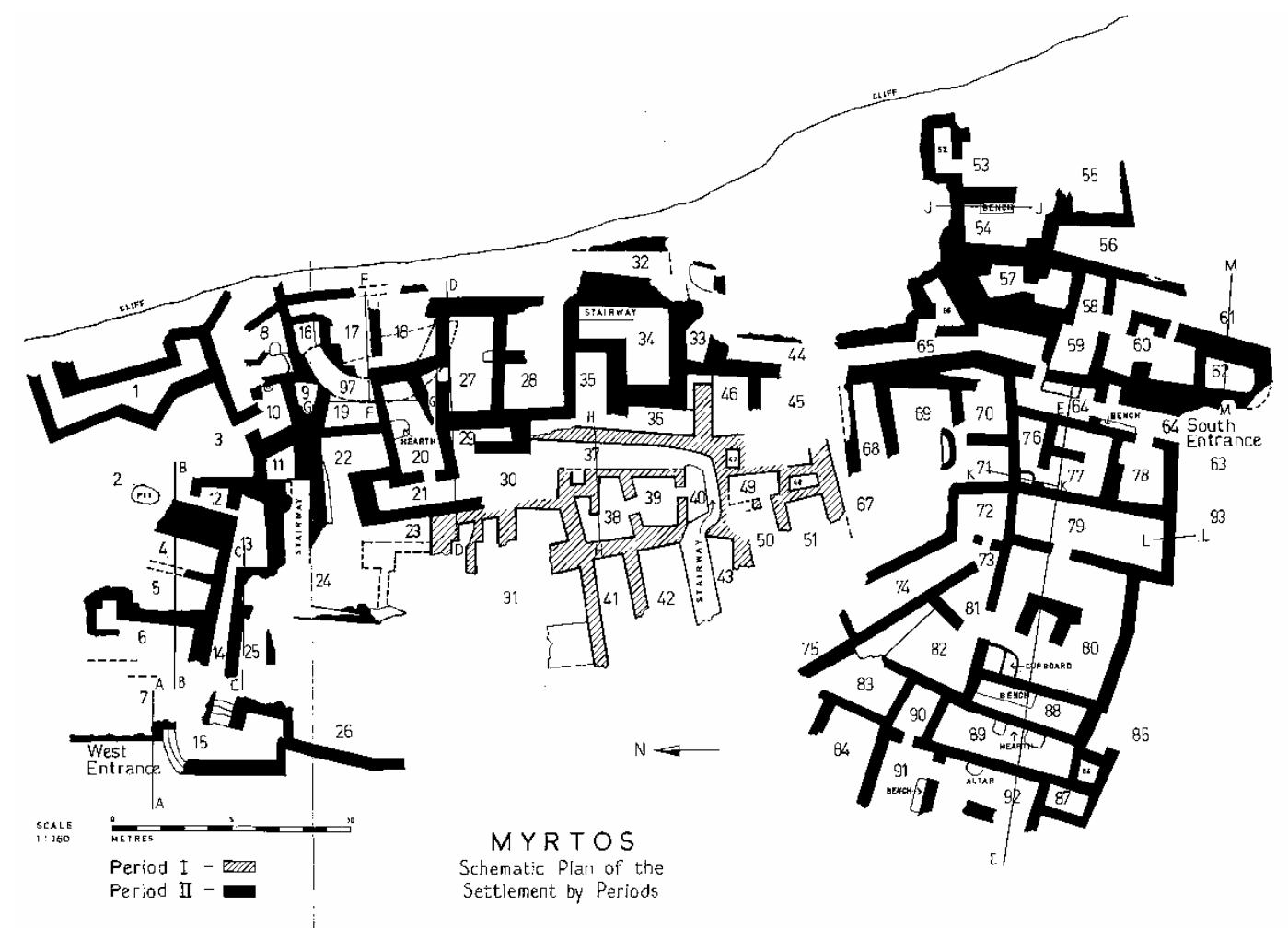

Plate 1: Plan of Myrtos. 


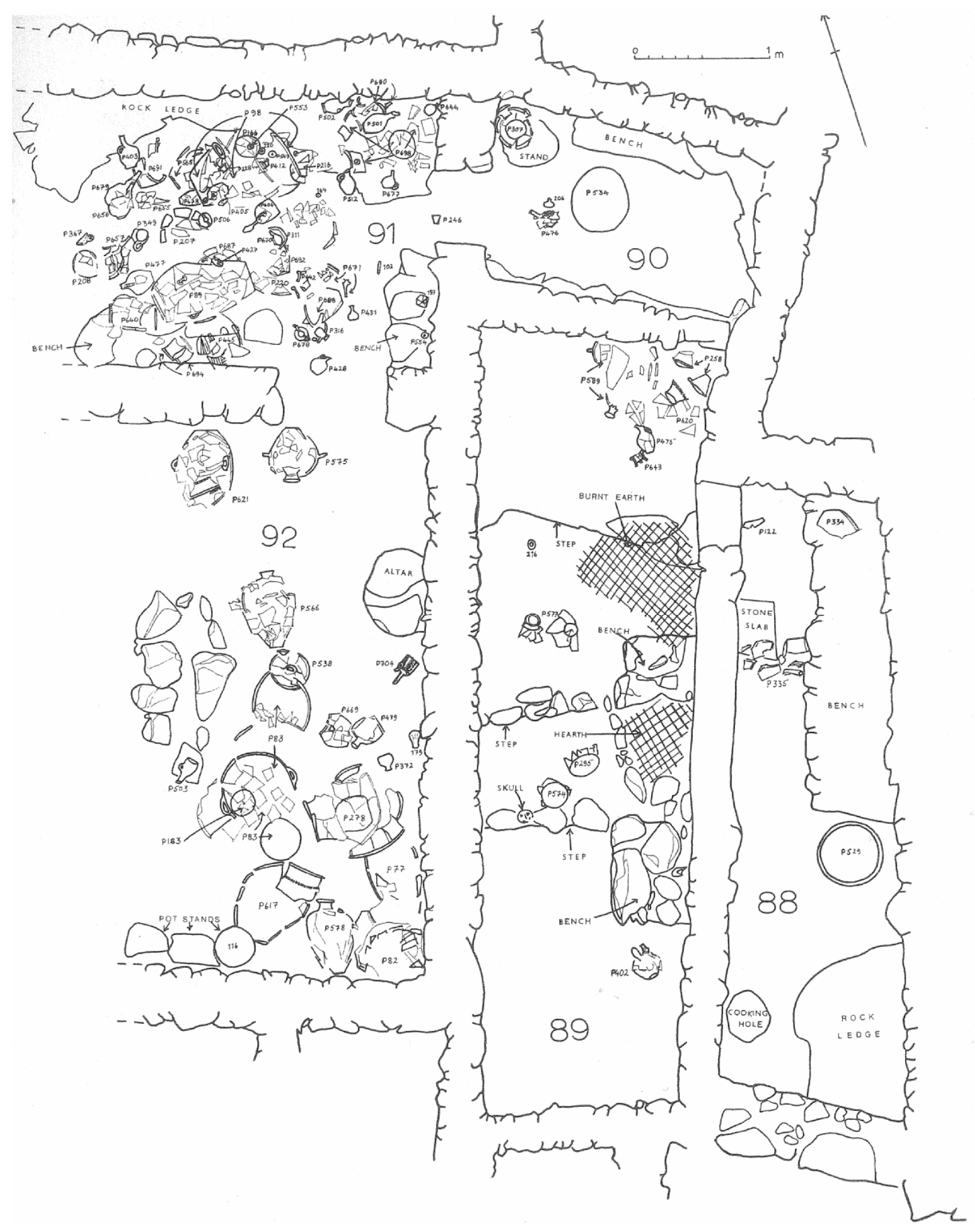

Plate 2: Drawing of 'house' or quarters from the south wing of Myrtos, including finds in situ. 


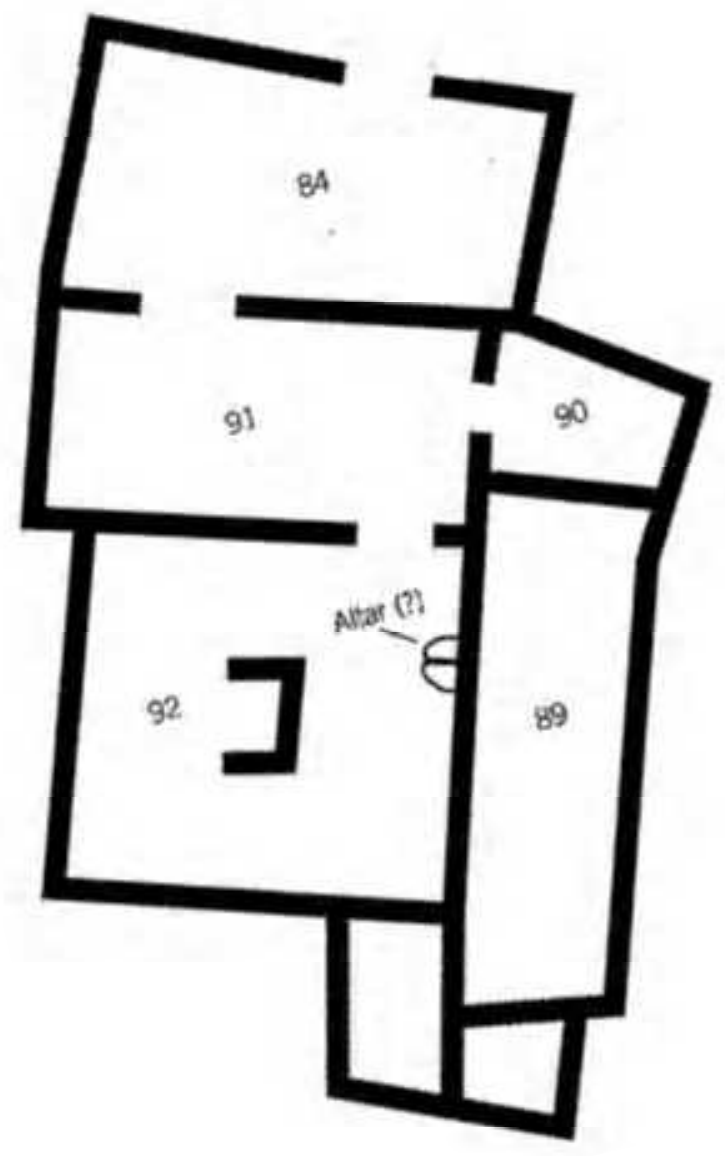

Plate 3: Basic plan of the 'house' or quarters from south wing of Myrtos. Note that room 88 is not present, unlike Plate 3. 


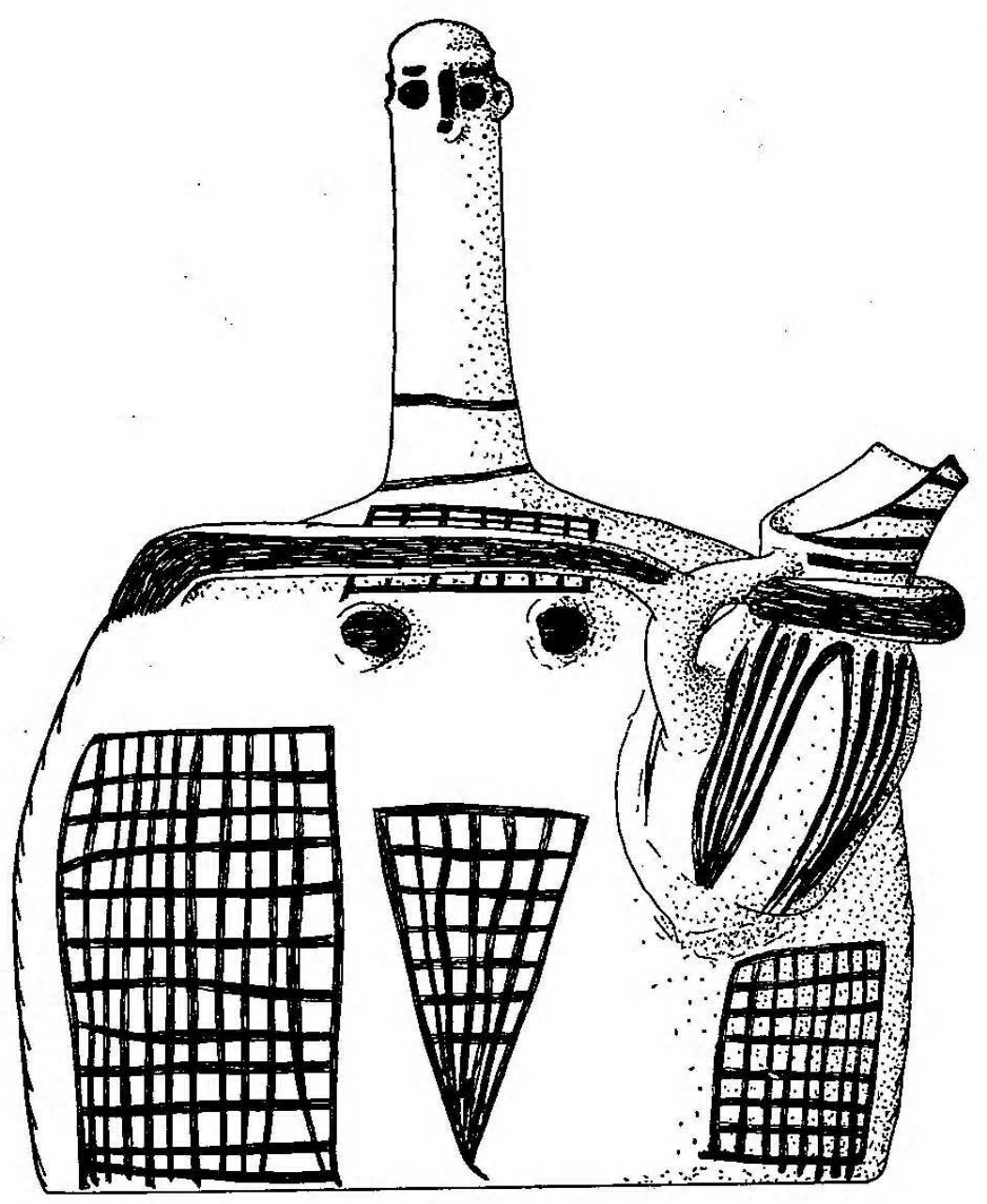

Plate 4: Goddess of Myrtos. 


\begin{tabular}{|c|c|c|c|c|c|c|c|c|c|c|c|c|c|c|c|}
\hline Syll: & bogram & ames & 025 & 丰 & f & 050 & $\uparrow$ & 1 & 075 & 6 & & ${ }^{x} 153 \%$ & {$[8]$} & .1771 & \\
\hline 001 & s & & 026 & $\mathrm{man}$ & & 051 & $\$$ & 4 & 076 & & 要 & $=154 \mathrm{~m}$ & & .1280 & \\
\hline$\infty 2$ & 8 & & 027 & bo & & 052 & $\ddot{p}$ & 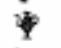 & on? & 0 & $\overline{7}$ & ${ }^{*} 155 \mathrm{Y}$ & $Y$ & $\underline{179} \neq$ & \\
\hline cov3 & 愈 & & 028 & $y^{\prime}$ & $V^{\prime}$ & 053 & 8 & 8 & 078 & 8 & & 156 邽 & 原 & *180 & \\
\hline$(x) 4$ & ช & & 029 & 38 & $\overrightarrow{v e}$ & 054 & $Q P$ & 8 & 079 & i & & ${ }^{*} 157$ & 0 & .181 & \\
\hline$(x) 5$ & $a$ & $\$$ & 030 & 4 & & 055 & $4 p$ & & 080 & 8 & & *15S 9 & & $-182 \quad i$ & \\
\hline $\mathrm{COG}$ & $" X^{n}$ & $\mathbf{x}$ & 031 & $Y$ & $\Psi$ & 056 & D & 更 & 081 & sy. & & ${ }^{*} 159$ ? & & Klasmitegrimmes & \\
\hline$(x) 7$ & $\vartheta$ & $\sqrt{ }$ & 032 & \&ै & & 057 & $\psi_{4}^{4}$ & $\psi$ & $\cos 2$ & $\Theta$ & & ${ }^{*} 159,0 \%$ & & $301 \mathrm{r}$, & \\
\hline COB & 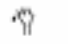 & 1 & 033 & $\Rightarrow$ & $x$ & 058 & $\theta$ & 0 & 683 & $\varphi$ & & ${ }^{*} 160$ Q & & $302 \triangle l$ & Ligotwres \\
\hline$\alpha \times 0$ & $\theta$ & 4 & 034 & $\mathrm{M}$ & 11 & 059 & $\uparrow$ & $\uparrow$ & cos4 & $\mathbb{W}$ & & ${ }^{*} 1610$ & & $303 \theta \quad$ t & $302 \cdot 303 \mathrm{lt}$ \\
\hline 010 & 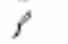 & 5 & 035 & $p$ & & 060 & $\uparrow$ & $r$ & LES & $A$ & & $* 1628$ & & $304 \wedge \quad \hbar$ & $302 \cdot 307 \quad$ L \\
\hline 011 & 0 & 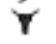 & 036 & $H$ & $n$ & $\infty 61$ & ? & 3 & 086 & $\nabla$ & & $\cdot 1630$ & & $305 \Xi \searrow$ & $304 \cdot 302$ \\
\hline 012 & 2 & 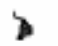 & 037 & A & & 062 & 1 & $\uparrow$ & c87 & Q & & *164 If. & & 306 iा $\quad \lambda^{\prime}$ & $304 \cdot 303$ \\
\hline 613 & $\infty$ & 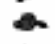 & 038 & 回 & tit & 1.63 & 1 & i & coss & $\infty$ & & ${ }^{*} 165$ If & & $307 \Sigma \quad$ & \\
\hline 014 & & $y$ & 039 & है & x & 064 & ф & & USS & $x$ & & ${ }^{*} 166$ & & 308 P & \\
\hline 215 & 6 & & 040 & $d x$ & $d x$ & 065 & 1 & {$[t]$} & 090 & * & & ${ }^{*} 1672$ & & $309 \lambda$ & \\
\hline 046 & $\xi$ & E & 041 & $\mathbb{N}$ & $\mathrm{B}$ & 066 & II & II & 091 & ses & & *168 & & Arithmegnamines & \\
\hline 017 & $\infty$ & $\sigma$ & 042 & $\phi$ & 4 & 067 & 1 & & 092 & $\uparrow$ & $\omega$ & ${ }^{x} \underline{160} r$ & & , ' & \\
\hline OIs & $\varepsilon$ & 由 & 043 & 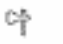 & 4 & OSs & 证 & 嚚 & 093 & A & & 1170 & & 10 & \\
\hline 019 & $\forall$ & $Y$ & 044 & f & $i$ & $0 ; i 3$ & R & 《k & 099 & A & A & *171 3 & & 10 & \\
\hline 020 & ร。 & $*$ & ous & Q & t & (100 & $\div$ & $x$ & ưs & & 8 & $-172 A$ & & 1000 & \\
\hline 021 & बि: & $\Delta$ & 046 & रे & $n$ & 971 & 䎅 & & OS6 & 4 & & ${ }^{*} 173 \mathrm{~A}$ & & Stitibugamanxes & \\
\hline $\cos 2$ & ชั & & 047 & 0 & $\theta$ & 972 & $\triangle$ & & Lin: & vgtamen & & $\times 174 Y$ & & $x$ & \\
\hline 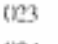 & "lo & ₹ & $64 \mathrm{~B}$ & & $\theta$ & 673 & 0 & 0 & $* 151$ & 䇰 & & $+175 \%$ & & & \\
\hline tra & $\mathrm{Y}$ & & 1249 & $\uparrow$ & $\uparrow$ & 074 & Q & & ${ }^{2} 15$ & 0 & & $* 1764$ & & & \\
\hline
\end{tabular}

Plate 5: Table of the Cretan Hieroglyphic Script symbols. 


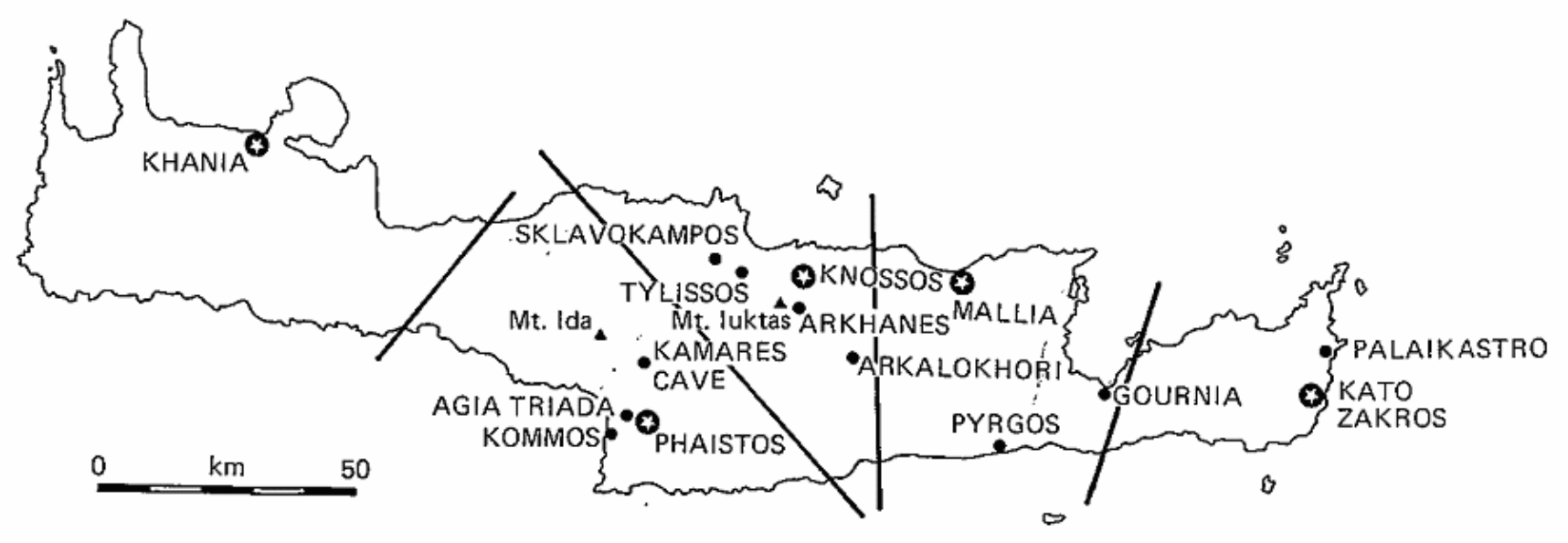

Plate 6: Proposed palatial control regions of Crete. 


\section{Chapter 3}

\section{Etruscan Case Study}

\section{Introduction: the Euboean settlement at Cumae}

Unlike the Minoans, who were a dominant culture in the Mediterranean preceding the Dark Ages c.1100-800 BCE, Etruscan civilisation was at its height during the Archaic and Orientalising periods, c.850-650 BCE. ${ }^{267}$ During this time they adapted a Greek alphabet to create their own which had a 'sacral and aristocratic character., 268 The Etruscans used their alphabet to write down prophecies, label figures on mirrors, wall paintings and pottery, and make public declarations. Etruscans were heavily influenced by Greek and Phoenician settlements on the Italian islands and coast, particularly in the adoption of their alphabet - which is the focus of this case study.

Etruscan culture was distinct from other Italian cultures in Italy and well established by the time Euboean Greeks from Chalcis settled at Cumae in the eighth century BCE [Plate 1]. ${ }^{269}$ Cumae was a port colony from which foreign influences spread to the wider Etruscan civilisation. ${ }^{270}$ Being surrounded by cultures of the Mediterranean, who had already established scripts and grammar for writing their languages, Etruscan culture faced many outside influences. ${ }^{271}$ Tacitus, in Annals XI: xiv, records the tradition that Etruscans learned their script from 'Demaratus the Corinthian.' However, despite the large corpus of Corinthian pottery found in Etruria this is not the alphabet from which Etruscan was derived. ${ }^{272}$ Greek immigration to

\footnotetext{
${ }^{267}$ Yunis, 2003, 3. Bonfante \& Swaddling, 2006, 8.

${ }^{268}$ Bonfante, 2006, 9.

${ }^{269}$ Blakeway, 1935, 129, 135, dates the foundation of Cumae between 775-750 BCE.

${ }^{270}$ Torelli, 1996, 572.

${ }^{271}$ Bonfante and Bonfante, 2002, 50.

${ }^{272}$ Carpenter, 1945, 453.
} 
Italy predated the foundation of Euboean Greeks at Cumae, but the archaeological evidence suggests that it was a distinctly Cumean Greek alphabet, which was adapted by southern Etruscans and spread further north, that was used to create their own alphabet. ${ }^{273}$ This case study will look at the transference of the Greek alphabet into Etruscan culture. Once an overview of Etruscan writing has been established, the role of Etruscan religion in this transference will be explored.

\section{Adaptation of a foreign alphabet}

Rhys Carpenter suggests trade alone and encounters with the Greek alphabet inscribed and painted on pottery was not enough for the Etruscans at Cumae to learn how to use the Greek alphabet. ${ }^{274}$ The grammar had to be taught in order to use the alphabet correctly and write the script legibly. The Chalcidian colony at Cumae may have provided such an opportunity to teach Etruscans the nuances of the Euboean Greek alphabet. ${ }^{275}$ The Etruscan alphabet closely resembles the Euboean Greek alphabet, and Carpenter writes that through 'sheer elimination there seems no other candidate' for an alphabetic precursor to Etruscan. ${ }^{276}$ It is conceivable that as settlements like Cumae grew, schools would have taught both Euboean Greek and Etruscan alphabets.

Around 700 BCE the Etruscans began to use an alphabet which had 26 characters [Plate 2]. ${ }^{277}$ Because the Greek alphabet was relatively simple, when compared to scripts of the Near East, literacy was potentially accessible to the public and not merely a priestly or scribal class. ${ }^{278}$ The new Etruscan alphabet is generally

\footnotetext{
273 Blakeway, 1935, 143, 147.

${ }^{274}$ Carpenter, 1945, 456.

${ }^{275}$ Carpenter, 1945, 456. Robinson, 2002, 159.

${ }^{276}$ Carpenter, 1945, 456.

${ }^{277}$ Pallottino, 1975, 209; Ridgway, 1992, 141; Bonfante and Bonfante, 2002, 49-51.

${ }^{278}$ Thomas, 1992, 17; Goody, 1987, 55.
} 
thought to be a mix of Phoenician and Greek alphabets, modified to represent the sounds of Etruscan speech. ${ }^{279}$ The alphabet had likely been transmitted to mainland Greece via the Euboeans' sea trade with the islands of Cyprus and Crete where they mixed with Phoenician traders. ${ }^{280}$ They then imported their alphabet to Italy when their trading colonies at Pithekoussai and Cumae were established.

Etruscan script differs from the Cumaean in several respects The Greek letters $\mathrm{B}, \mathrm{D}$, and $\mathrm{O}$ were not used in Etruscan writing, probably because their language had no sounds for them. The Etruscans also converted the values of some Greek letters to different sounds so as to fit their language. ${ }^{281}$ For example, the letter ' $\mathrm{X}$ ' in the Cumean Greek alphabet came with the pronunciation ' $\mathrm{k}+\mathrm{s}$ ', but when written in Etruscan it has the Phoenician pronunciation of 'sh' a soft 's' like the letter Shin. ${ }^{282}$ The interchangeability of the letters Shin, San, Samekh and Tsade with Sigma, Chi and $\mathrm{Xi}$ is a perplexing example of the flexibility of languages which affects the written alphabet when adopted by foreign cultures. ${ }^{283}$ Such processes allow for the modification of a script. Steven Houston writes that:

Cultural values have inhibited change sufficiently that most fundamental innovations in the nature of writing systems have occurred when scripts were being adapted for writing new languages. ${ }^{284}$

As Houston notes, Etruscan is a clear example: the Etruscans modified the Cumaean Greek alphabet to suit their linguistic needs; their modifications then later filtered through to influence the Latin alphabet. Inscriptions of names such as Larth Telicles and Rutile Hipucrates demonstrate a combination of Etruscan and Greek language,

\footnotetext{
${ }^{279}$ Pallottino, 1975, 209.

280 Thomas, 1992, 53.

${ }^{281}$ Bonfante and Bonfante, 2002, 52.

282 Torelli, 2000, 481-3; Bonfante and Bonfante, 2002, 52.

${ }^{283}$ Carpenter 1945, 456-8.

${ }^{284}$ Houston, 2004, 67.
} 
and in the natural course of colonisation, Etruscans and Greeks intermarried and cohabitated together in Italian towns showing cultural combinations also. ${ }^{285}$

The appropriation of Greek mythological figures for Etruscan bronze mirrors and other artistic media is testimony to the Etruscan appreciation and knowledge of Greek culture. Unlike the Greeks, however, significant surviving examples of Etruscan writing record sacred texts. The knowledge of the lost texts of the Disciplina Etrusca draw parallels, not to Greek religious texts, but to Eastern counterparts such as the Vedas or the Torah. ${ }^{286}$ Julian Thomas suggests that high Greek culture valued the skill of oral rhetoric to such an extent that the creation of sacred texts (of the calibre of the Disciplina Etrusca) seems to have been inhibited. What may be more likely is that the Greek states' concerns with law and philosophy resulted in the prevalence of these types of literature. ${ }^{287}$

\section{Literary remains from Etruria}

The earliest Etruscan inscriptions are found on pottery. ${ }^{288}$ The 'Nestor' cup, c.730720 BCE, from Pithekoussai [Plate 3] bears the inscription in sinistrograde: 'I am the delicious cup of Nestor. Whoever drinks from this cup the desire of beautifully crowned Aphrodite shall seize. ${ }^{289}$ While this is not the cup of Nestor mentioned in the Iliad (11.631-636), it displays a humorous commentary on Homeric verse in the eighth century BCE. Another example is a brown polished impasto pot, c.700-650

\footnotetext{
${ }^{285}$ Ridgway, 1992, 141.

${ }^{286}$ Henrichs, 2003, 40.

287 Thomas, 1992, 3.

288 The earliest Etruscan inscription is from a globular vase, c.770 BCE, from a grave in the cemetery of Osteria dell'Osa. R. Ross Holloway, 1995, The Archaeology of Early Rome and Latium, Ch. 8. Osteria dell'Osa, 112. Taking into account the high dating of 950-880 BCE for the grave, Wiseman prefers c.800 BCE. T. P. Wiseman, 2004, The Myths of Rome, Exeter, 13, Fig. 5.

${ }^{289}$ Thomas, 1992, 58.
} 
$\mathrm{BCE}$, from Tarquinia that has an inscription running around the shoulder written in retrograde with incised orientalising style animals on the body [Plate 4]. ${ }^{290}$

Two artefacts are considered to be examples of the early perception the Etruscans had of the Greek alphabet - that it was decorative and magical. ${ }^{291}$ The first is a miniature writing tablet from Marsigliana d'Albegna has been dated to c.650 BCE. $^{292}$ It has the 26 letter Etruscan alphabet inscribed along the upper border in sinistrograde, reading from right to left, above the place where a wax surface would have been used to inscribe the practice of the individual letters [Plate 5]. The opposite side of the tablet was covered with gold leaf. ${ }^{293}$ The significance of writing a modified Greek alphabet in the reverse direction is debateable, with suggestions from the fields of neurology and linguistics, which will be discussed below. The second is a charismatic bucchero ink well c.600 BCE, from Viterbo, in the shape of a rooster bearing a model Etruscan alphabet [Plate 6]. Writing guides, implements and tablets are considered prestige items in tomb deposits and are indicative of the wealth, contacts and education of the person buried with them. ${ }^{294}$ By studying significant surviving Etruscan texts, one can understand how writing fitted into Etruscan culture and why they used it.

Translation of Etruscan is not an objective in this case study. Rather, it is to understand Etruscan cultural perception of alphabetic writing. Legends, art, archaeological evidence and secondary sources, primarily from Roman authors, will illustrate the importance of writing for Etruscan people. Etruscans had unique

\footnotetext{
${ }^{290}$ Hugh Hencken, 1968, Volume I, 420-421, Fig. 445.

${ }^{291}$ Bonfante and Bonfante, 2002, 55.

${ }^{292}$ Bonfante and Bonfante, 2002, 132-3.

${ }^{293}$ Bonfante and Bonfante, 2002, 133.

${ }^{294}$ Bonfante and Bonfante, 2002, 55. Borrelli and Targia, 2003, 90.
} 
traditions of a child prophet, Tarchies (Latin Tages), and a nymph called Lasa Vecuvia (Latin Vegoia or Begö̈), whose prophecies belong to the corpus of the Disciplina Etrusca. ${ }^{295}$ Through later Latin sources such as Ovid, Livy, Cicero and Suetonius, it is clear that writing was very important in Etruscan culture. ${ }^{296}$ These sources name three types of expert in Etruscan divination: augurs - bird sign diviners; haruspices - organ and entrails readers; and fulguriators - thunder and lightning interpreters. Larissa Bonfante argues that 'Etruscan religion provides a striking example of the symbolic, religious significance of writing' which can be studied through art and indigenous Etruscan legends. ${ }^{297}$

Surviving Etruscan texts have been dated to the fifth or fourth centuries BCE, and are usually religious in nature. Many are short dedicatory inscriptions on votives, or monuments like grave markers or boundary stones. Some however, provide more than simply the names of people and gods. A few notable examples are the Capua tile, the Pyrgi sheets and the bronze Piacenza liver. The Capua tile is dated to the fifth or fourth century BCE, and has 62 lines of inscription and nearly 300 legible words. ${ }^{298}$ The lower part of the text is not legible and the writing is boustrophedonic [Plate 7]. ${ }^{299}$ Larissa Bonfante discusses the tile in The Religion of the Etruscans, writing that it documents a sacred calendar and proposes that the unusual 'piercings' on the tile were part of a horizontal storage system for a stack of similar terracotta tiles, suggesting the tile was mounted for viewing in a temple. ${ }^{300}$ This theory is plausible

\footnotetext{
295 Brendel, 1978, 145 mentions only Tages. Pallottino, 1975, 153-154 includes Vegoia or Begoë.

${ }^{296}$ Bonfante, 2006, 21.

${ }^{297}$ Bonfante, 2006, 23.

${ }^{298}$ Bonfante and Bonfante, 2002, 58.

299 Pallottino, 1975, 199.

${ }^{300}$ Bonfante, 2006, 11.
} 
for a series of clay tiles that were for temple use and not display, like the Pyrgi sheets discussed below. For heavy terracotta tiles, vertical wall display does not seem ideal.

\section{The Pyrgi sheets}

In 1964 three gold sheets were found at Pyrgi, one of the ports of Caere, under the excavation of Giovanni Colonna [Plate 8]. ${ }^{301}$ The initial significance of these sheets when they were found was that they seemed to be bilingual - not in Etruscan and Greek, but in Etruscan and Phoenician. ${ }^{302}$ Two of the sheets are written in Etruscan (E1 and E2), the third Punic (P), and they equate the Etruscan goddess Uni (Juno) with Phoenician Astarte - not with the Greek Hera. ${ }^{303}$ Dated to c.500 BCE, the sheets were found ritually buried in a niche between Temples A and B on the site, with other valued artefacts and archive materials. ${ }^{304}$ The three sheets were found together, rolled up with holes in them where they had possibly been nailed to the temple, as suggested on the bronze mirror from Volaterrae, with Uni nursing Hercle [Plate 9]. ${ }^{305}$ Of the Pyrgi tablets, one Etruscan tablet, E1, has fifteen lines of text with 36 or 37 words; the Punic tablet is its equivalent with ten lines.

According to Jaques Heurgon, the translation does not function word for word and $\mathrm{P}$ was the primary one. Therefore E1 was worked from it; the shorter Etruscan tablet E2 with nine lines of inscription and fifteen words being related but apart from the main Punic-Etruscan duo. ${ }^{306}$ Heurgon's theory states the evidence supporting the close relationship between $\mathrm{P}$ and E1: both P and E1 use the full sheet of gold for the

\footnotetext{
${ }^{301}$ Spivey, 1997, 98-99.

302 Bonfante and Bonfante, 2002, 58.

${ }^{303}$ Bonfante and Bonfante, 2002, 67.

${ }^{304}$ Heurgon, 1966, 5.

${ }^{305}$ Heurgon, 1966, 6. Bonfante and Bonfante, 2002, 155.

${ }^{306}$ Heurgon, 1966, p12. Pallottino, 1975, 200. Abbreviations in accordance with Heurgon, 1966.
} 
inscription, while E2 only uses half; both $\mathrm{P}$ and E1 have 10 nail holes in the same places, but E2 has 12 nail holes. Almost all of the gold-headed bronze nails were found inside the rolled up sheets E1 and E2, and their length, approximately $37 \mathrm{~mm}$, indicates that they were nailed to wood at least $40 \mathrm{~mm}$ thick - a large wooden temple door seems possible. ${ }^{307}$ Temple B's foundations, however, reveal that it was built in the Greek 'peripteral, tetrastyle, seven columns along each side, and a cella opening into the adyton. ${ }^{308}$ Hence, confusion results from the Etruscan inscription following a Punic antecedent in a ritual burial containing objects from a Greek temple. The Etruscans borrowed from many cultures, however, and this fact is not disputed here. Meanwhile the Greeks borrowed from the Phoenicians as well, but this is not as widely acknowledged. I suspect that the confusion over the Pyrgi tablets is due to the strong desire, on the part of Europeans, for the Greeks to be perfect, as they are considered to be the antecedents of European culture.

The text describes a dedication of the king of Caere, Thefarie Velianas, to the goddess Uni-Astarte, and is a historical as well as religious document, which relates to the period from the sixth to the fourth century BCE, when the Phoenician/Punic Carthaginians were close allies with the Etruscans. ${ }^{309}$ This may seem at odds with Caere's philhellenic disposition, but perhaps the planning for Temple B was either designed by a Greek architect, or done in the Greek style, and had nothing to do with the political associations between Carthage and Caere. ${ }^{310}$ The borrowed style need not have bearing on the people who used or revered Temple B and Uni. I also

\footnotetext{
${ }^{307}$ Heurgon, 1966, 6.

${ }^{308}$ Heurgon, 1966, 5.

${ }^{309}$ Pallottino, 1991, 82.

${ }^{310}$ Heurgon, 1966, 3.
} 
propose that c.500 BCE public dedication inscription formulae were still being learnt by Etruscan scribes, and so they used the Punic inscription formula as a guide.

\section{The Zagreb mummy wrappings}

The longest surviving Etruscan text comes from the wrappings of the Zagreb mummy [Plate 10]. ${ }^{311}$ The Zagreb text is conservatively dated to c.150-100 BCE. ${ }^{312}$ Pallottino thought that a poor Egyptian, who could not afford bandages, found the abandoned Etruscan text and recycled it to make strips of cloth to wrap a deceased female. ${ }^{313}$ Another possibility is that the one wrapping the mummified body was conscious of the sacred nature of the Etruscan text and intentionally imbued the Egyptian burial with Etruscan ritualistic overtones. In any case, Etruscologists are indebted to the reuse of the sacred material text (liber linteus), which is comprised of approximately 1200 Etruscan words written in ink. ${ }^{314}$ Like the inscription on the Capua tile, the Zagreb mummy text outlines gods and their necessary prayers and sacrifices according to a sacred calendar used in the regions of Perugia and Cortona in the third to second centuries BCE.

Etruscans used writing for short texts on boundary stones, mirrors, vases, tomb paintings and tablets, and for longer texts were influenced by Punic writing formulas in c.500 BCE. Notable surviving Etruscan inscriptions, and the Zagreb mummy written text, are often dedications or sacred calendars. The predominance of such remains being predominant would lead one to assume that the Etruscans employed writing for religious purposes primarily. There are no surviving tragedies, poetry,

\footnotetext{
${ }^{311}$ Pallottino, 1975, 198.

${ }^{312}$ De Grummond, 2006a, p43. Robinson, 2002, 172.

${ }^{313}$ Pallottino, 1975, 198. Bonfante and Bonfante, 2002, 58.

${ }^{314}$ Robinson, 2002, 172.
} 
epics or philosophies such as the Greeks left. Of course the lack of these types of literature does not mean that they did not exist, merely that they did not survive or have not yet been found.

\section{The legends of Tarchies and Lasa Vecuvia ${ }^{315}$}

Nancy Thomson de Grummond states that the majority of prophetic representations in Etruscan art belong to the Middle Etruscan period, c.400-300 BCE. ${ }^{316}$ Tarchies appears on one or two Etruscan mirrors, a popular media for depicting prophets who disclosed the information which contributed to the sacred books of the Etruscans [Plates 11a, b]. By beginning with an analysis of the Tarchies legend, the infant prophet with the wisdom of an elderly sage who enlightened the Etruscan peoples, the nature of the legend itself allows us to understand the importance of writing in Etruscan culture.

According to secondary sources, the prophet Tarchies appeared before Tarchon - the founder of the famous Etruscan city of Tarquinia. ${ }^{317}$ In De Divinatione Cicero recounts the myth of Tages (and then derides it). ${ }^{318}$ Tages imparted the art of prophecy which was readily accepted by the local Etruscans and written down. The key detail in Cicero's account is that Tages ordered his prophecy to be written down. The command emphasises the importance of literacy, archives and the notion of historicity maintained in Etruscan culture. ${ }^{319}$ Ovid describes Tages as emerging from a ploughed furrow and giving prophecies to Tarchon in Metamorphoses (XV.553). A

\footnotetext{
${ }^{315}$ I will use the English form 'Tarchies' (of the Etruscan Tarxies) instead of the Latin 'Tages' in this chapter except when discussing the writing of Latin authors who obviously refer to 'Tages'. For the sake of research, Tages is more frequently discussed than Tarchies.

${ }^{316}$ De Grummond, 2006a, 23.

317 Hencken, 1968, 18.

${ }^{318}$ Cicero, De Divinatione II: XXIII $50 \mathrm{ff}$.

${ }^{319}$ Bonfante and Bonfante, 2002, 10.
} 
carnelian scarab, 300-200 BCE, shows a man (Tarchon) helping an infant (Tarchies) arise from the ground [Plate 12]. The scarab's artistic representation of the birth of Tarchies corresponds with Ovid's account in the Metamorphoses. Writing in $238 \mathrm{CE}$, Censorinus emphasises that the prophecy was written down by the Etruscan rulers: 'lucumones tum Etruriae potentes exscripserunt' (De Die Natali IV: xiii). At this point in Etruscan legendary time, the people already had an established script with which to write down important ritual knowledge. ${ }^{320}$

The possession of these divine sanctions was apparently a source of pride and supported their dominance during the height of Etruscan supremacy. To include a written component to an oral prophecy could be a later addition to the story, but such an extrapolation indicates the Etruscan attitude towards the importance and uses of writing: that Etruscan culture valued the new innovation as much as ancient traditions. However, valuing both old and new practices is not unique to Etruscan cultural perceptions; Greeks and Romans also include 'writing' in myths and legends, such as the myth of Bellerophontes. ${ }^{321}$ Cheryl L. Sowder notes that while the Tarchon and Pava Tarchies mirror from Tuscania is dated c.300 BCE, the literary sources mentioned above are at least 200 years older, but it may be that contemporary Etruscan literary sources describing the legend have not survived. ${ }^{322}$ Otto J. Brendel, however, suggests that the scene is not legendary, but merely shows a contemporary Etruscan haruspex (netsvis) at work [Plates 11a, b]. ${ }^{323}$

\footnotetext{
${ }^{320}$ Even though the tradition of writing alphabetically may be later than Tarchon's time.

${ }^{321}$ Glaukos tells the story of his ancestors, including Bellerophontes, to Diomedes in Iliad VI:155-202. The reference to the death note Proitos sends with Bellerophontes is famous as the only mention of writing in Homer; 'He shrank from killing him, since his heart was awed by such action, but sent him to Lykia, and handed him murderous symbols, which he inscribed in a folding tablet, enough to destroy his life, and told him to show it to his wife's father, that he might perish' Iliad VI: 167-170, Richmond Lattimore (trans.), 1951.

${ }^{322}$ Sowder, 1982, 123.

${ }^{323}$ Brendel, 1978, 417.
} 
One more interesting point is that the term exaratus used by Censorinus had both the meaning of 'being ploughed up' and 'to write precisely with a stilus in wax. $^{, 324}$ That Tarchies' unique birth from the ground became synonymous with exact inscription is a linguistic reflection of cultural attitudes and the mingling of language, meaning and legend. A further connection between writing and ploughing is the very term 'boustrophedon' - 'as the ox ploughs', confirming a link between agricultural sedentism and literate cultures.

While the prophecy of Tarchies has been placed at the beginning of Etruscan history, the prophecy of Lasa Vecuvia belongs to the end of Etruscan history. ${ }^{325}$ Corresponding to first century BCE, the eighth saeculum, or period, of Etruscan history encompassed the final phase of Romanisation in Etruria. ${ }^{326}$ At this time boundaries of space and time were primary concerns for Etruscan civilisation, and divination was required to read the signs of the gods pertaining to such matters. Vecuvia's prophecy relates to the delivery of the orders of Tinia (Jupiter) about the sacredness of maintaining boundary stones and the dangers of humanity, such as greediness. $^{327}$ Like Tarchies, Vecuvia speaks to a native Etruscan man, Arruns Veltymnus. $^{328}$ The prophecy begins with a cosmogony before insisting on the placement of permanent boundary stones, with the threat of natural disasters (clear signs for an augur or fulguriator to interpret) mirrored by chaos and wars in Etruscan

\footnotetext{
${ }^{324}$ P.G.W Glare (ed.), Oxford Latin Dictionary, Oxford, 1982, ad loc.

${ }^{325}$ De Grummond, 2006b, 31.

${ }^{326}$ De Grummond, 2006a, 41. De Grummond, 2006b, 31.

${ }^{327}$ Heurgon, 1959, 41.

${ }^{328}$ De Grummond, 2006a, 41. Arruns also appears in Virgil's Aeneid XI: 759-866 where he is the cowardly slayer of the Amazonian Camilla. Arruns Veltymnus' name is also very similar to the name Veltune (Tinia, Jupiter) on the mirror with Pava Tarchies, perhaps indicating that Arruns was a priest of Veltune.
} 
civilisation. ${ }^{329}$ Vecuvia's prophecies were held in the Libri Fulgurales and are also contained in the Libri Rituales.

There are a few visual representations of Lasa Vecuvia in Etruscan art. ${ }^{330}$ In Plate 13, c.300-275 BCE, a winged Lasa Vecuvia accompanies Menrva (Minerva, Athena) in an outdoor setting. Both have been labelled with their names and this pairing indicates that Etruscan Menrva had prophetic powers. From the same period as Lasa Vecuvia's mirror representation, is a bezel ring with Lasa Vecuvia's name again inscribed next to the female figure on the left [Plate 14]. This figure labelled, Lasa Vecuvia, stands with her back to the viewer in three-quarter pose and looks into a mirror, representing the mirror's role in prophecy. The figure on the left is a female attendant. Lasa figures were popular inclusions to female in toileting scenes, or attendants to Turin (Venus, Aphrodite).

The books attributed to Tarchies were called Libri Tagetici, and included the Libri Haruspicini primarily on the reading of the livers of sacrificed animals, and the Libri Acherontici - 'on life beyond the grave and the rituals of salvation. ${ }^{, 331}$ The Libri Fulgurales detailed divination from lightning and the Libri Rituales dealt with the formalities of rituals, building towns and making boundaries. ${ }^{332}$ The Etruscans used writing to canonise their religion, and once written down in a religious, sacred context, the canon remained unchanged and served as a reference point for the

\footnotetext{
${ }^{329}$ De Grummond, 2006b, 31.

${ }^{330}$ De Grummond, 2006b, 31, the female figure holding a lightning bolt on a mirror from Vetulonia, c.300-275 BCE seems likely to be the same Lasa nymph.

${ }^{331}$ Pallottino, 1975, 154.

332 Pallottino, 1975, 154.
} 
future. $^{333}$ The fact that we know of the legends of Tarchies and Lasa Vecuvia and the books of the Disciplina Etrusca today is due to their importance in Etruscan times which was upheld in both Roman and modern literature. ${ }^{334}$

Romans especially respected the religious training available from Etruscan haruspices and augurs, and Livy writes that notable patricians sent their sons to Etruria to learn 'letters' and the arts of divination. ${ }^{335}$ Suetonius, in Life of Claudius 42.2, notes that the Emperor Claudius was an avid historian and authored two great works, twenty volumes of Etruscan history and eight volumes of Carthaginian. Both appear to have been respected in antiquity, the entire works being recited orally for the public at the Museum of Alexandria each year by a team of orators. ${ }^{336}$ The preservation of Etruscan history, and not just elements of Etruscan religion, was clearly important to the Romans. Claudius was not the only Etruscan historian, but he was influenced by Livy in this respect, and had the advantage of Etruscan literature at his disposal. $^{337}$

\section{Prophecy and ritual texts on Etruscan mirrors}

The mirror featuring Tarchon and Pava Tarchies from Tuscania, is an example of the use of prophecy and ritual texts on Etruscan mirrors. During the Middle Etruscan period (400-300 BCE) artists were competent at inscribing the names of the figures depicted on a large number of Etruscan bronze mirrors. A later example is another mirror from Tuscania dated to the third century BCE, showing a haruspication scene

\footnotetext{
333 See Goody, 2000, 119-131, for a discussion on the nature of canonisation in oral and literate cultures.

${ }_{334}^{34}$ Pallottino, 1975, 153.

335 Bonfante, 2006, 21; Atkin and Rykwert, 2005, 159. Livy 9:36.3.

${ }^{336}$ Suetonius, Life of Claudius, 42.2.

${ }^{337}$ Hall, 1996, 4, 244, indicates that Claudius apparently claimed Etruscan descent and this detail may have been a motive for his love of Etruscan history and language.
} 
with the name Chalchas, a native Etruscan haruspex, clearly inscribed in the Etruscan alphabet but in dextrograde letters [Plate 15]. ${ }^{338}$ The name suggests a parallel to the Greek Kalchas. ${ }^{339}$

On a selection of mirrors, ritual scenes depict what must have been a feature of Etruscan religion - writing - on plaques, tablet books and scrolls. The mirror showing the adoption of Hercle by Uni shows a plaque, describing the scene, attached to the temple in the background [Plate 8]. ${ }^{340}$ A figure points to the plaque that could be either Tinia (Jupiter) or Nethuns (Neptune), the Etruscan water god, holding a trident. $^{341}$ The plaque is comparable with the gold sheets, c.500 BCE, from Pyrgi. ${ }^{342}$ Other examples include a mirror with Cacu, another indigenous Etruscan prophet, and his companion Artile holding a wax tablet/book and about to be ambushed; and a funerary scene with a Lasa holding a scroll with her name, and the names of two dead heroes, Aivas (Ajax) and Hamphiar (Amphiaraos) [Plates 16, 17]. ${ }^{343}$ Each of the above examples is an archaeological artefact that reflects the religious context in which Etruscans employed writing, and show two varieties of media used - the public dedication plaque and the private wax tablet/book.

From the Etruscan bronze mirrors, one can also see the connection between oral prophecy and the importance of the written word for rituals, especially those pertaining to death and marriage. Ornate writing implements found in seventh century BCE tombs demonstrate the elitism of early writing in Etruria. But by the

\footnotetext{
${ }^{338}$ Brendel, 1978, 417.

${ }^{339}$ Brendel, 1978, 360.

${ }^{340}$ Bonfante, 2006, 23. See Fig. 11.8, 15.

${ }^{341}$ Bonfante, 2006, 14-15.

${ }^{342}$ Bonfante, 2006, 13-14. See Fig. 11.6, 14.

${ }^{343}$ Bonfante, 2006, 21.
} 
fifth and fourth centuries, mirrors with named figures, scrolls and plaques represented on them seem to take over this function. ${ }^{344}$ Writing was the human result of understanding divine signs from the gods, of communicating that understanding publicly by nailing plaques to buildings and temples, and making lists of the dead or of ones achievements to carry with one to the afterlife, as on the sarcophagus of Laris Pulenas [Plate 18]. The fame of the books of Tarchies and Lasa Vecuvia and their importance for the art of divination is attested to by our knowledge of them without our having any surviving Etruscan copies. When the Roman Republic integrated Etruscan divination priesthoods into their state religion, they continued the tradition of following written canons, probably similar to prophetic books and guides like the Libri Haruspicini and Libri Rituales. ${ }^{345}$

Despite reverence for Etruscan traditions, Roman assimilation would be the first event to contribute to the demise of native Etruscan texts. John Coldstream argues that the religious or pagan texts which survived assimilation were probably eradicated by the early Christian church. ${ }^{346}$ But just as Etruria was influenced by Greek and Phoenician alphabets, other peoples were influenced by the Etruscan alphabet [Plate 19]. According to Goody, 'the Runic writing of northern Europe and the Oghamic characters used by some of the Celts were possibly descendants of Etruscan or Venetic writing. ${ }^{347}$ However, the most important culture influenced by Etruscan culture and language was that of the Latins. ${ }^{348}$

\footnotetext{
${ }^{344}$ Bonfante, 2006, 23.

${ }^{345}$ North, 1990, 66.

${ }^{346}$ Ridgway, 2002, 35.

${ }^{347}$ Goody, 1987, 52.

${ }^{348}$ Bonfante and Bonfante, 2002, p28.
} 


\section{Influences on Latin}

Just as the Cretan Hieroglyphic Script and Linear A influenced Cypro-Minoan Script, Etruscan influenced Latin. A review of Latin vocabulary reveals Etruscan roots for many words, often associated with 'luxurious living and higher culture, including writing. 349 Etruscan roots can be found in other Italic languages, notably OscoUmbrian. ${ }^{350}$ For example, note the borrowing path of Etruscan itus - 'full moon' into Latin via Osco-Umbrian:

i) Etruscan itus

ii) Osco-Umbrian eidus

iii) Latin $i d u s^{351}$

Etruscan and Latin are two different languages. Latin may have Etruscan loan-words but the direction Latins write their language, for example, dextrograde or sinistrograde, particular formulae for religious dedications, or the word order within sentences, will ultimately depend on the language in its oral form. Since oral communication is a social phenomenon, social habits and cultural beliefs will affect the transition from oral to written literature, for instance whether writing is done dextrograde or sinistrograde.

\section{Dextrograde or sinistrograde?}

The direction in which a script is written can stem back to fundamental conventions. If a culture created a pictographic script as did the Minoans, Phoenicians and Egyptians then the right side of their brains would be used principally to read and understand the signs. ${ }^{352}$ As a result, reading sinistrograde ensured that the left side of the eye ball was the last side to receive information and thus the last to send

\footnotetext{
${ }^{349}$ Robinson, 1995, 152.

${ }^{350}$ Palmer, 1961, 5.

${ }^{351}$ Whatmough, 1931, 168-169.

${ }^{352}$ Goody, 1987, 248.
} 
information to the right hemisphere of the brain for contextualising. ${ }^{353}$ If one is reading pictures sinistrograde, it is common that when a culture develops a symbolic script into a linear one that the reading direction remains the same for ease of teaching and learning. Conversely, cultures, such as Greek and Roman, which encountered Eastern alphabets when they had become standardised from pictographs to linear letters, do not already have the evolutionary tendency to send literary information to the right hemisphere of the brain.

The phonetic system requires the processing of sequencing and contiguity to recognise groups of letters as specific words with specific meanings. Writing in the phonetic system is best processed in the left hemisphere of the brain; thus reading in a dextrograde direction is more beneficial because literary information is last read by the right side of the eye ball and sent straight to the left hemisphere of the brain. ${ }^{354}$ Although, ancient peoples did not have specific neurological knowledge, their brains were evolving this way. One may suggest that echoes of these physical changes can be found in social conventions. For example, on Attic vases, if there are two duelling warriors, the odds are highly in favour of the one on the viewer's left moving in a dextrograde direction against his foe. Likewise, the word 'sinister' in Latin is with the left hand or moving in a leftwards direction. In summary, going rightwards is good or lucky, and going leftwards is bad or unlucky.

A visual analysis of Phoenician, Euboean Greek and Etruscan scripts will reveal that the directions in which they are written are not all the same. Why? Historically, Semitic scripts, such as Phoenician, have been uniformly inscribed and

\footnotetext{
${ }^{353}$ Wolf, 2008, 36.

${ }^{354}$ Kerckhove, 1986, 288-89.
} 
written in sinistrograde - from right to left. ${ }^{355}$ When the Greeks adopted the Phoenician script and added vowels there was a transitional period when the Greeks wrote in sinistrograde, dextrograde, boustrophedon and stoichedon. The appearance of boustrophedon writing in the sixth century BCE, where even the letters were facing the direction in which the line was read, gave rise to the stoichedon style. ${ }^{356}$ Like boustrophedon writing, stoichedon does not differentiate words from each other or contain punctuation, but is uniformly spaced lettering (sometimes achieved with a grid outline) in continuous run-on sentences. ${ }^{357}$ Since the main purpose for this style was geometric equidistance between each letter, boustrophedon's custom of flipping the letters on each alternative line created shapes that were not vertically all lined up. Hence, this aspect of reversed writing of letters was abolished and the Greeks decided just to write and read in dextrograde, for the aesthetics. ${ }^{358}$ Eventually the Greeks settled on dextrograde writing and this was made law for bureaucratic documents in Athens in 403/2 BCE by Archinos (Theopompos: Philipii: Frag.115. 155).

When the Etruscans began learning the Euboean Greek alphabet from the settlers of Cumae c.700 BCE however, they were learning a Greek alphabet heavily influenced by the consonantal Phoenician alphabet in a transitional phase of Greek adaptation. As mentioned previously, the alphabet was introduced to Greece through Euboea by their close Phoenician trading connections and through Ionian colonies. ${ }^{359}$ The same people that introduced the alphabet to Greece introduced it to Etruria. When the Euboean Greeks in Cumae were influencing Etruscan cities with their phonetic form of the alphabet in dextrograde, Phoenician-Punic communications with

\footnotetext{
${ }^{355}$ Kerckhove, 1986, 280.

${ }^{356}$ Kerckhove, 1986, 277.

${ }^{357}$ Kerckhove, 1986, 278-9.

${ }^{358}$ Kerckhove, 1986, 279.

${ }^{359}$ Powell, 1991, 14-15. The earliest Greek inscriptions at Lefkandi are dated c.775-750 BCE.
} 
the same Etruscan cities, e.g. Populonia, Spina, Caere, Orvieto, Vulci and Tarquinia, were being simultaneously influenced by the Semitic consonantal alphabet written in sinistrograde. $^{360}$ One may propose that if the Greeks had not settled at Cumae and Pithekoussai, the Etruscans would still have created a similar alphabet of their own through Punic influences.

An overview of Mediterranean scripts in the seventh century BCE shows that Greek and Latin were written dextrograde and Phoenician, Cypriot and Etruscan were written sinistrograde. The scripts are separated geographically, those written and read in dextrograde are from the western Mediterranean and those written and read in sinistrograde are eastern Mediterranean. Etruscan is the anomaly because it may be derived from a syllabic rather than a strictly alphabetical language. But then the Etruscan language has puzzled linguists since Etruscan inscriptions were first found. Minoan Linear A and the Mycenaean Linear B were both dextrograde. It is possible that when the Greeks re-created their own writing after the Dark Ages, with the sinistrograde Phoenician system, they eventually found their way back to dextrograde writing because of a genetic predisposition for reading Linear B, which favoured the left hemisphere of the brain for sequencing and contiguous reading. ${ }^{361}$

Therefore, the Etruscans being subjected to both Phoenician and Greek influences, may have chosen to write and read in sinistrograde due to a genetic predisposition similar to Near Eastern cognition systems which favoured reading from right to left, focusing on the right hemisphere of the brain which specialised in supplying vowel sounds and contextualising symbols - an evolutionary result of some

360 Turfa, 1977, 373.

${ }^{361}$ Kerckhove, 1986, 285-87. 
early pictorial scripts in the eastern Mediterranean cultures. ${ }^{362}$ The implications for the indigenous Etruscan argument could be detrimental here, or it may suggest that the Etruscans once used a pictographic script in the Bronze Age, however further study is required to determine archaeological evidence for this.

\section{Conclusions}

The Etruscan culture and language appears to have embraced the introduction of written script in a context of Archaic Greek colonisation. Surviving Etruscan literature has a religious flavour. Dedications, sacred calendars and divination canons suggest that writing was an important aspect of Etruscan religion. This is interesting because one would presume that the introduction to the Greek alphabet in the eighth century BCE was through trade relations and colonisation efforts on behalf of Euboean Greeks at Cumae and Pithekoussai. Etruscans may have used perishable materials for trade and administrative writing, which is why no archives of clay tablets, have been discovered as in the Minoan situation. Despite this allowance for un-recovered archaeological evidence, the surviving documents we do have are impressive. Three gold sheets from Pyrgi with a dedication to Uni-Astarte, found ritually buried on sacred ground; a liturgical calendar saved by its use in the Egyptian mummification process, rediscovered in Zagreb; the orders of Etruscan prophets incorporated into the Disciplina Etrusca; and the allocation of elite grave goods, from writing implements to Etruscan mirrors, all demonstrate the significance of literature in Etruscan culture.

\footnotetext{
${ }^{362}$ Kerckhove, 1986, 285-87
} 


\section{Etruscan Plate sources}

1. Location of Cumae, Italy.

Borrelli and Targia. (2003). 57.

2. Etruscan alphabets.

Pallottino. (1975). Fig. 6. 211.

3. a. Nestor's cup.

Bonfante and Bonfante. (2002). Fig. 1. 6.

b. Reconstruction of inscription on Nestor's cup.

http://www1.union.edu/wareht/greek3/writing nestor.jpg

Last accessed $26^{\text {th }}$ July 2009.

4. Impasto pot.

Hencken. (1968). Fig. 445.

5. Ivory Tablet from Marsiliana d'Albegna with model alphabet.

Bonfante and Bonfante. (2002). Fig. 11a. 132.

6. Bucchero rooster with abecadarium.

Bonfante and Bonfante. (2002). Fig. 14. 135.

7. The Capua tile.

Borrelli and Targia. (2003). 81.

8. Pyrgi sheets.

Borrelli and Targia. (2003). 82-3.

9. Dedication plaque on mirror.

Bonfante. (2006). Fig. 11.8. 15.

10. Zagreb Mummy wrappings.

Borrelli and Targia. (2003). 119.

11. a. Pava Tarchies and Tarchon.

De Grummond. (2006b). Fig. 111.4. 30.

b. Pava Tarchies and Tarchon

Christofani. (1979). 93.

12. Carnelian Scarab.

Borrelli and Targia. (2003). 90.

13. Lasa Vecuvia and Menrva.

De Grummond. (2006b). Fig. 111.5. 32.

14. Lasa Vecuvia on bezel ring from Todi.

De Grummond. (2006b). Fig. 111.6. 33.

15. Chalcas reading internal organs.

De Grummond. (1982). Fig. 89.

16. Tablet book (diptych) on mirror.

Line drawing made for the next volume of: Etruscan Mirrors. Corpus

Speculorum Etruscorum, Great Britain 1, The British Museum I, The British

Museum Press, 2001, to be published by Judith Swaddling in 2008/9.

17. Lasa with scroll on mirror. Swaddling. (2001). Fig. 28b. 159.

18. Sarcophagus of Laris Pulenas with scroll listing life achievements.

Top plate: Borrelli and Targia. (2003). 83.

Bottom plate: Bonfante. (2006). Fig. 11.7. 14.

19. Spread of the Etruscan alphabet.

Bonfante and Bonfante. (2002). Map 3. 53. 


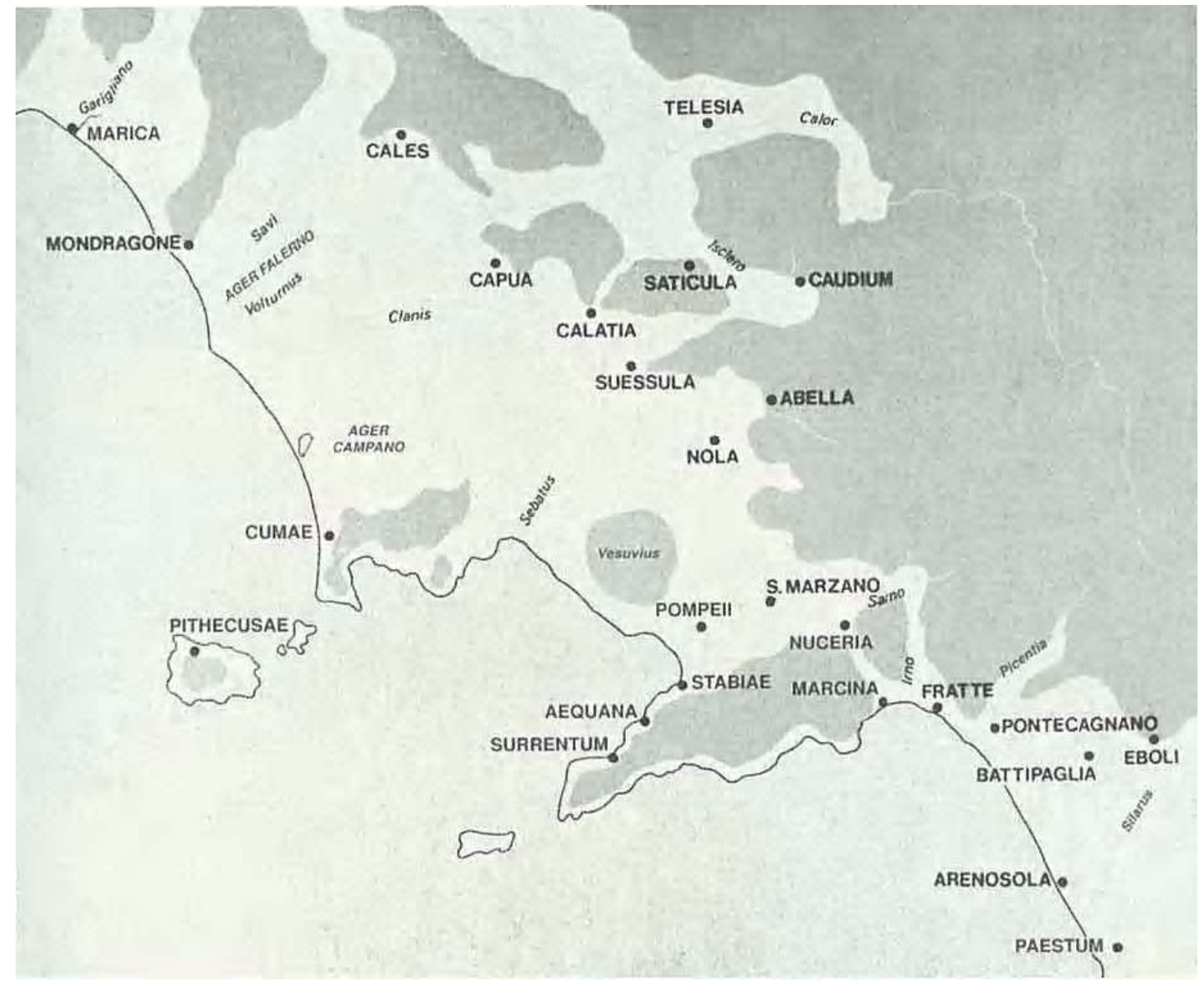

Plate 1: Location of Cumae, Italy. 


\begin{tabular}{|c|c|c|c|c|c|c|}
\hline \multicolumn{2}{|l|}{ Phoenician } & \multicolumn{4}{|c|}{ Archaic Greek } & \multirow[t]{2}{*}{ Latin } \\
\hline & : & 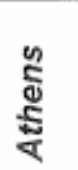 & פ & 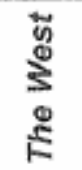 & & \\
\hline$\leftarrow^{3}$ Aleph & $A$ & $\Delta$ & $\Delta$ & $A$ & Alpha & A \\
\hline 9 Bet & $r$ & B & B & B & Beta & B \\
\hline TGirnel & $r$ & $\wedge$ & r & $<, c$ & Gamma & $\mathrm{C}, \mathrm{G}$ \\
\hline$\triangle$ Dalet & $\Delta$ & $\Delta$ & $\Delta$ & $\triangle, D$ & Delta & $\mathrm{D}$ \\
\hline$\approx \mathrm{He}$ & B & $E$ & $E$ & $E$ & Epsilon & $\mathrm{E}$ \\
\hline$Y$ Vav & $F$ & F & - & $\zeta, F$ & Digamma & $\mathrm{F}$ \\
\hline I Zayin & $\mathrm{I}$ & I & I & I & Zeta & $\mathrm{Z}$ \\
\hline 目 Het & $\begin{array}{l}\mathrm{B} \\
-\end{array}$ & $\begin{array}{l}\text { 日 } \\
-\end{array}$ & - & $\begin{array}{l}8-1 \\
-\end{array}$ & $\left.\begin{array}{c}-\mathrm{h} \\
\bar{e}\end{array}\right\}(\mathrm{H}) \mathrm{Eta}$ & $\mathrm{H}$ \\
\hline$\otimes$ Ṭet & $\theta$ & $\theta$ & $\otimes$ & $\otimes$ & Theta & \\
\hline$\approx$ Yod & $\xi$ & 1 & 1 & 1 & lota & I \\
\hline * Kaph & $k$ & k & k & k & Kappa & $\mathrm{K}$ \\
\hline L Lamed & $r$ & $\downarrow$ & $r$ & $r$ & Lambda & $\mathrm{L}$ \\
\hline M Mem & M & m & $H$ & M & Mu & $\mathrm{M}$ \\
\hline לNun & $N$ & $N$ & $\mathrm{~N}$ & $N$ & $\mathrm{Nu}$ & $\mathrm{N}$ \\
\hline 平 Samekh & $E$ & $x$ & \pm & 田 & $x_{i}$ & $X$ \\
\hline $0{ }^{\circ}$ Ayin & 0 & 0 & 0 & o & Omicron & $\mathrm{O}$ \\
\hline ר $\mathrm{Pe}$ & $r$ & $\Gamma$ & $\Gamma$ & $\Gamma$ & $\mathrm{Pi}$ & $\mathrm{P}$ \\
\hline r S Sade & M & - & - & M & San $(=5)$ & \\
\hline$\Phi$ Qoph & 9 & (9) & (9) & 9 & Koppa & Q \\
\hline A Resh & $p$ & $p$ & $p$ & $R$ & Rho & $\mathrm{R}$ \\
\hline W Shin & - & 5 & $s$ & $s$ & Sigma & $\mathrm{S}$ \\
\hline \multirow[t]{6}{*}{$\times$ Tav } & $T$ & $T$ & $T$ & $T$ & Tau & $T$ \\
\hline & $v$ & $Y$ & $v$ & $Y$ & Upsilon & $\mathrm{V}, \mathrm{Y}, \mathrm{U}$ \\
\hline & $\phi$ & $\phi$ & $\phi$ & $\phi$ & $\mathrm{Phi}$ & \\
\hline & $x$ & $x$ & $x$ & & Chi & \\
\hline & + & - & + & - & Psi & \\
\hline & - & - & $\Omega$ & - & Omega & \\
\hline
\end{tabular}

Plate 2: Etruscan alphabets 


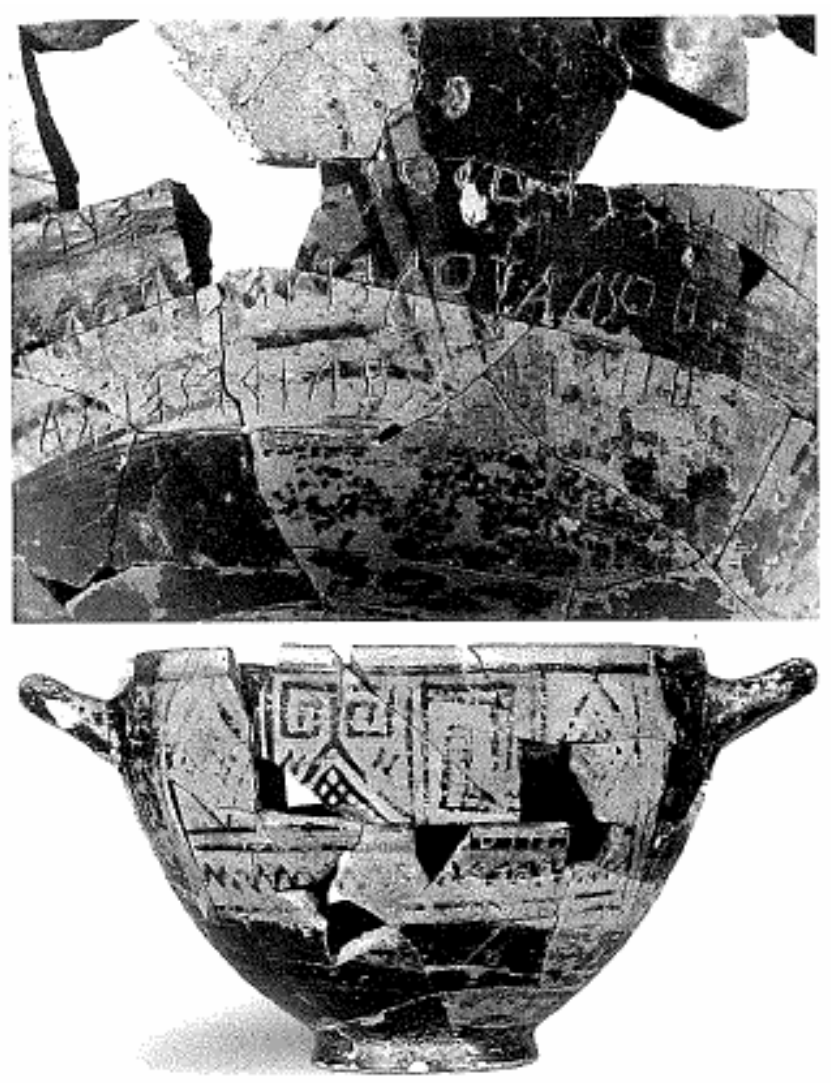

Plate 3a: Nestor's cup. c.730-720 BCE, from Pithekoussai. Naples, Archaeological Museum. 


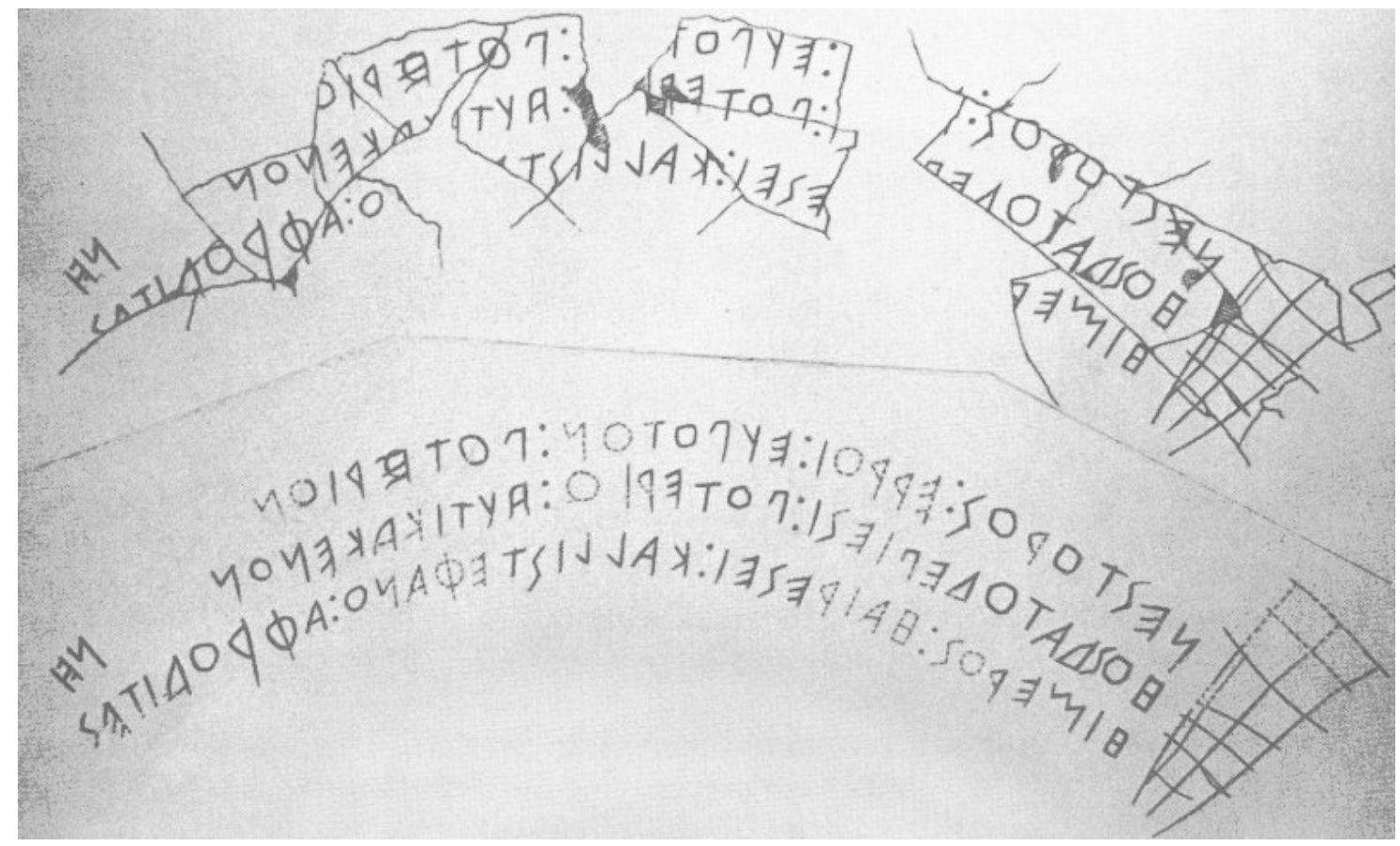

Plate 3b: Reconstruction of inscription by Raymond Schoder. 

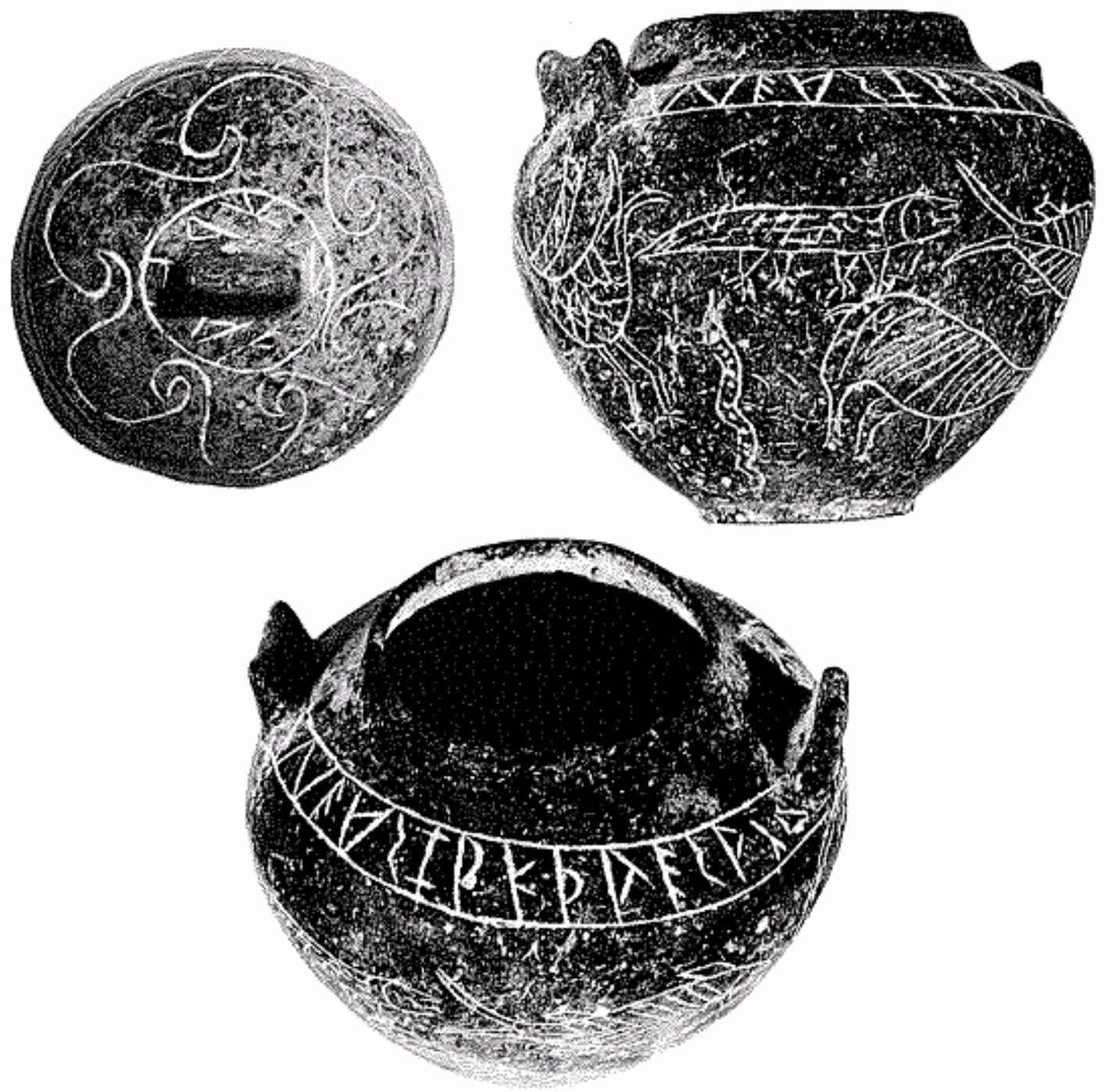

Plate 4: Handmade pot of polished brown impasto, $13 \mathrm{~cm}$ high, 700-650 BCE, National Museum, Tarquinia. 


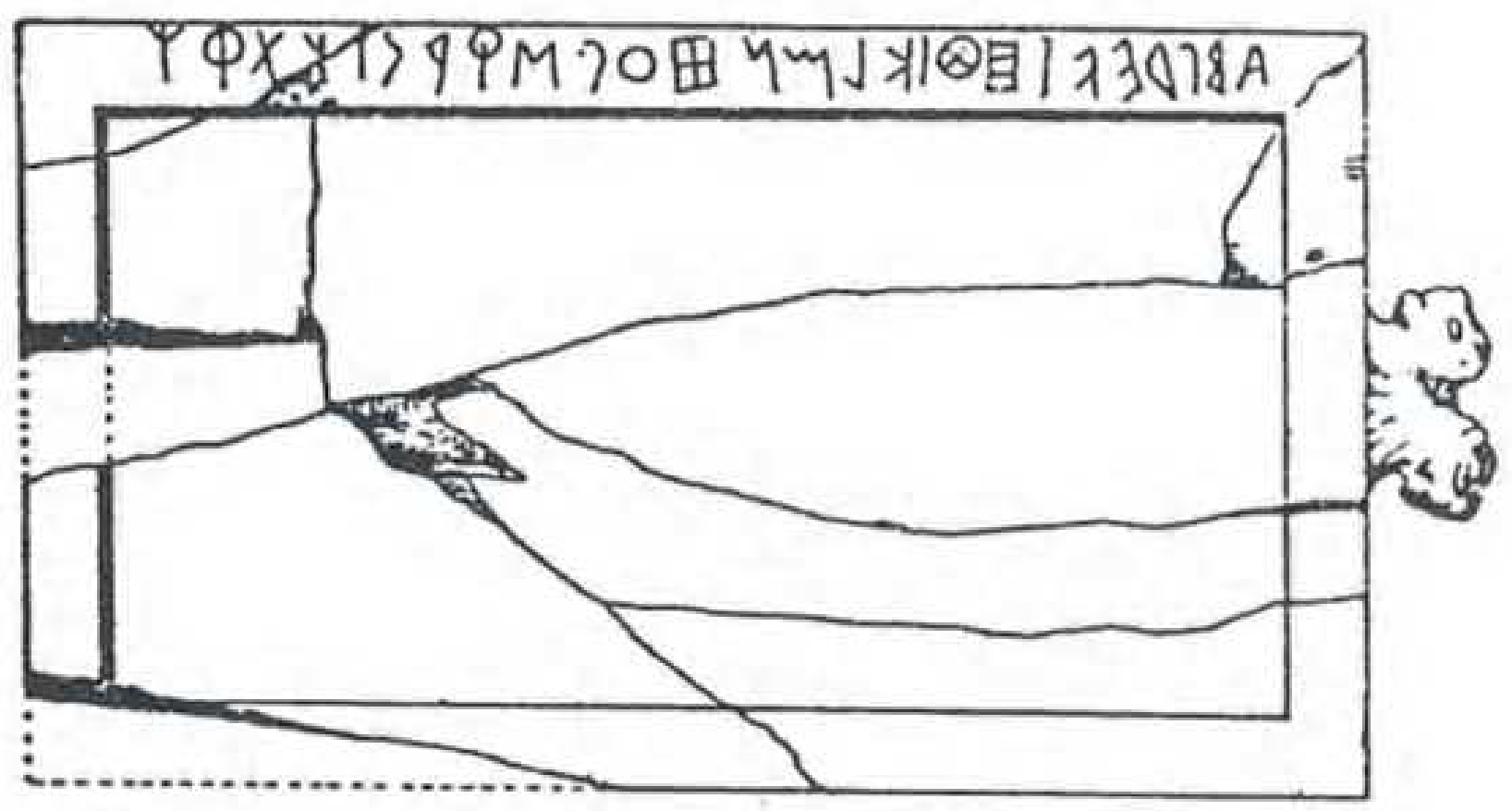

Plate 5: Ivory Tablet from Marsiliana d'Albegna with model alphabet. $8.8 \mathrm{~cm} \times 5 \mathrm{~cm}$, c.675-650 BCE. Florence, Archaeological Museum. 

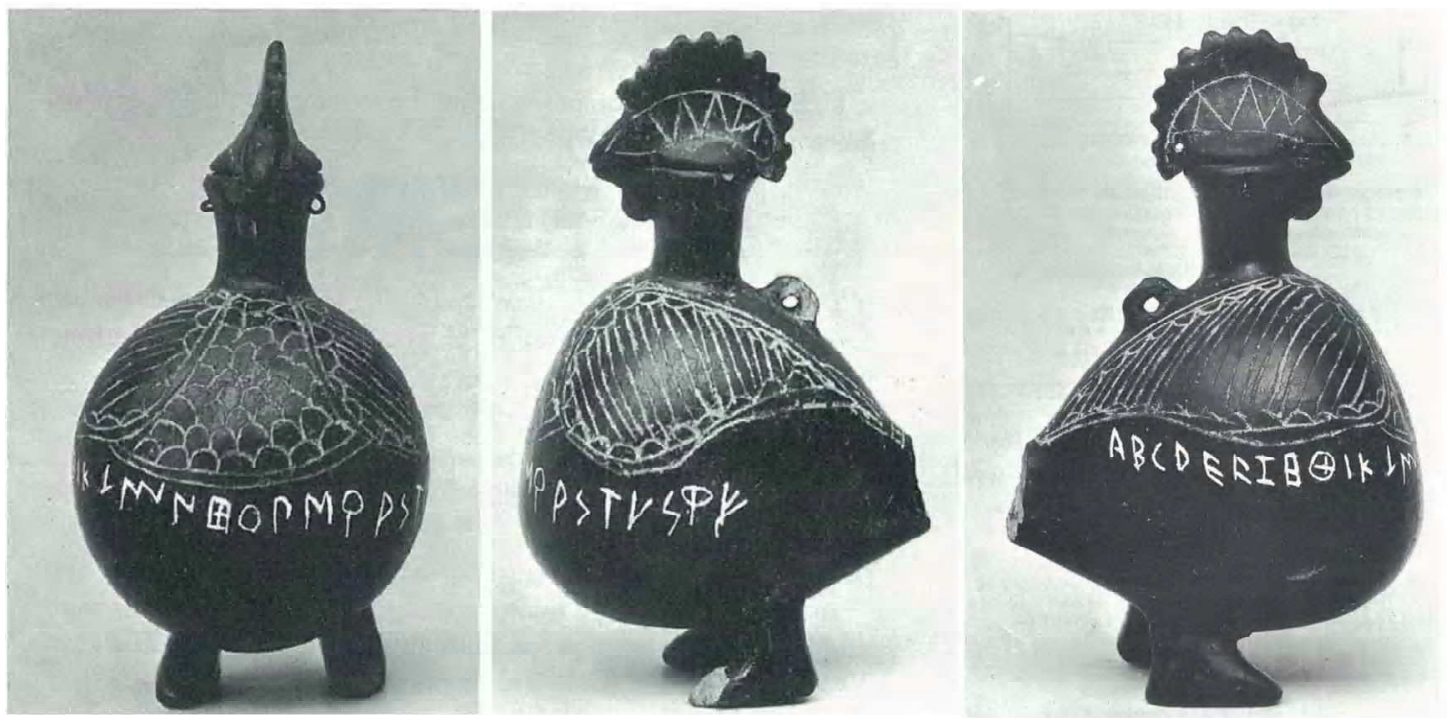

Plate 6: Bucchero rooster with abecadarium, from Viterbo, c.630-620 BCE. New York, Metropolitan Museum of Art. 


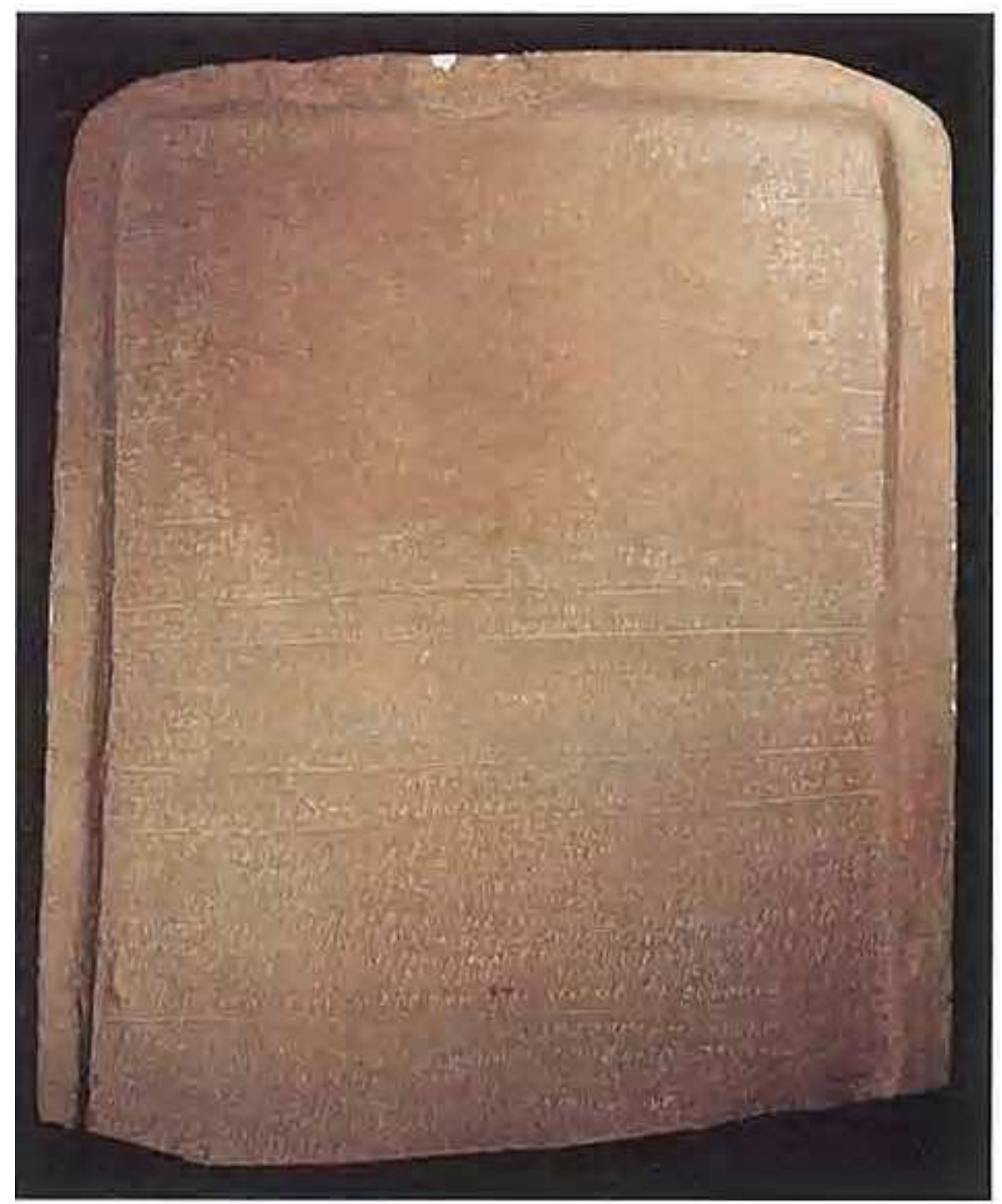

Plate 7: The Capua tile. Fifth or fourth century BCE. Berlin, Staatliche Museen. 

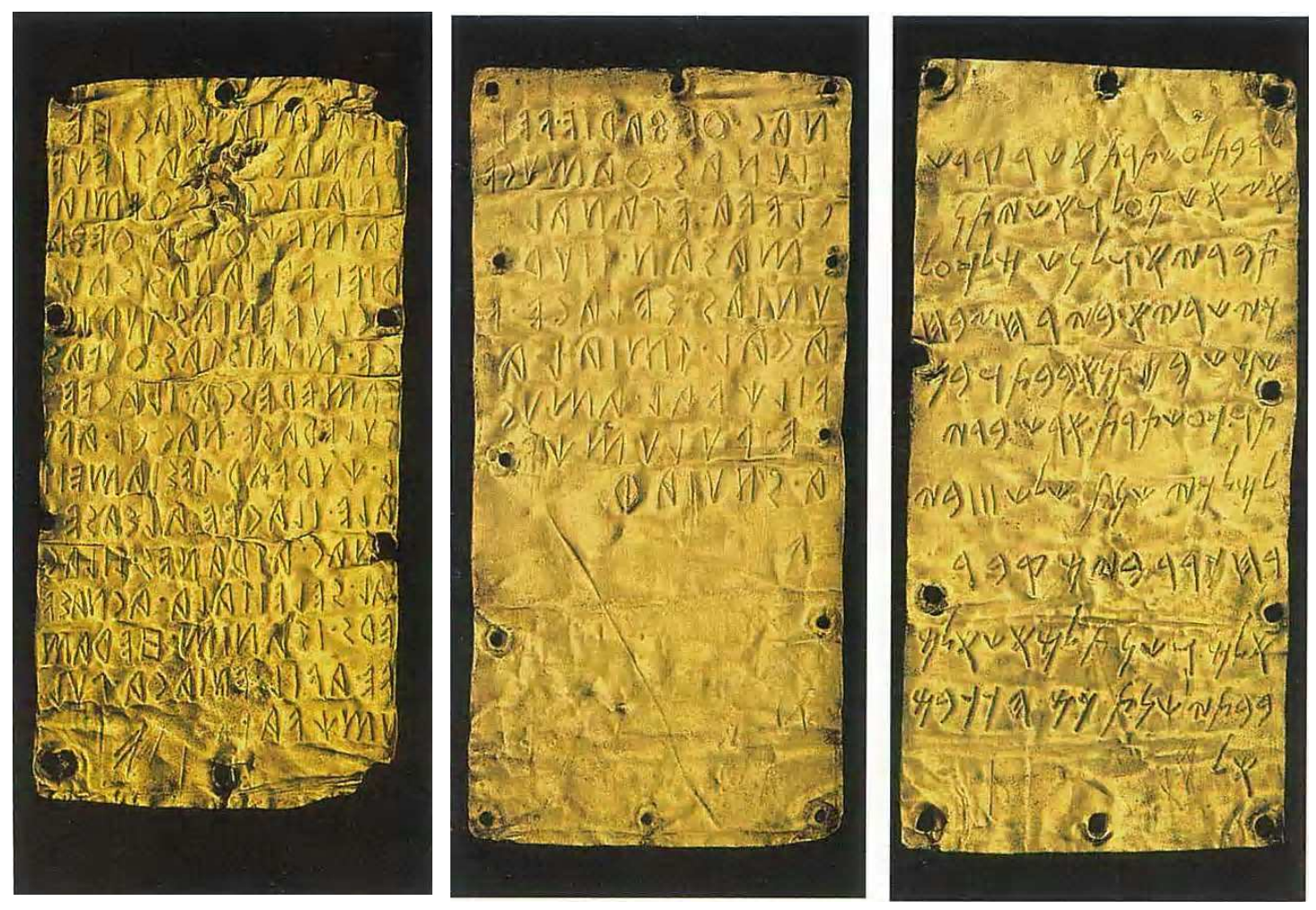

Plate 8: Pyrgi tablets. c.500 BCE. Rome, National Etruscan Museum. 


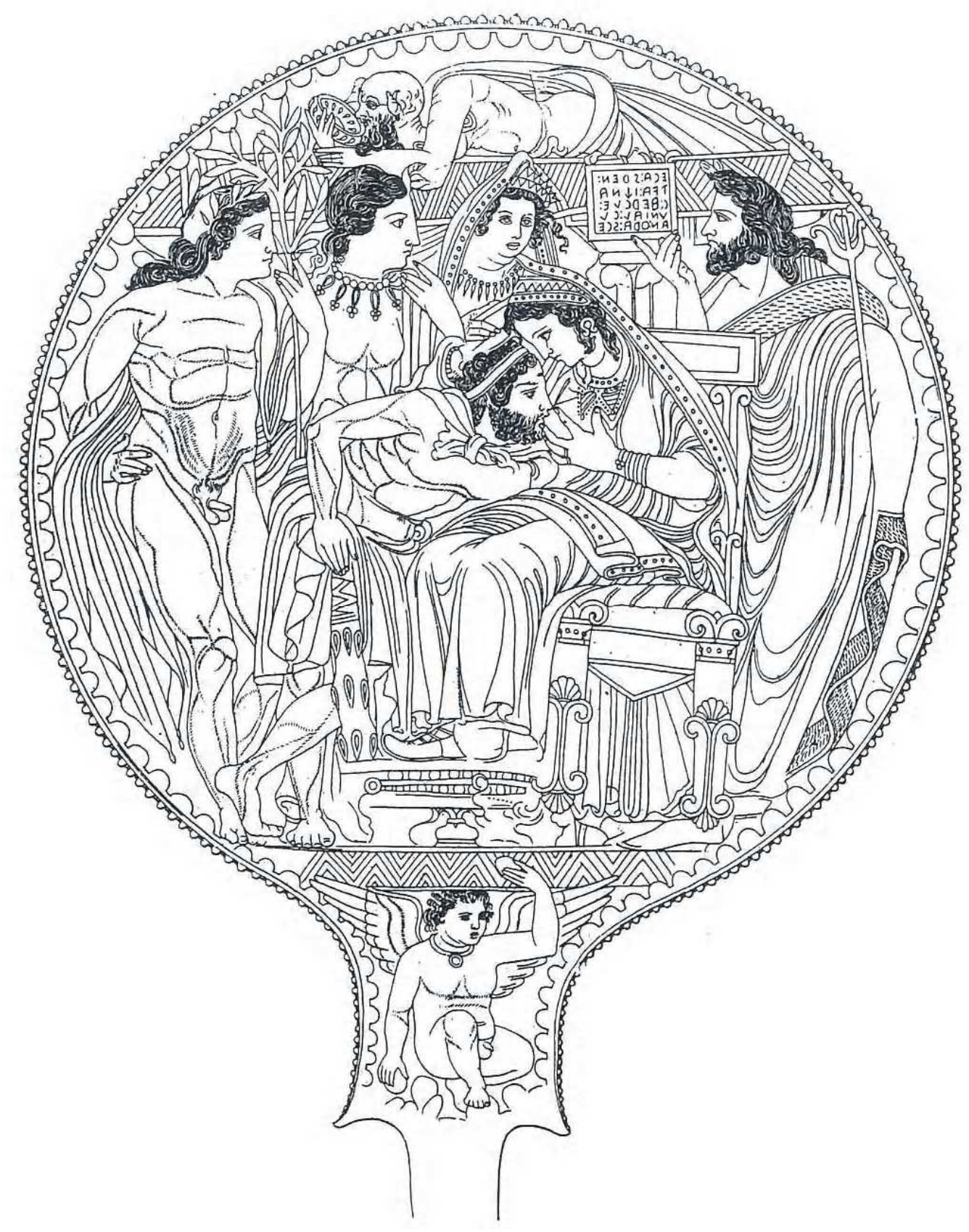

Plate 9: Dedication plaque on mirror featuring Uni nursing Hercle, from Volaterrae. 325-300 BCE. Florence, Archaeological Museum. 

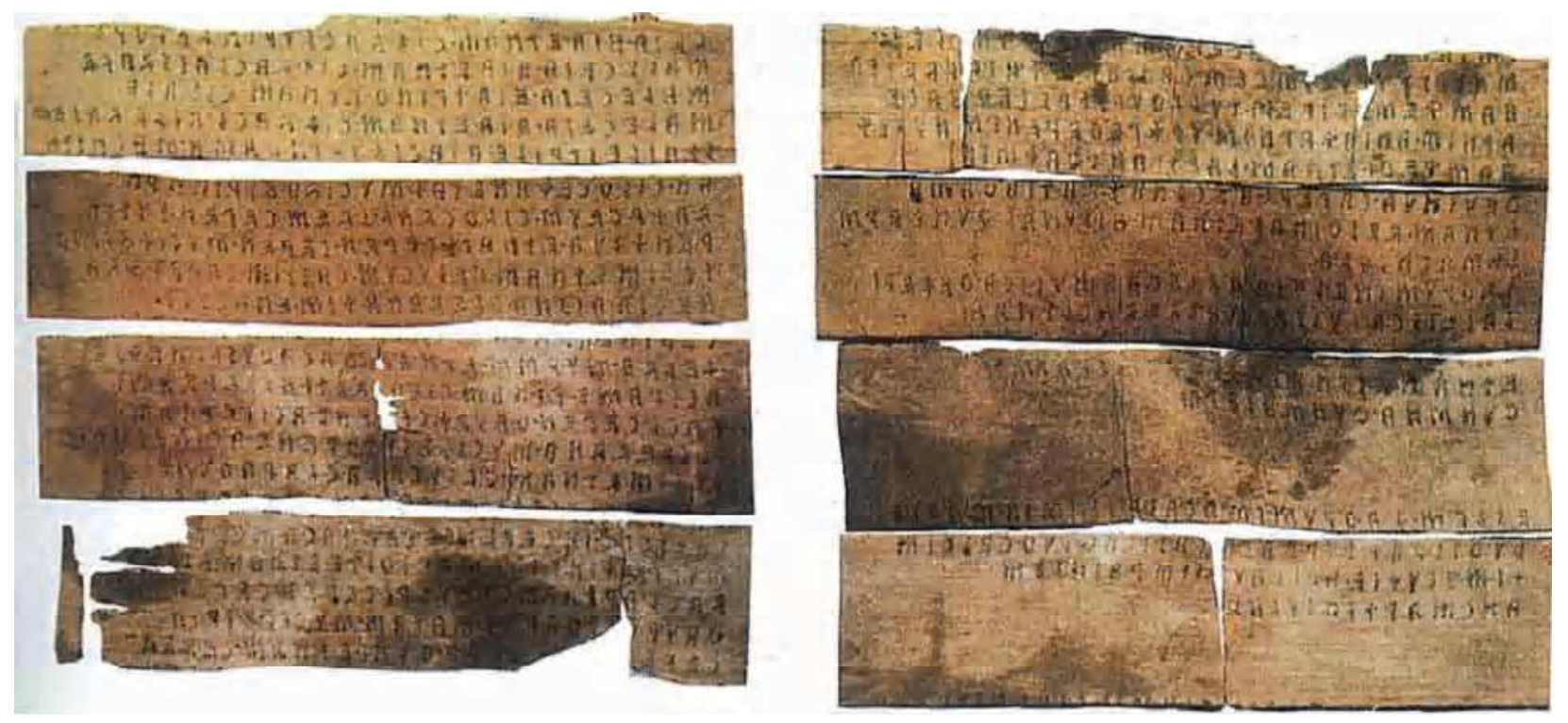

Plate 10: Zagreb mummy wrappings, sinistrograde. Second century BCE. Zagreb, National Museum. 


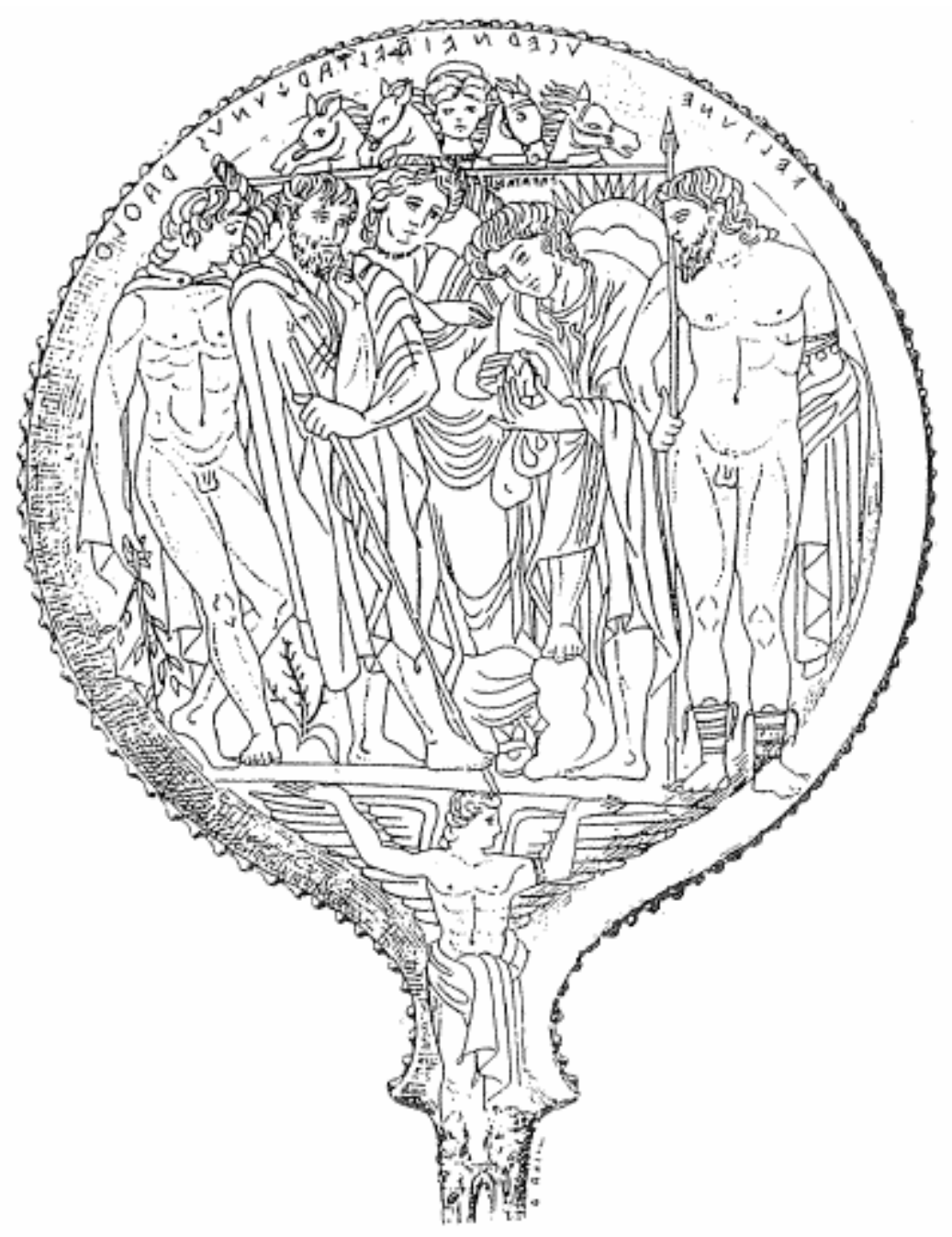

Plate 11a: Line drawing of mirror in 11b; Pava Tarchies and Tarchon from Tuscania. Early third century BCE, Florence, Archaeological Museum. 


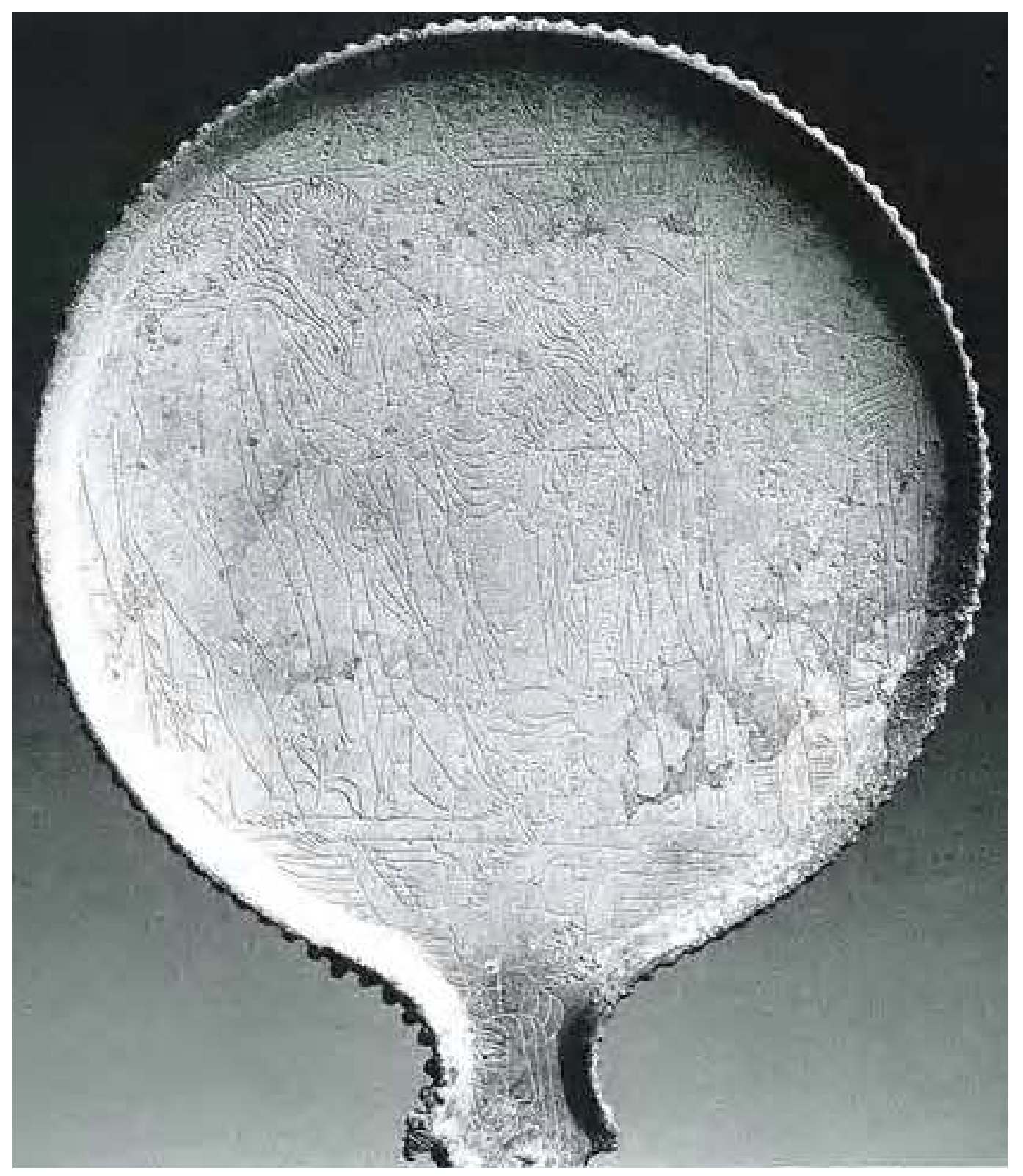

Plate 11b: Pava Tarchies and Tarchon from Tuscania. Early third century BCE, Florence, Archaeological Museum. 


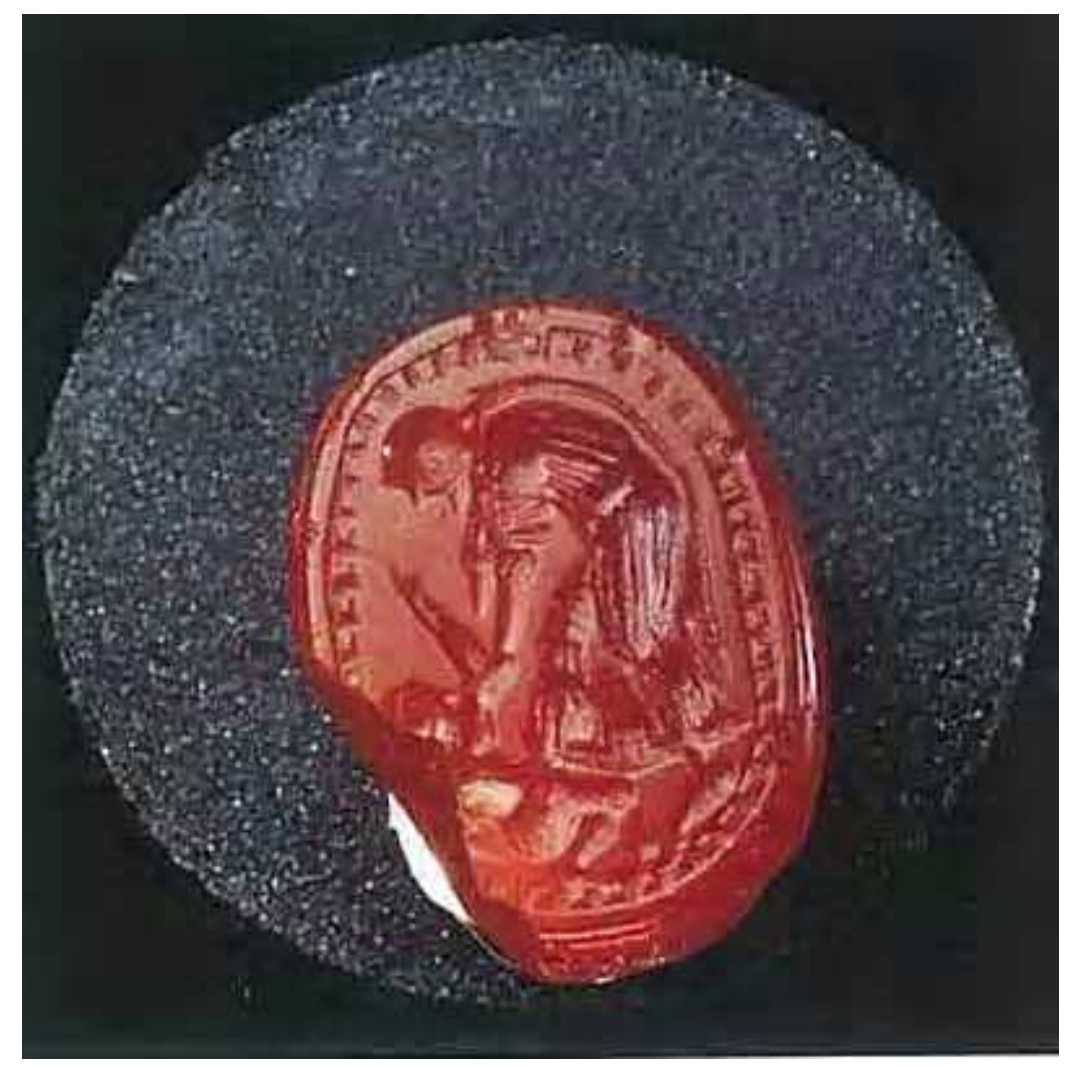

Plate 12: Scarab in carnelian. From the third or fourth centuries BCE. Rome Museo di Villa Giulia. On its base, within a frame fashioned like a thin cord, the farmer kneels over Tarchies, who is depicted as he emerges from the earth. 


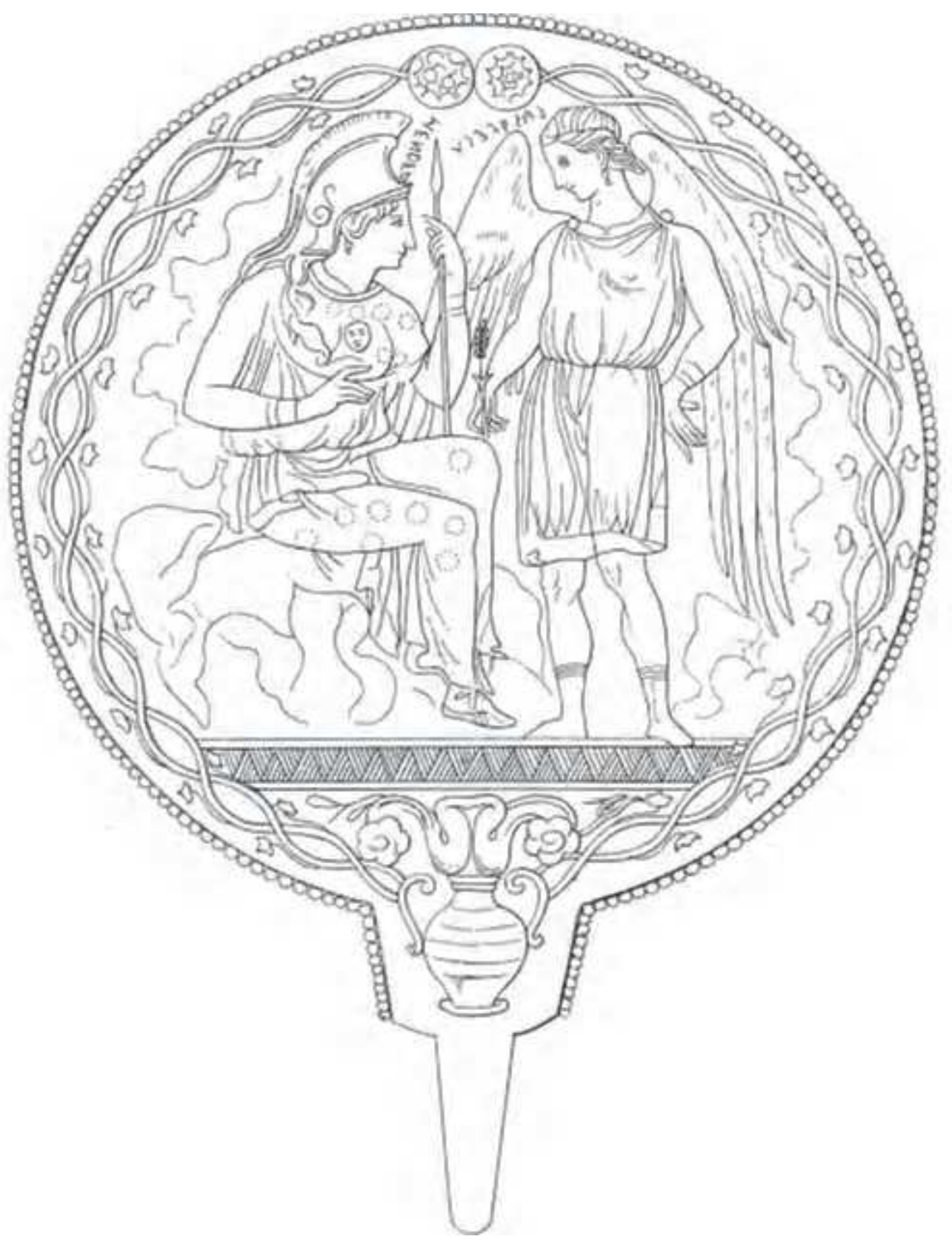

Plate 13: Lasa Vecuvia and Menrva. Early third century BCE. Rome, Museo Etrusco di Villa Giulia. 


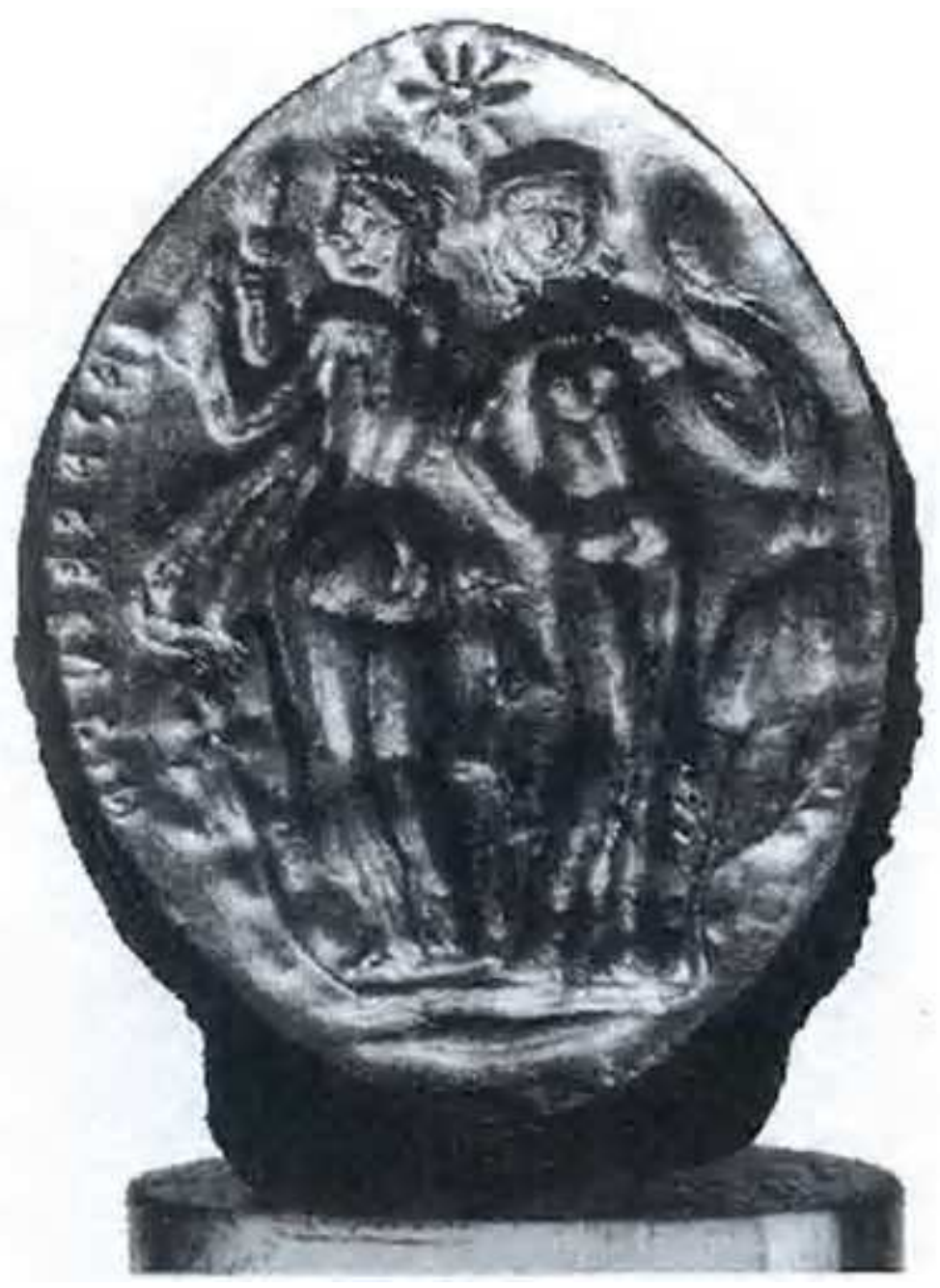

Plate 14: Lasa Vecuvia on bezel ring from Todi. Early third century BCE. Rome, Museo Etrusco di Villa Giulia. 


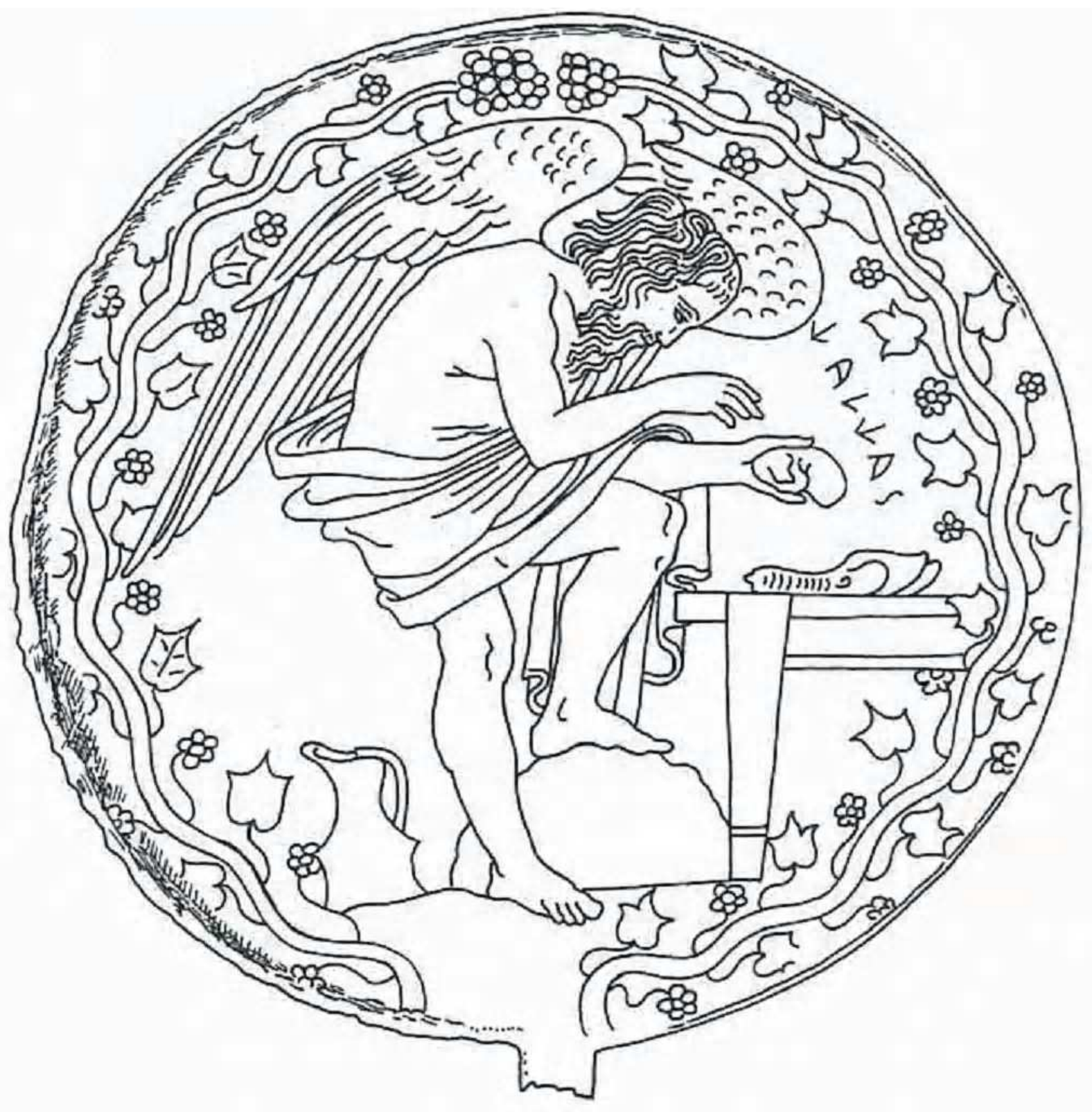

Plate 15: Chalcas inspecting organs. c.400 BCE. Vatican Museums. 


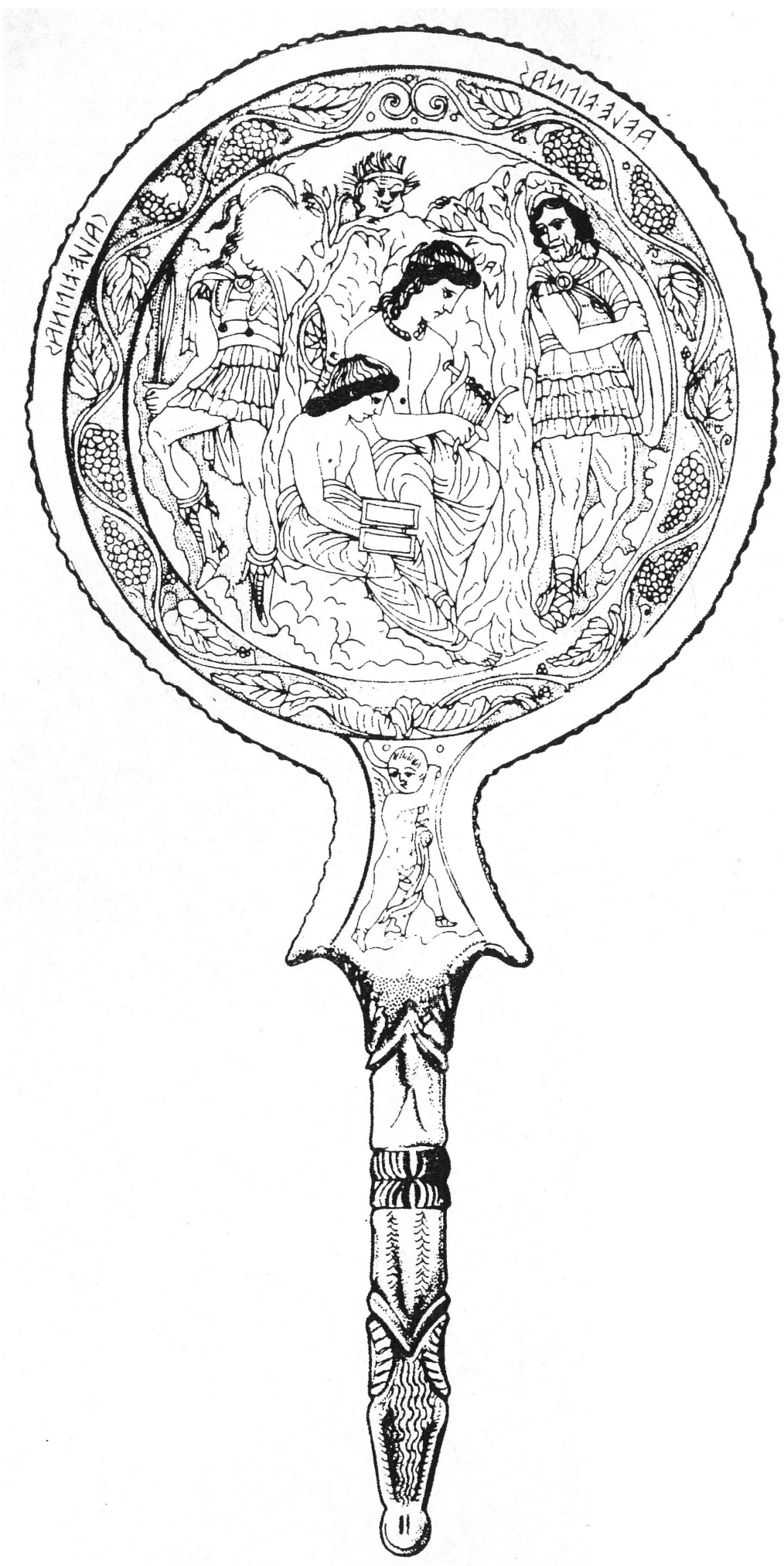

Plate 16: Tablet book (diptych) on mirror from Bolsena, featuring Cacu being seized by Avle Vipinas and Caile Vipinas. c.300 BCE. London, British Museum. 


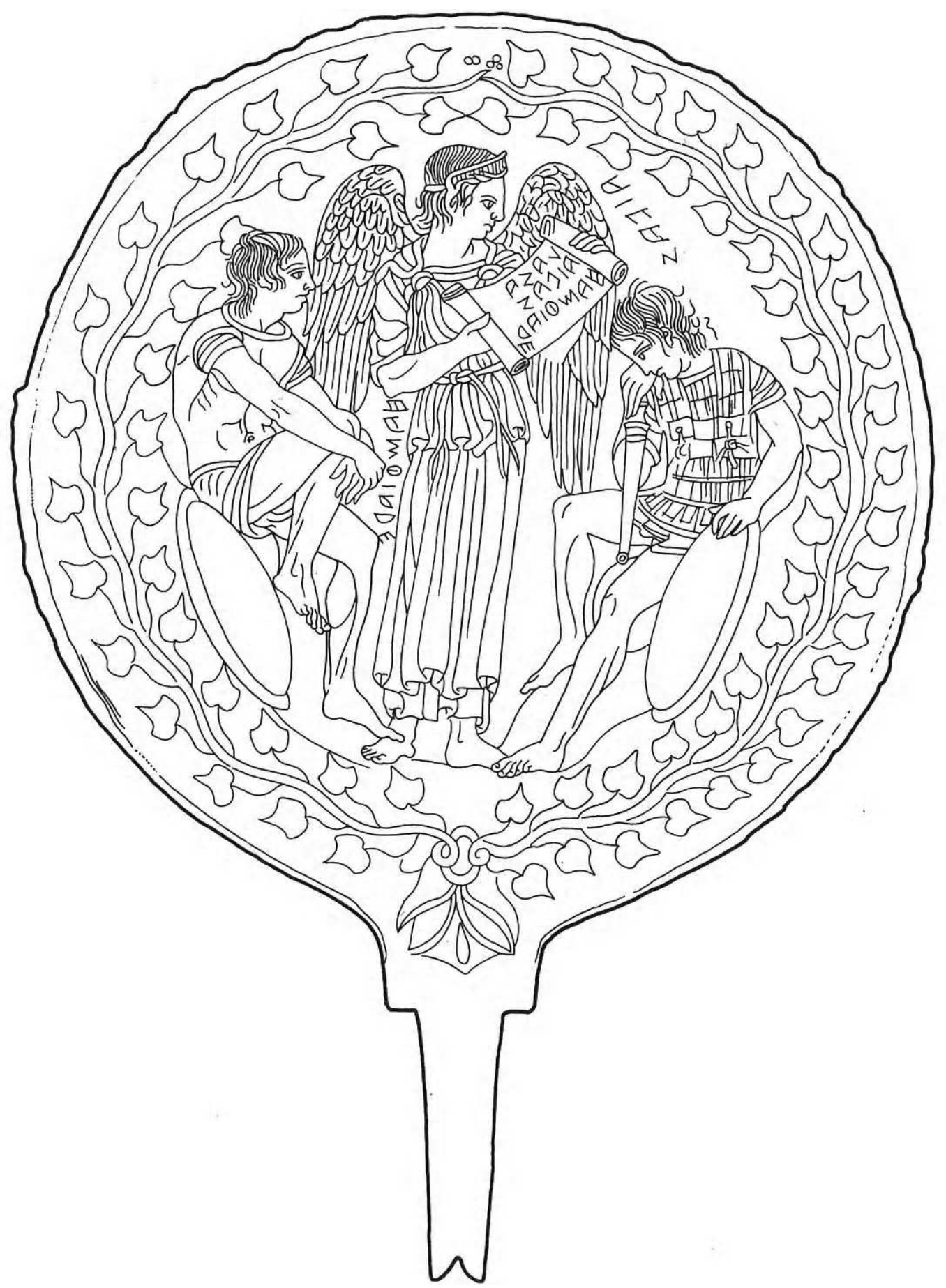

Plate 17: Lasa with scroll on mirror featuring Hamphiar and Aivas. 350-300 BCE. London, British Museum. 

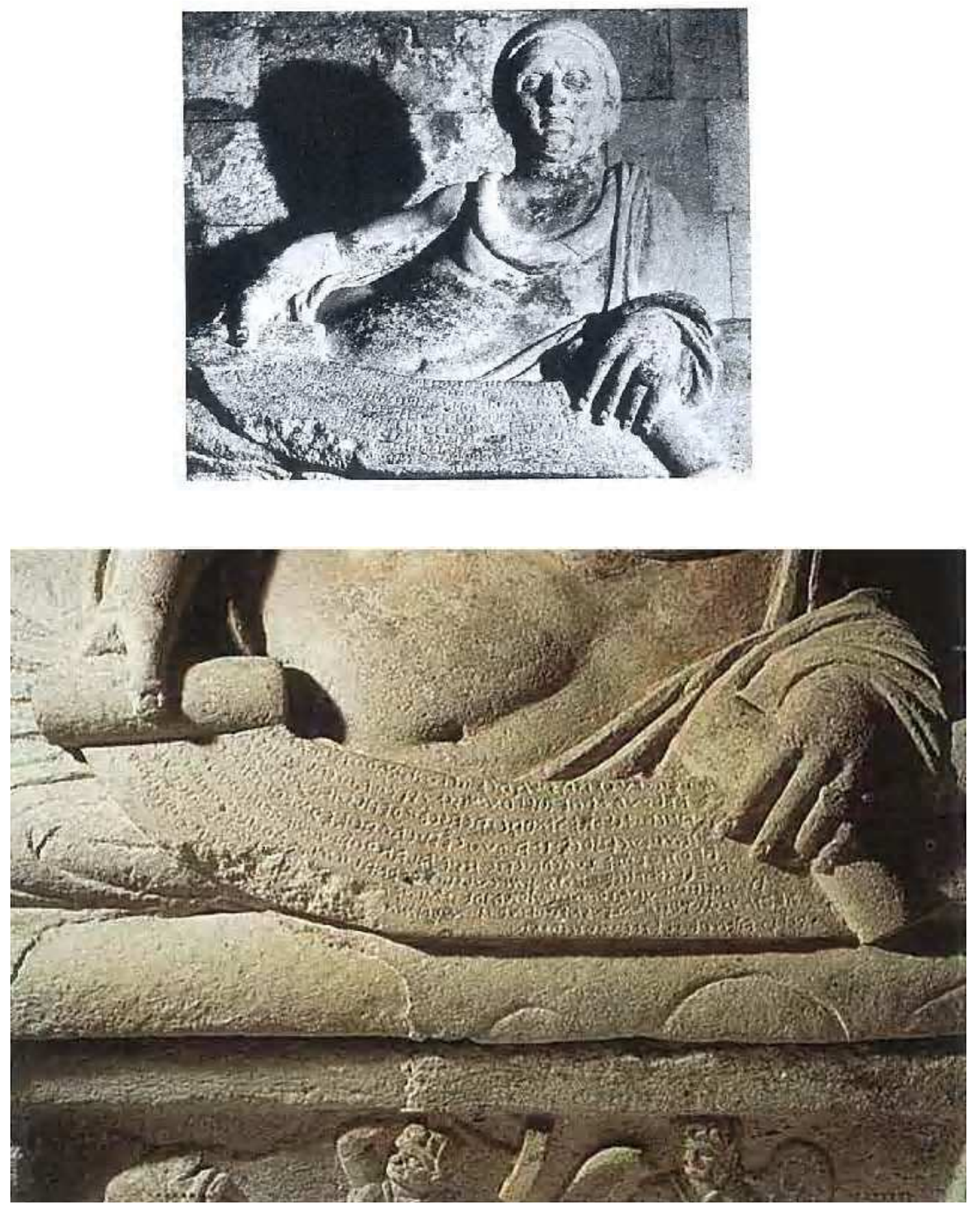

Plate 18: Sarcophagus of Laris Pulenas with scroll listing life achievements. 250-200 BCE. Tarquinia, Museo Nazionale. 


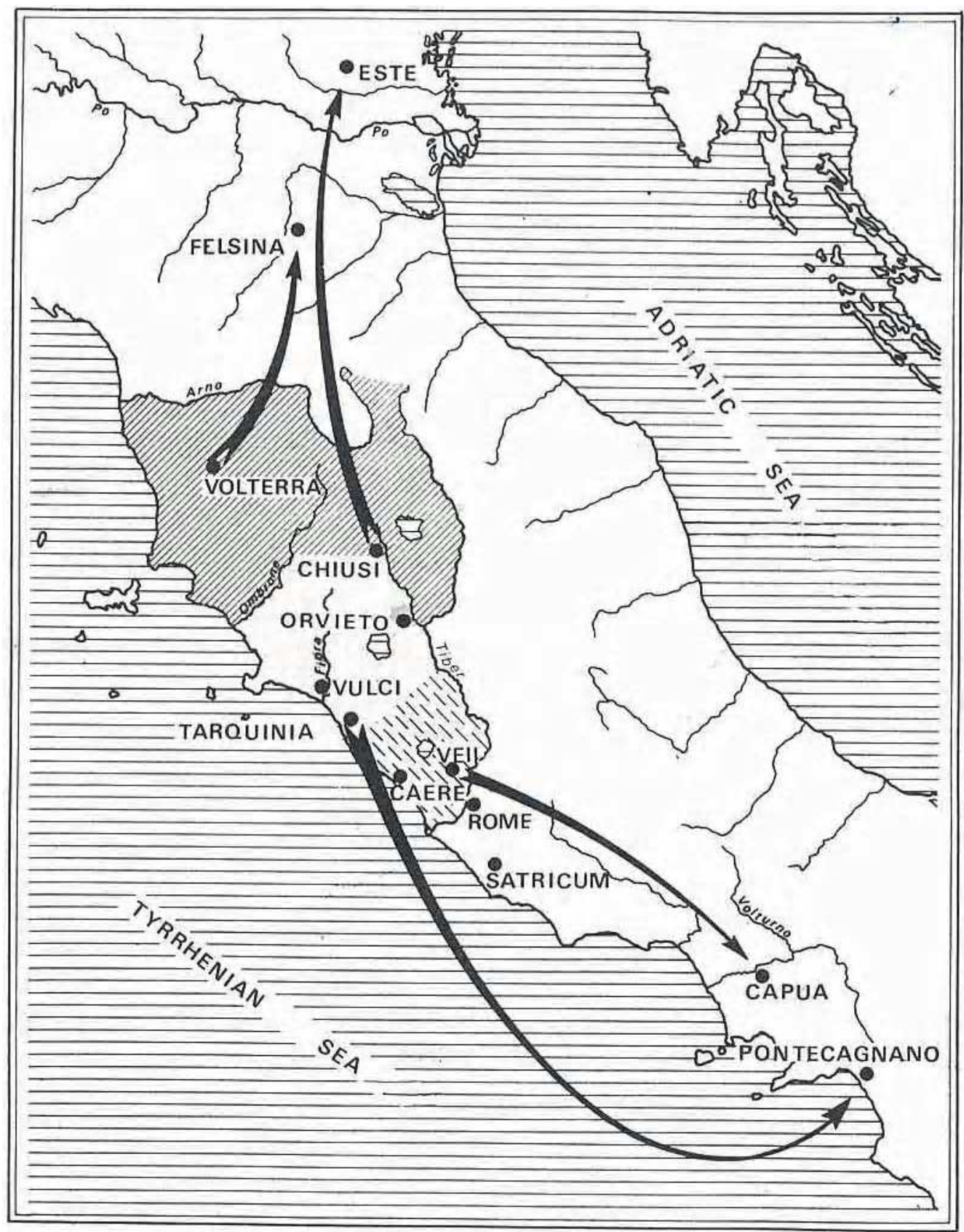

Plate 19: Spread of the Etruscan alphabet. 


\section{Conclusions}

This study has incorporated case studies of three quite different cultures. Nyikina culture maintained an oral tradition until colonisation in the twentieth century. Their nomadic hunter-gatherer-fisher culture contrasts dramatically with the sedentary lifestyles developed by the Minoan and Etruscan cultures. The physical environment and booroo played equal roles in the establishment of world-views. White colonisation of Australia imposed literacy frameworks on the indigenous population, and by studying Nyikina culture, one can see how twenty-first-century Australians are attempting to revitalise severely endangered languages, and create language-specific resources for indigenous education. Acknowledging the importance of oral storytelling in a new environment which inflicts multimedia literature (and expects multimedia literacy), results in a struggle for indigenous voices to be heard. Indigenous and non-indigenous Australians have worked together with varying degrees of success to capture the Aboriginality of oral storytelling. The colonisation of Australia is a modern example of what one can only imagine was the experience of local Etruscans during the colonisation of Southern Italy by Greek and Phoenician settlers. Both indigenous Aborigines and indigenous Etruscans had their own language that was heavily influenced by the incoming culture, leading to their use of foreign scripts to write their languages.

Minoan culture became sedentary in the Bronze Age, and this event was the foundation for increased populations and the stratification of society. Religion was an important tool for maintaining social structures, and it also facilitated harmonious living. In the MM period, palace complexes were built to be organisational centres for the control of the expanding religious practices, trade, and to house the elite 
members of society who undertook these roles. Included among these elite were the priest-scribes, who created, developed and used the Cretan Hieroglyphic Script, using a set of symbols already familiar to them from their priestly roles in Minoan society. This script was 'invented' without much foreign influence. From talismanic beginnings, the religious symbols of the CHS were joined by other commodity based pictographs. The script developed into a more standardised form, Linear A, when it became necessary to write series of records on clay tablets for administrative purposes in the palace complexes. In this linear form, the signs were now written with a stylus instead of impressed by seal stones. Linear B grew from Linear A, in the LM period, and the language it recorded was Greek. Unfortunately, the language which the CHS and Linear A recorded has not been identified beyond doubt. It appears to be the local Minoan language, but until the signs can be deciphered, this postulation cannot be proven.

By the fall of the Minoan culture and the end of the bronze and so-called Dark Ages, the Phoenician alphabet reached and affected the western Mediterranean and writing was 'reborn.' The Euboean Greeks took their alphabet with them to Southern Italy where they settled at sites such as Cumae and Pithekoussai in the eighth century. The Iron Age was a period of transition for the Greek alphabet. At the time the Etruscans encountered and adopted the Euboean Greek alphabet from the region around Cumae, it was written in various directions. Although the letters of the Etruscan alphabet were predominantly Greek, the Etruscans eventually settled on writing in sinistrograde - the opposite of the Greeks who chose dextrograde. A Phoenician influence may have been at work on the Etruscan script, however, as these colonists from the eastern Mediterranean had historically written in sinistrograde, 
since the invention of their own pictographic script in the Bronze Age. Etruscan culture was influenced by Greek and Phoenician culture, both having strong literary traditions of religious, administrative, and likely epic and poetic texts. However, how the Etruscans appear to have chosen certain aspects of Greek and Phoenician literary tradition is interesting. The surviving texts from Etruria indicate that Etruscan culture incorporated writing into their religious practices. No great stores of administrative documents written in Etruscan, however, have been discovered, like the stores of Minoan examples. From that comparison one can understand the significance of how a society uses language and writing, and the ways it reflects their cultural values and world-views. The Minoans used a script developed for religious use that changed to accommodate their accounting systems, the Etruscans created an alphabet from Phoenician and Greek alphabets, and surviving records show a strong religious context for its use. In comparison, Nyikina culture did not create its own script, as oral literature was the tradition passed on from bookarrarra. However, like Etruscan the Etruscan language, Nyikina language is written with a borrowed alphabet, the Roman alphabet, to phonemically represent the sounds of its language. It is nothing short of ironic that an indigenous Australian culture has still been affected by the root alphabets of the ancient Mediterranean in its own colonisation process.

Nyikina, Minoan, and Etruscan cultures are all different. Because they are so different from each other in respect to environment, periods in history, and worldviews one can begin to understand the manifold ways in which culture affects the transition from oral to written literature. Whether a culture is nomadic, sedentary, independent or colonised plays a defining role in attitudes towards writing within the frameworks of each culture. 


\section{Bibliography}

Aeschylus (2002). Agamemnon. Christopher Collard (trans.). Oxford.

Andrews, M. (2004). The Seven Sisters of the Pleiades. Melbourne.

Atkin, T. and Rykwert, J. (eds.) (2005). "Etruscan Boundaries and Prophecy". In Structure and Meaning in Human Settlements. Philadelphia.

Banner, S. (2005). "Why Terra Nullius? Anthropology and Property Law in Early Australia". Law and History Review. 23.1.95-131.

Berndt, C. H. (1985). "Traditional Aboriginal oral literature." In Papers from the First National Conference of Aboriginal Writers. Jack Davis and Bob Hodge (eds.). Canberra.

Berndt, R. M. and Berndt, C. H. (1989). Speaking Land: Myth and Story in Aboriginal Australia. Ringwood, Victoria.

Best, J. and Woudhuizen, F. (eds.) (1988). Ancient Scripts from Crete and Cyprus. Leiden.

Billigmeier, J. C. (1973) "Linear A Fractions: A New Approach". American Journal of Archaeology. 77.1.61-65

Billigmeier, J. C. (1976) "Toward a Decipherment of Cypro-Minoan". American Journal of Archaeology. 80.3.295-300.

Birch, M. (1998). 'Re/constructing Research Narratives, Self and Sociological Identity in Alternate Settings'. In Feminist dilemmas in qualitative research. J. Ribbens and R. Edwards (eds.). London.

Blakeway, A. (1935). "Demaratus: A Study in Some Aspects of the Earliest Hellenisation of Latium and Etruria". JRS 25.129-149.

Bonfante, G. and Bonfante, L. (2002). The Etruscan language, an introduction, revised edition. First edition 1983. Manchester.

Bonfante, L. (2006). "Etruscan Inscriptions and Etruscan Religion”. In The Religion of the Etruscans. Thomson de Grummond, Nancy and Simon, Erika (eds.). Austin.

Bonfante, L. and Swaddling, J. (2006). Etruscan Myths. Austin.

Bonnefoy, Y. (1991). Greek and Egyptian Mythologies. Wendy Doniger (trans.). Chicago.

Borelli, F. and Targia, M. C. (2004). The Etruscans; Art, Architecture and History. Stefano Peccatori and Stefano Zuffi (eds.). Thomas Michael Hartmann (trans.) Los Angeles. 
Bowden, R. and Bunbury, B. (1990). Being Aboriginal: Comments, Observations and Stories from Aboriginal Australians. Sydney.

Brendel, O. J. (1978). Etruscan Art. New York.

Brice, W. C. (ed.) (1961). Inscriptions in the Minoan Linear Script of Class A. In the notes of Sir Arthur Evans and Sir John Myres. Oxford.

Brice, W. C. (1991a). "Notes on the Cretan Hieroglyphic Script”. Kadmos. 31.21-24. (1991b). "Notes on linear A". Kadmos. 30.42-48.

Capell, A. (1949-50). 'Some Myths of the Garadjeri Tribe, Western Australia'. Mankind.4.2.46-61; 4.3.108-125; 4 .4.148-162.

Carpenter, R. (1945). "The Alphabet in Italy". AJA 49.4.452-464.

Carr, D. M. (2005). Writing on the Tablet of the Heart, origins of Scripture and Literature. Oxford University Press. Oxford and New York.

Censorinus (1983). De Die Natali Liber IV:XIII. Nicolaus Sallmann (ed.). Leipzig.

Chadwick, J. (1990). "Linear B, Ch. 7: The Phaistos Disk." Reading the Past: Ancient Writing From Cuneiform to the Alphabet. Introduced by J.T. Hooker. Berkley and Los Angeles.

Cherry, J. (1986). "Polities and palaces: some problems in Minoan state formation." Peer polity interaction and socio-political change. C. Renfrew and J. Cherry (eds.). Cambridge.

Childe, V.G. (1930). The Bronze Age. Cambridge.

Cicero. (1923). De Divinatione II: xxxiii (50). William Armistead Falconer (trans.). Cambridge, Massachusettes, London.

Coldstream, J. N. (2003). Geometric Greece: 900-700 BC. London and New York.

Coulmas, F. (1989). Writing Systems of the World. Oxford.

Cowan, J. G. (1994). Myths of the Dreaming: interpreting Aboriginal legends. Dorset.

Crawford, I. M. (1972). 'Function and Change in Aboriginal Rock Art, Western Australia'. In World Archaeology. Vol. 3.3.301-312.

Cristofani, M. (1979). The Etruscans: a new investigation. Brian Phillips (trans.). Echoes of the Ancient World series. New York.

Daniel, J. F. (1941). "Prolegomena to the Cypro-Minoan Script". AJA. 45.249-282.

Davaras, C. (1976). Guide to Cretan Antiquities. New Jersey. 
David, B.; Baker, B. and McNiven, I. (eds.). (2006). The Social Archaeology of Australian Indigenous Societies. Canberra.

Davies, W.V. (1987). Egyptian Hieroglyphics. Berkeley.

Davis, J. and Hodge, B. (eds.) (1985). Papers from the First National Conference of Aboriginal Writers. Canberra.

de Grummond, N. T. (ed.) (1982). A Guide to Etruscan Mirrors. Tallahassee, Florida.

de Grummond, N.T. (2006a). Etruscan Myth, Sacred History and Legend. Philadelphia.

(2006b). "Prophets and Priests". In The Religion of the Etruscans. Nancy Thomson de Grummond and Erika Simon (eds.). Austin.

De Kerckhove, D. (1986). “Alphabetic Literacy and Brain Processes". In Visible Language XX.3.274-293.

Department of Indigenous Affairs (2005). Overcoming Indigenous Disadvantages in Western Australia Report 2005. Perth.

Dickinson, O.T.P.K. (1994). Aegean Bronze Age. Cambridge.

Diodorus Siculus (1970). Library of History. 3.5.64-80. C. H. Oldfather (trans.). Massachusetts.

Dixon, R. M. W. (1980). The Languages of Australia. Cambridge.

Dow, S. (1971). "Literacy in Minoan and Mycenaean Lands." The Linear Scripts and the Tablets as Historical Documents. Part A 2.8. Cambridge.

Duhoux, Y. (1977). Le Disque de Phaestos. Leuven.

Easterling, P. and Handley, C. (2001). Greek Scripts: An Illustrated Introduction. London.

Edmonds, P. and Furphy, S. (2006). Rethinking Colonial Histories: New and Alternative Approaches. History Department, University of Melbourne. Melbourne.

Ellis, J. A. (1994). This Is The Dreaming: Australian Aboriginal Legends. North Blackburn.

Eno, R. (1996). "Deities and Ancestors in Early Oracle Inscriptions." Religions of China in Practice. Donald S. Lopez, Jr. (ed.). New Jersey.

Evans, A. (1894). "Primitive Pictographs and a Prae-Phoenician Script from Crete and the Peloponnese”. JHS 14.1893-4.

(1909). Scripta Minoa I. Oxford.

(1952). Scripta Minoa II. Oxford. 
Galanakis, K. (2005). Minoan Glyptic: Typology, Deposits and Iconography from the Early Minoan Period to the Late Minoan IB Destruction in Crete. BAR 1442. Oxford.

Galmur, J. (1991). Wakwak en imiyu. Illustrations by Manuel Pamkal. Katherine, Western Australia.

Glare, P.G.W. (1982). Oxford Latin Dictionary. London.

Goar, R. J. (1968). “The Purpose of De Divinatione”. APA 99.241-248.

Goody, J. (1987). The Interface between the Written and the Oral. Cambridge. (2000). The Power of the Written Tradition. Washington and London.

Gordon, C. H. (1966). Evidence for the Minoan Language. New Jersey.

Guilaine, J. (ed.) (1991). Prehistory, the world of early man. New York.

Hall, R. F. (1996). Etruscan Italy. Indiana.

Hansen, W. (2004). A Guide to the Mythical World of the Greeks and Romans. Oxford.

Harper, G. (1998). Society, culture, socialization and the individual. Stocktan.

Hattersley, C. Personal communication 5/11/2008. Discussion on Joy's story about her Father, and the transcription of Nyikina words Joy used.

Hattersley, C.; Marshall, L. and McKenry, R. (2004). Mandajarra Nyikina: Cultural resources for Nyikina language and culture courses. A printed document (Dynamic Digital Print, Tweed Heads, NSW) which was the product of Nyikina Cultural Workshops held in March 2004, and using the Nyikina Historical Wordlist (C) Bronwyn Stokes 1980-2004 under license.

Hencken, H. (1968). Tarquinia and Etruscan Origins. Dr Glyn Daniel (gen. ed.). London.

Henrichs, A. (2003). "Writing Religion: Inscribed Texts, Ritual Authority, and the Religious Discourse of the Polis". In Written texts and the Rise of Literate Culture in Ancient Greece. Harvey Yunis (ed.) Cambridge.

Herodotus (1996). Histories. Aubrey De Sélincourt (trans.). Revised with introductory matter and notes by John Marincola. London.

Hesiod (2006). Theogony, Works and Days, Testimonia. Edited and translated by Glenn W. Most. Loeb Classical Library series. Harvard University Press. Cambridge, Massachusetts.

Heurgon, J. (1959). “The Date of Vegoia's Prophecy”. JRS 49.1\&2.41-45.

(1966). “The Inscriptions of Pyrgi”. JRS 56.1\&2.1-15. 
Hodder, I. (ed.) (2001). Archaeological Theory Today. Cambridge.

Hodder, I. (1990). The domestication of Europe: structure and contingency in Neolithic societies. Social Archaeology. B. Blackwell. Cambridge, Massachusetts.

Holloway, R. R. (1996). The Archaeology of Early Rome and Latium. London.

Homer (1951). Iliad. Richmond Lattimore (trans.). Chicago and London.

Homer (1965) Odyssey. Richmond Lattimore (trans.). New York.

Hooke, S. H. (1962). Babylonian and Assyrian Religion. Oxford.

Houston, S. D. (ed.) (2004). The First Writing: Script Invention as History and Process. Cambridge.

Innis, H. A. (2007). Empire and Communications. Toronto.

Izzet, Vedia (2007). The Archaeology of Etruscan Society. Cambridge.

Kent, S. (ed.) (1989). Farmers as hunters: The implications of sedentism. Cambridge.

Kimberley Land Council (1998). The Kimberley: Our Place, Our Future. Broome, Western Australia.

Knapp, B. (1992). "Bronze Age Mediterranean Island Cultures and the Ancient Near East”. The Biblical Archaeologist. 55.2.52-72.

Kolig, E. (1996). Studies in Kimberley Languages in honour of Howard Coate. William McGregor (ed.). München.

Krzyszkowska, O. (2005). Aegean Seals: An introduction. London.

Lévi-Strauss, C. (1978). Myth and Meaning: five talks for radio. Toronto.

Livy (1934). IX: 36.3. W. B. Anderson (ed.). Cambridge.

Lourandos, H. (1997). Continent of Hunter Gatherers: New perspectives in Australian Prehistory. Cambridge.

Manning, S. W. (1995). The Absolute chronology of the Aegean Bronze Age: Archaeology, Radiocarbon, and History. Monographs on Mediterranean Archaeology: 1. A. Bernard Knapp (exec. ed.). Sheffield.

Marinatos, S. (1960). Crete and Mycenae. London.

Marshall, L. and Hattersley, C. (2004). Reflections of a Kimberley Woman. Broome, Western Australia.

Mathews, J. (1994). The Opal that turned Into Fire. Isobel White (ed.). Broome, Western Australia. 
Matsas, D. (1996). "Aspects of relationships between Crete and the Northeastern Aegean in the Middle Bronze Age". Cretan Studies 5.121-122.

McGregor, W. (1988). Handbook of Kimberley Language.Vol.1: General Information. A project of the Kimberley Language Resource Centre. Canberra.

McIntosh, J. R. (2005). Ancient Mesopotamia: new perspectives. Santa Barbara.

Morgan, H. T. (1942). Chinese Symbols and Superstitions. South Pasadena.

Mudrooroo (1997). The Indigenous Literature of Australia: Milli Milli Wangka. Melbourne.

Nangan, J. and Edwards, H. (1976). Joe Nangan's Dreaming. Melbourne.

Newberry, J. S. (1934). "The Prehistory of the Alphabet". Harvard Studies in Classical Philology 45.105-156.

Noonuccal, O. (1992). Australia's Unwritten History, more legends of our land. Milsons Point, New South Wales.

North, J. (1990). "Diviners and Divination at Rome". In Pagan Priests: Religion and Power in the Ancient World. Mary Beard and John North (eds.). London.

Nulungu Catholic College (1988). Kimberley Aboriginal Communities. Revised 1991. Broome, Western Australia.

Ovid (1986). Metamorphoses XV. A.D. Melville (trans.). Oxford.

Owens, G. A. (1996a). "Evidence for the Minoan language: The Minoan Libation Formula". Cretan Studies 5.163-208.

Kadmos 35.2.105-110.

Packard, D. W. (1974) Minoan Linear A. Berkley.

Pallottino, M. (1975). The Etruscans. J. Cremona (trans.). London.

London.

Palmer, L. R. (1961). The Latin Language. London.

Pandilo, M. (2003a). Wanyjina: Rain-maker. Transcribed by Margaret Sefton, original art by the students of Kalumburu Remote Community School. Halls Creek, Western Australia.

(2003b). Wur bûrrûngkeima, Germany-yanga: Two men who flew from Germany. Transcribed by Margaret Sefton, original art by the students of Kalumburu Remote Community School. Halls Creek, Western Australia. 
Papathanassopoulos, G. (1981). Neolithic and Cycladic civilisation. National Archaeological Museum. Athens.

Parker, K. L. (1993). Wise Women of the Dreamtime, Aboriginal Tales of Ancestral Powers. Johanna Lambert (ed.). Rochester, Vermont.

Plato (1919). Euthyphro, Apology, Crito, Phaedo, Phaedrus. H. N. Fowler (trans.). London.

Powell, B. B. (1991). Homer and the Origin of the Greek Alphabet. Cambridge.

Preziosi, D. and Hitchcock, L. A. (1999). Aegean Art and Architecture. Oxford.

Rappaport, J. (1995). 'Empowerment meets narrative: listening to stories and creating settings'. American Journal of Community Psychology, 23.795-807.

Reid, J. (2005). Minoan Kato Zakro: A Pastoral Economy. A thesis submitted to the Victoria University of Wellington in fulfilment of the requirements for the degree of Doctor of Philosophy in Classical Studies.

Renfrew, C. (1996). "Who were the Minoans? Towards a population history of Crete". Cretan Studies 5.1-28.

(2001). "Symbol before Concept; Material Engagement and the Early Development of Society”. Archaeological Theory Today. Cambridge.

Ridgway, D. (1992). The First Western Greeks. Cambridge.

(2002). The World of The Early Etruscans. Pocket-book 162 for Studies in Mediterranean Archaeology and Literature.

Rigney, L. (1996). ‘The World Indigenous Peoples' Conference'. Education.

Robertson, B. M. (2000). Oral History Handbook. First edition 1983. Adelaide.

Robinson, A. (1995). The Story of Writing. London.

Scripts. New York.

(2002). Lost Languages: The Enigma of the World's Undeciphered

Roe, P. (1983). Gularabulu. Stephen Muecke (ed.). South Fremantle.

Schmandt-Besserat, D. (1982). "How writing came about". Zeitschrift für Papyrologie und Epigraphik. 47.1-5.

Schmidt, A. (1990). The Loss of Australia's Aboriginal Language Heritage. Canberra.

Schoep, I. (1996). Minoan Administration on Crete; an Interdisciplinary Approach to documents in Cretan Hieroglyphic and Linear A (MMI/II-LMIB). Leuven.

Senner, W. M. (ed.) (1989). The Origins of Writing. Lincoln. 
Small, J.P. (1986). "Cacu and the Porsennae”. In Italian Iron Age Artifacts. 459-462. London.

Smith, L. T. (1999). Decolonizing Methodologies: Research and Indigenous Peoples. Zed Books \& University of Otago Press. London, New York, Dunedin.

Sowder, C. L. (1982). "Etruscan Mythological Figures". In A Guide to Etruscan Mirrors. 100-128. Nancy Thomson de Grummond (ed.). Florida.

Spivey, N. (1997). Etruscan Art. London.

Stanner, W. E. H. (1979). White Man Got No Dreaming. Canberra.

Strabo (2000). Geography V.10.4.6. Horace Leonard Jones (trans.) London.

Suetonius (1957). "Life of Claudius". The Twelve Caesars 42.2. Robert Graves (trans.). London.

Swaddling, J. (2001). CSE Great Britain 1: The British Museum. Fasicule I. London.

Taylor, P. (1992). Telling it like it is; a guide to making Aboriginal and Torres Strait Islander History. Canberra.

The National Indigenous Languages Survey Report (2005). Report submitted to the Department of Communication, Information Technology and the Arts by AIATSIS in association with the Federation of Aboriginal and Torres Strait Islander Languages.

Theopompos (1962). Philipii: Frag.115. 155. In Die Fragmente der Griechischen Historiker. F. Jacoby. Leiden.

Thomas, J. (1988). "Neolithic Explanations revisited: The Mesolithic-Neolithic Transition in Britain and South Scandinavia". Proceedings of the Prehistoric Society 54.59-66.

(1991). First edition (CUP) titled: Rethinking the Neolithic. Second edition (Routledge) 1999, titled: Understanding the Neolithic. Cambridge.

Thomas, R. (1992). Literacy and Orality in Ancient Greece. Cambridge. (1992). Literacy and Orality in Ancient Greece. Cambridge.

Torelli, M. (1996). "The Encounter with the Etruscans". In The Western Greeks. Giovanni Pugliese Carratelli (ed.). Venice.

Turfa, J. M. (1977). "Evidence for Etruscan-Punic Relations”. AJA 81.3.368-374.

Wachsmann, S. (1998). Seagoing Ships \& Seamanship in the Bronze Age Levant. London.

Walsh, M. and Yallop, C. (1993). Language and Culture in Aboriginal Australia. Canberra.

Warren, P. (1972). Myrtos; An Early Bronze Age Settlement in Crete. London. 
Watson, J. (2000). Balkayi. Derby, Western Australia. (2000). Booroo. Derby, Western Australia.

Weingarten, J. (1986). "The sealing structures of Minoan Crete: MMII Phaistos to the destruction of the palace at Knossos. Part I: The evidence until the LMIB destructions". OJA 5.279-298.

Whatmough, J. (1931). "The Calendar in Ancient Italy outside Rome". HSCP 42.157-179.

Whittaker, H. (2005). "Social and symbolic aspects of Minoan writing". European Journal of Archaeology 8.1.29-41.

Wilson, I. (2006). Lost World of the Kimberley; Extraordinary glimpses of Australia's Ice Age ancestors. Allen \& Unwin. Crows Nest, New South Wales.

Wiseman, T.P. (2004). The Myths of Rome. Exeter.

Wolf, M. (2008). Proust and the Squid: The Story and Science of the Reading Brain. Cambridge.

Woonyoomboo (2002). Written and illustrated by students of the Nyikina Mangala Community School in the Jarlmadangah Burru Community. @Jarlmadangah Burru Aboriginal Corporation.

Yule, P. (1983). "Notes on Scarabs and Aegean Chronology". BSA 78.359-367. London.

Yunis, H. (2003). "Introduction: Why Written Texts?" Written texts and the Rise of Literate Culture in Ancient Greece. Harvey Yunis (ed.). Cambridge. 